\title{
Report
}

on

\section{Achieving Maximum Crack Remediation Effect from Optimized Hydrotesting}

\author{
Prepared for
}

US Department of Transportation PHMSA

Client Contract Number: DTPH56-08-T-000008-WP\#355

by

\section{Weixing Chen, PhD, PEng}

June 15, 2011

University of Alberta

Edmonton, Alberta 
This report is a work prepared for the United States Government by the University of Alberta no event shall either the United States Government or the University of Alberta have any responsibility or liability for any consequences of any use, misuse, inability to use, or reliance upon the information contained herein, nor does either warrant or otherwise represent in any way the accuracy, adequacy, efficacy, or applicability of the contents hereof. 


\section{Acknowledgments}

This report presents work that leverages co-funding by TransCanada Pipelines Limited, Spectra Energy Transmission, and Natural Science and Engineering Council of Canada. 


\section{ABSTRACT}

This project developed and validated models that will allow the industry to predict the overall benefits of hydrotests. Such a prediction is made with a consideration of various characteristics of a pipeline including the type of operation, stage of cracking, environmental susceptibility, steel metallurgy, and operation history. When hydrotesting is necessary, the model will help operators select the parameters that would generate the most effective crack remediation. 


\section{Executive Summary}

Hydrostatic test is a key method for managing SCC in oil and gas pipelines. Benefits are achieved by eliminating defects of critical size for the hydrotest pressure and hence achieving a post-test period without operating failure. Other benefits are related to temporary growth retardation after hydrotest because of crack tip blunting. Conversely, benefits of such a test could be offset by stable flaw growth in the previously dormant population and growth of cracks during hydrostatic loading. Although this type of growth behaviour has been previously analyzed by Leis and Brust [1], they only modelled the cracking advance from tests in air, which neglects the effects of the corrosive environment on the crack advance.

However recent research has shown that crack growth can occur during hydrotests at much smaller crack dimensions than those originally analyzed. The adverse effect of hydrotesting is negligible if it initiates crack growth only on large-size cracks that are near the final stage of pipeline life. However, benefits of hydrotest would become uncertain if hydrostatic loading induces crack growth when crack dimensions are relatively small. This reduction in pipeline remaining lifetime by hydrostatic testing can be significant considering the fact that several hydrotests may be performed in the lifetime of a pipeline. Although hydrotests would usually recondition the crack tip so that a lower crack growth rate can be expected for a limited time, it is questionable whether the reduced growth rate would compensate for the loss of life because of the crack growth during hydrotesting. Therefore, the overall benefits of hydrotesting must be evaluated from the viewpoint of life extension and pipeline safety.

The study of effects of hydrostatic tests in this investigation is built on two competing morphological conditions at the crack tip before, during and after hydrostatic testing, that is, crack tip blunting and crack tip sharpening. Crack tip sharpening is related to the hydrogen effects and mechanisms of cyclic loading, while the crack tip blunting is attributed to low temperature creep of the pipeline steels. The ultimate goal of the proposed research is to determine how maximum crack remediation effect can be achieved from optimized hydrotesting. The report will start with simulations of hydrotests under various conditions. The results of simulation will be analyzed to determine the fundamental natures of materials, environments and mechanical conditions that are responsible for achieving maximum crack remediation effect from hydrostatic loading. At the end, recommendations will be made for the purpose of optimized hydrostatic testing to achieve maximum crack remediation effect, pipeline safety and lifetime extensions. 


\section{TABLE OF CONTENTS}

\section{ABSTRACT}

\section{EXECUTIVE SUMMARY}

$1 \quad$ INTRODUCTION

1

References 4

2 OBJECTIVES AND SCOPE

3 SIMULATION OF CRACK GROWTH DURING HYDROSTATIC TESTING OF PIPELINE STEEL IN NEAR-NEUTRAL PH ENVIRONMENT 6

$3.1 \quad$ Introduction $\quad 6$

3.2 Experimental approaches $\quad 6$

$\begin{array}{lll}3.3 & \text { Results } & 10\end{array}$

3.3.1 Effect of crack dimension 10

3.3.2 Effect of loading rate 18

3.3.3 Effect of pressure hold 22

3.3.4 Effect of hydrostatic test on post hydrostatic test crack growth 25

References $\quad 28$

4 UNDERSTANDING OF CRACK GROWTH IN NEAR NEUTRAL pH

$\begin{array}{lll}4.1 & \text { Introduction } & 29\end{array}$

4.2 Hydrogen effects in near-neutral pH environments 36

4.3 Low temperature creep behavior of pipeline steels 37

4.4 Modelling crack growth of pipeline steels in near-neutral pH environments 45

$\begin{array}{lll}4.5 & \text { Effect of materials } & 66\end{array}$

4.6 Surface short/shallow cracks vs. long crack/deep cracks 78

$5 \quad$ DEVELOPMENT OF HYDROSTATIC TEST GUIDLINES 88

$\begin{array}{lll}5.1 & \text { Introduction } & 88\end{array}$

5.2 Best strategies of hydrostatic testing 91

5.3 Strategies for producing the least crack growth during hydrostatic loading 91

$5.4 \quad$ Strategies for avoiding over-estimate of the remaining life 92

5.5 Strategies for achieving maximum post-test benefits 92

$6 \quad$ RECOMMENDATION $\quad 93$ 
Table of Contents (continued)

\section{List of Figures}

Fig. 1-1 Predicted crack growth caused by hydrotest based on CF model [3] and test results from [2]

Fig. 1-2 Schematic showing environmentally assisted cracking driven by hydrogen embrittlement

Fig. 1-3 A change of crack tip morphology due to low temperature creep

Fig. 3-1 Schematic showing (a) Type I specimen for internal-hydrogen-assisted cracking;

(b) Type II specimen for hydrogen-environment-assisted cracking.

Fig. 3-2 Simulated loading procedure for hydrostatic testing.

Fig. 3-3 Different loading rates used during hydrostatic loading in Stage I a) and Stage II b).

Fig. 3-4 Potential changes during hydrostatic test simulation for the cracks with assumed depth of $1.5 \mathrm{~mm}$.

Fig. 3-5 SEM photographs showing fracture surface morphology of specimen (a) CT-01, (b) CT-02, (c) CT-03 and (d) CT-04 after hydrostatic testing

Fig. 3-6 The measured potentials of the specimens corresponding to crack with assumed depth of $3.22 \mathrm{~mm}$ before and after hydrostatic testing simulation with different procedure in $\mathrm{C} 2$ solution.

Fig. 3-7 SEM photographs showing fracture surfaces of specimens (a) CT-05, (b) CT-06, (c) CT-12 and (d) CT-07 tested in 2-step procedure hydrostatic testing simulation.

Fig. 3-8 Cross sections of specimens (a) CT-05 and (b) CT-06 after 2-step procedure hydrostatic testing simulation

Fig. 3-9 SEM photographs showing fracture surfaces of specimens (a) CT-13, (b) CT-10, (c) CT-14 and (d) CT-15 after 1-step procedure hydrostatic testing simulation.

Fig. 3-10 SEM photographs showing fracture surfaces of specimens (a) CT-17, (b) CT-18 tested in air.

Fig. 3-11 Fracture surface morphology of specimen (a) CT-21, (b) CT-22, (c) CT-19, (d) CT-20.

Fig. 3-12 Crack advance vs. crack depth or the ratio of crack depth/wall thickness with different experiment conditions.

Fig. 3-13 Net crack growth measured as a function of loading rate in Stage I

Fig. 3-14 Net crack growth as a function of loading rate in Stage II

Fig. 3-15 Change of potential drop recorded in a test with different hold times at the same overload stress.

Fig. 3-16 Effect of overload hold time on the crack growth rate after the overload

Fig. 3-17 Crack length increment as a function of test time in two different soil solutions

Fig. 3-18 Crack growth rate before and after hydrostatic test as a function of $\Delta K_{C}$

Fig. 3-19 Loading schemes used for determining crack growth rate before and after hydrotest

Fig. 3-20 Crack growth determined on the fracture surface of CT specimen after the loading schemes shown in Fig. 3-19 
Fig. 4-1 A schematic showing the competition between crack tip blunting and crack tip sharpening in the pipeline steels exposed to near neutral $\mathrm{pH}$ environments under constant stresses (situation of stress corrosion cracking).

Fig. 4-2 A schematic showing the competition between crack tip blunting and crack tip sharpening in the pipeline steels exposed to near neutral $\mathrm{pH}$ environments under cyclic loading condition (scenario of corrosion fatigue).

Fig. 4-3 Variation of da/dN with loading frequency for tests with different starting $\mathrm{K}_{\max }$ and $\Delta \mathrm{K}$ values, a) $\mathrm{X} 52$ pipeline steel, b) X80 pipeline steel.

Fig. 4-4 Fatigue crack growth rate, da/dN, of X52 pipeline steel as a function of new combined driving force, a) linear scale, b) log-log scale.

Fig. 4-5 Fatigue crack growth rate, da/dN, of $X 80$ pipeline steel as a function of new combined driving force, a) linear scale, b) log-log scale.

Fig. 4-6 Crack growth rate $d a / d N$ as a function of $\Delta \mathrm{K}$ a) and $(\Delta \mathrm{K})^{0.667} \mathrm{~K}_{\max }{ }^{0.333} / \mathrm{f}^{0.033} \mathrm{~b}$ ) for X52 pipeline steel

Fig. 4-7 Crack growth rate $\mathrm{da} / \mathrm{dN}$ as a function of $\Delta \mathrm{K}$ and $(\Delta \mathrm{K})^{0.667} \mathrm{~K}_{\max }{ }^{0.333 / f^{0.033}}$ for $\mathrm{X} 52$ pipeline steel

Fig. 4-8 Comparison of crack growth rate in air and in near-neutral $\mathrm{pH}$ environment as a function of loading frequency a) as a function of $\left.(\Delta \mathrm{K})^{0.67} \mathrm{~K}_{\max }{ }^{0.33} \mathrm{~b}\right)$

Fig. 4-9 [HEF] as a function of $(\Delta \mathrm{K})^{0.67} \mathrm{~K}_{\max }{ }^{0.33} \mathrm{a}$ ) and $[\mathrm{HEF}]$ normalized by $(\Delta \mathrm{K})^{0.67} \mathrm{~K}_{\max }{ }^{0.33}$ / $\left.f^{0.095} \mathrm{~b}\right)$.

Fig. 4-10 Comparison of experimental results with the prediction

Fig. 4-11 [HEF] normalized by $(\Delta \mathrm{K})^{0.67} \mathrm{~K}_{\max }{ }^{0.33} / f^{0.0647}$ a) and predicted crack growth rate as a function of $[\mathrm{HEF}]$ normalized by $\left.(\Delta K)^{0.67} K_{\max }{ }^{0.33} / f^{0.0175} \mathrm{~b}\right)$.

Fig. 4-12 Crack growth curve obtained from Test 10 listed in Table 3.

Fig. 4-13 Crack growth rate of $X 52$ pipeline in near-neutral $\mathrm{pH}$ environment

Fig. 4-14 SEM microstructure pictures of X65(I), X65(II), X52 and X80 pipeline steels.

Fig. 4-15 Variations in weight loss of different pipeline steels with time when exposed to C2 solution

Fig. 4-16 Crack growth rate $\mathrm{da} / \mathrm{dN}$ as a function of $\Delta \mathrm{K}$ and $(\Delta \mathrm{K})^{2} \mathrm{~K}_{\max } / \mathrm{f}^{0.1}$ for $\mathrm{X} 80$ and $\mathrm{X} 50$.

Fig. 4-17 Crack growth rate da/dN as a function of $(\Delta K)^{2} K_{\max } / f^{0.1}$ for the steels used in this study.

Fig. 4-18 Crack growth rate $\mathrm{da} / \mathrm{dN}$ as a function of $(\Delta \mathrm{K})^{2} \mathrm{~K}_{\max } / \mathrm{f}^{0.1}$ for the steels used in this investigation

Fig. 4-19 Crack growth data normalization representing different $\alpha$ values for different steels

Fig. 4-20 SEM picture of a crack which was propagated in X65(I) pipeline steel.

Fig. 4-21 SEM picture of a sharp tip of a crack which was propagated in $\mathrm{X65}$ (I) pipeline steel.

Fig. 4-22 SEM picture of a crack tip branching of a crack which was propagated in X52 pipeline steel

Fig. 4-23 Illustration showing the evolution of crack dimension and its significance in terms of integrity managements

Fig. 4-24 Specimen design and test setup for studying surface cracks: a) geometry of the specimen with three surface cracks within the reduced section, b) surface crack 
in the reduced section of a), c) test cell used, d) actual test cell and specimen mechanically loaded by Instron.

Fig. 4-25 Loading schemes used for Test I and Test II, respectively. Both tests started with the same loading conditions. Crack growth was monitored using accurate potential drop system.

Fig. 4-26 Surface morphology of the specimen after Test II

Fig. 4-27 Crack morphology after pre-fatigue loading in air

Fig. 4-28 A comparison of crack tip morphology on sample surface after Test I and Test 2

Fig. 4-29 A comparison of crack tip morphology on the cross section along the crack depth direction after Test I and Test 2

Fig. 4-30 Morphology of fractured surface of surface crack after exposure in near-neutral pH soil solution

Fig. 4-31 Enlarged SEM image showing the morphology at the ledge found on the fractured surface in Fig. 4-30.

Fig. 5-1 Crack growth during hydrotest reduces the remaining life of the pipeline.

Fig. 5-2 Crack growth behaviour during hydrotest and remaining pipeline lifetime as discussed in Scenario II for actual cracks with a dimension shorter than the critical crack dimension defined by $\mathrm{R} 1$.

Fig. 5-3 Crack growth behaviour during hydrotest and remaining pipeline lifetime as discussed in Scenario II for actual cracks with a dimension longer than the critical crack dimension defined by $\mathrm{R} 1$.

\section{List of Tables}

Table 3.1 Matrix of experiment conditions

Table 4-1 Chemical composition of X52 and X-80

Table 4-2 Mechanical properties of X52 and X80

Table 4-3 Mechanical loading conditions

Table 4-4 Cyclic loading frequency

Table 4-5 List of test conditions for all corrosion fatigue tests performed

Table 4-6 Chemical composition of the pipeline steels used in the investigation

Table 4-7 Mechanical properties of the pipeline steels used in the investigation

Table 4-8 Testing conditions for all corrosion fatigue tests including all of the samples

Table 4-9 Environmental and corrosion rate comparison of different steels.

Table 4-10 Critical combined factors and crack growth rate 
Hydrostatic test is a key method for managing SCC in oil and gas pipelines. Benefits are achieved by eliminating defects of critical size for the hydrotest pressure and hence achieving a post-test period without operating failure. Other benefits are related to temporary growth retardation after hydrotest because of crack tip blunting. Conversely, benefits of such a test could be offset by stable flaw growth in the previously dormant population and growth of cracks during hydrostatic loading. Although this type of growth behaviour has been previously analyzed by Leis and Brust [1], they only modelled the cracking advance from tests in air, which neglects the effects of the corrosive environment on the crack advance.

Chen and Sutherby [2] have recently conducted more than 10 laboratory simulations of hydrotests on cracks of various dimensions in $\mathrm{NNpH}$ soil environments. These simulations showed that crack growth can occur during hydrotests at much smaller crack dimensions than those originally analyzed by Leis et al. [1]. The simulations have also confirmed temporary retardation of crack growth after hydrotesting.

The adverse effect of hydrotesting is negligible if it initiates crack growth only on large-size cracks that are near the final stage of pipeline life, a situation being analyzed in Ref [1]. However, benefits of hydrotest would become uncertain if hydrostatic loading induces crack growth when crack dimensions are relatively small, which our simulations indicate can occur. For example, the observed crack advance of $0.5 \mathrm{~mm}$ in the shorter cracks corresponds to approximately two years growth at a typical in-service crack growth rate of $10^{-8} \mathrm{~mm} / \mathrm{s}$. This reduction is significant considering the fact that several hydrotests may be performed in the lifetime of a pipeline. Although hydrotests would usually re-condition the crack tip so that a lower crack growth rate can be expected for a limited time, it is questionable whether the reduced growth rate would compensate for the loss of life because of the crack growth during hydrotesting. Therefore, the overall benefits of hydrotesting must be evaluated from the viewpoint of life extension and pipeline safety.

It was determined by Chen and Sutherby [3] that the so-called NNpH SCC can be best fit into a true corrosion fatigue (CF) model using $\Delta K^{2} K_{\max } / f^{\gamma}$ for long cracks, where $\Delta K$ is the stress intensity factor range, $K_{\max }$ the maximum stress intensity factor, $f$ the loading frequency, and $\gamma$ a factor related to the corrosivity of the environments. All actively growing long cracks approach the same CF curve, where the threshold value separates active crack growth from dormancy. Chen also plotted the growth data of small surface cracks from cyclic loading of full scale pipe tested by CANMET [4], which shows a similar growth trend above the threshold value of long cracks but active crack growth below the threshold conditions. Cracks on both liquid lines and gas lines spend most of their life as small cracks.

A hydrotest corresponds to one-cycle of fatigue in behaviour. Crack growth arising from the cyclic loading in a hydrotest can be predicted by the above CF model [3]. This prediction is presented together with the values obtained from experiments in Fig. 1-1. The predicted line generally agrees well with the experimental values. Deviations, however, are seen when crack sizes are small (the circled region), which should result from the effect of crack dimension on 
growth rate. The experimental values for growth rate were obtained using long crack specimens [for example, compact tension (CT) specimen]. Small or shallow cracks can grow at appreciable rates below the threshold of long cracks. This prediction also suggests that crack growth in hydrotests can occur at very small crack size, e.g., as low as $10 \%$ of wall thickness.

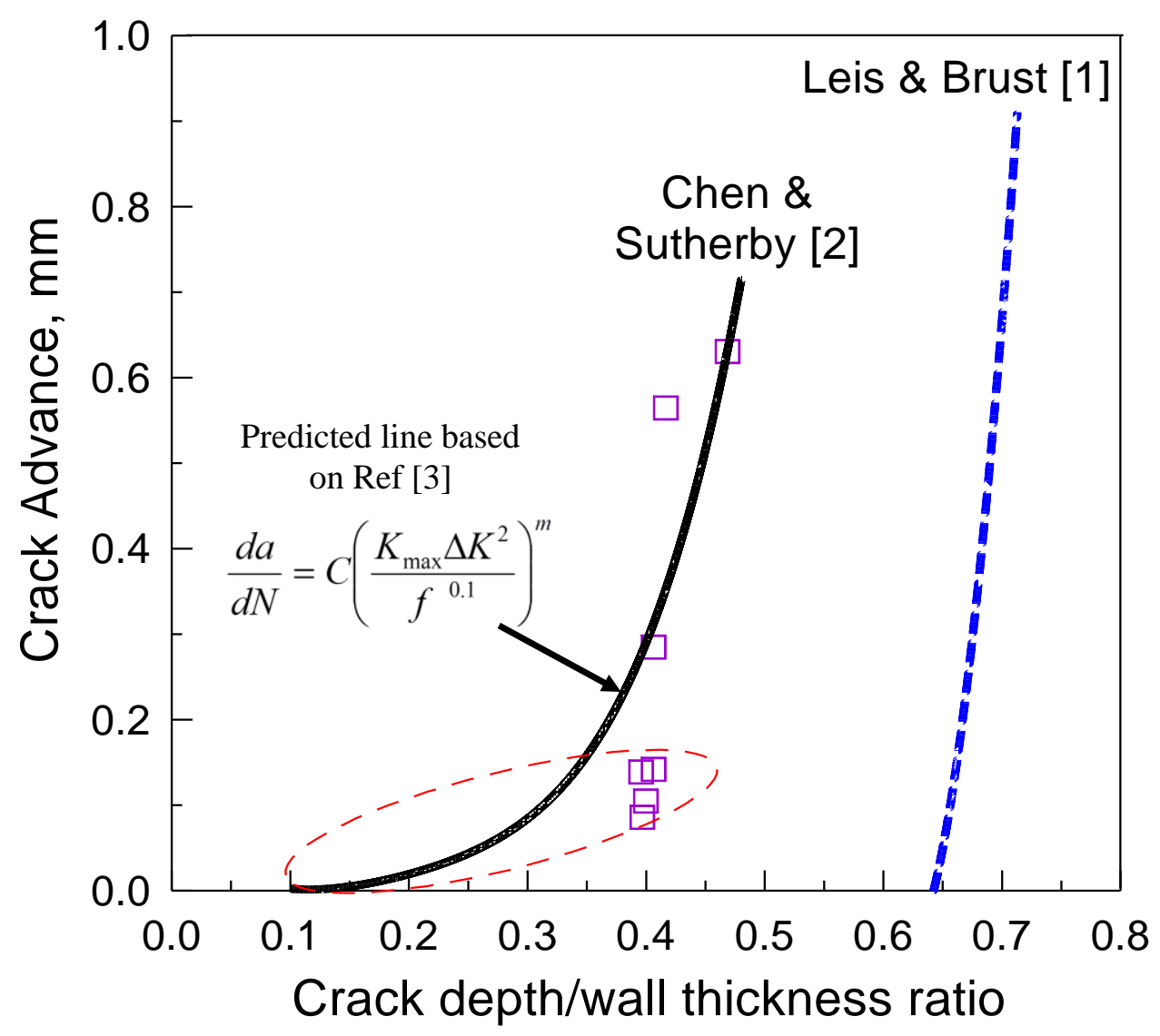

Fig. 1-1 Predicted crack growth caused by hydrotest based on CF model [3] and test results from [2]

The above CF model provides ways of minimizing crack growth during hydrotests. Loading frequency is an obvious variable that can be optimized to reduce crack growth. Step loading to attenuate the effect of $\Delta \mathrm{K}$ may also be effective in minimizing the crack growth, since as frequency increases the crack growth decreases.

It has been determined recently that hydrogen is a key factor in governing the crack growth in pipeline steels exposed to near neutral $\mathrm{pH}$ environments [6-11]. The increase of hydrogen concentration in the steel promotes the crack propagation [10] and reduces fracture toughness of pipeline steel [11]. Gangloff [12] has categorized the hydrogen effects on crack growth into the following two types: internal-hydrogen-assisted cracking (IHAC) and hydrogen-environmentassisted cracking (HEAC). Fig.1-2 [12-13] is a graphical representation of the above two 
mechanisms. IHAC and HEAC are distinguished by the source of the hydrogen that causes cracking. In HEAC, atomic hydrogen is produced on the crack surface and diffuses to the crack tip. In IHAC, atomic hydrogen diffuses through the crystal lattice to the crack tip from other regions. It has been determined by Chen [6] that IHAC is primarily responsible for the crack growth in pipeline steels exposed to near-neutral pH environments.

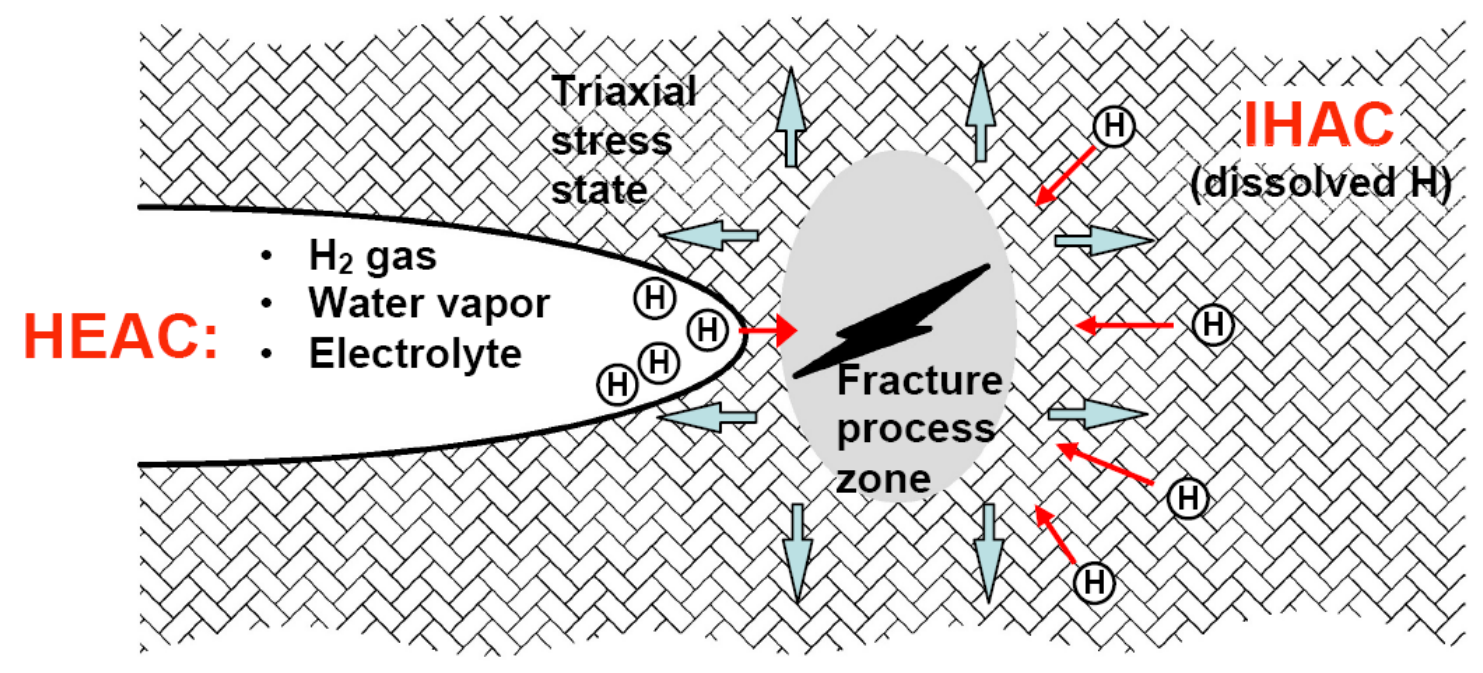

Fig. 1-2 Schematic showing environmentally assisted cracking driven by hydrogen embrittlement.

Low temperature creep (LTC) is another factor that may be crucial to produce effective crack remediation during hydrotests [5]. LTC generates plastic deformation during pressure holding or during loading at low loading rates that can blunt the crack tip and subsequently lower the growth rate. At the same time, it may work-harden the material at the crack tip [5], which would usually yield a higher risk of hydrogen embrittlement (HE), particularly for cracks that were at the dormant state prior to hydrotest, and because the growth of NNpH SCC follows the mechanisms of $\mathrm{HE}$, as is now believed.

In order to better understand the blunting of crack tip as caused by low temperature creep and the sharpening of crack tip caused by competing hydrogen and/or fatigue mechanisms, a change of crack tip morphology before and after test in near neutral $\mathrm{pH}$ environment is shown in Fig. 1-3. The crack morphology in the inset of Fig. 1-3 was produced by pre-fatigue cracking in air, which is usually considered to be a sharp crack. A specimen with this sharp crack morphology was exposed to near neutral $\mathrm{pH}$ environment under cyclic loading for a few weeks. In the first two weeks, the specimen was loaded under a cyclic load waveform that had not caused any crack growth as monitored by potential drop system (an accurate technique to detect crack growth). It is clear in Fig. 1-3 that the sharp crack before corrosion exposure had become a blunt one after corrosion exposure, for which the defect had better defined as a 
"notch". After the initial exposure for two weeks, the same specimen was loaded with more severe cyclic loading, a new crack with a sharp morphology had initiated from blunt root of the notch. This simply demonstrates the so-called competitive crack tip sharpening and blunting phenomenon of pipeline steels in near-neutral $\mathrm{pH}$ environments. This sharpening-blunting phenomenon is a key to the understanding of cracking mechanisms and also forms the basis of crack growth modelling and crack growth control in the field to be described in this report.

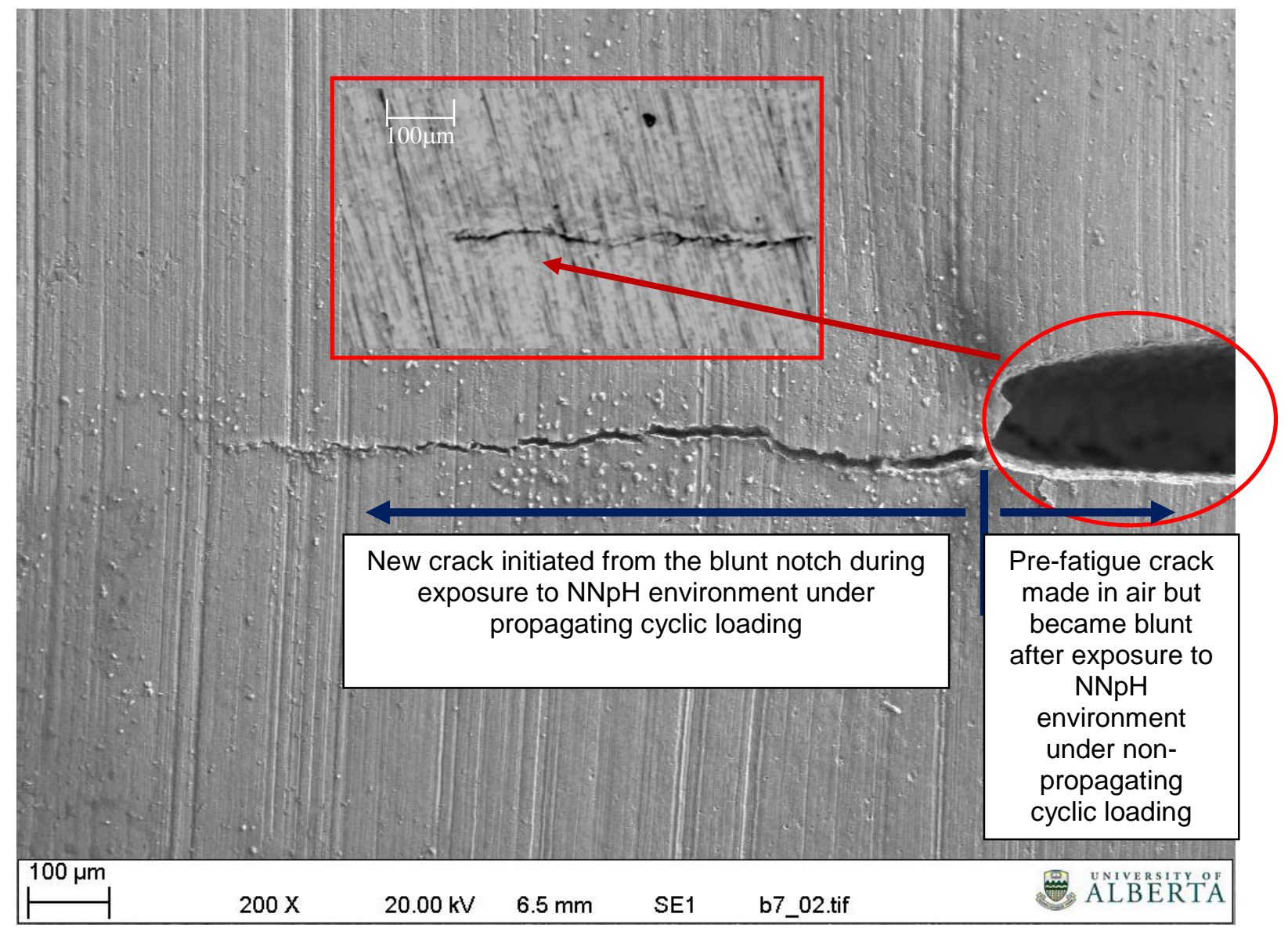

Fig. 1-3 A change of crack tip morphology due to low temperature creep

\section{References}

1. B. N. Leis, F. W. Brust, "Hydrotest Strategies for Gas Transmission Pipelines Based on Ductile-Flaw-Growth Considerations”, NG-18 Report No\# 194, July 31, 1992

2. W. Chen, R. L. Sutherby, "Laboratory Simulation of Hydrostatic Test in Near-Neutral pH Soil Environments", International Pipeline Conference 2006, paper \# IPC06 10477

3. W. Chen, R. L. Sutherby, Met. \& Mater. Trans A, 38A, 1260-1268, 2007.

4. W. Zheng, B. Tyson, G. Shen, R. W. Revie, et al , GRI Report\# GRI-05/8668, 2005.

5. S. Wang, W. Chen, Mater. Sci. Eng A. A301, (2001) 147-153. 
6. W. Chen, R. Kania, R. Worthingham, G.V. Boven, Tansgranular crack growth in the pipeline steels exposed to near-neutral pH soil aqueous solutions: the role of hydrogen, Acta Mater., 57 (2009), 6200-6214.

7. W. Chen, F. King and E. Vokes, Characteristics of near-neutral-pH stress corrosion cracks in an X-65 pipeline, Corrosion, 58 (2002), 267-275.

8. S. Asher, P.M. Singh, Hydrogen production and permeation of X-65 pipeline steel in nearneutral pH environments, Corrosion 2008, NACE International, Houston, 2008, paper No. 08411.

9. B.T. Lu, J.L. Luo, P.R. Norton, H.Y. Ma, Effect of dissolved hydrogen and elastic and plastic deformation on active dissolution of pipeline steel in anaerobic groundwater of near-neutral $\mathrm{pH}$, Acta Mater., 57 (2009) 41-49.

10. B.T. Lu, J.L. Luo and P.R. Norton, Environmentally assisted cracking mechanism of pipeline steel in near-neutral pH groundwater, Corrosion Science, 52 (2010) 1787-1795.

11. R. Wang, Effects of hydrogen on the fracture toughness of a X70 pipeline steel, Corrosion Science, 51 (2009) 2803-2810.

12. R.P. Gangloff, Hydrogen-assisted cracking, in: I. Milne, R.O. Ritchie, B. Karihaloo (Eds), Comprehensive Structure Integrity, volume 6: Environmentally-Assisted Fracture. Elsevier, Oxiford, 2003, vol. 6, pp.31-34.

13. T.L. Anderson, Fracture Mechanics: Fundamentals and Applications, third ed., CRC press, Taylor \& Francis, Boca Raton, 2005.

\section{OBJECTIVE AND SCOPE}

It is obvious that a dilemma is associated with hydrotesting on pipelines experiencing SCC cracks, as indicated in Introduction. The ultimate goal of the proposed research is to determine how maximum crack remediation effect can be achieved from optimized hydrotesting. The following are two specific objectives of the proposed research:

- To design practical hydrotesting procedures that would bring about the least crack growth induced by hydrostatic loading but the maximum post crack growth retardation.

- To establish a working model that will allow industry to predict the overall benefits of hydrotesting. The model will be designed to determine the effect of various factors of a pipeline on crack remediation including type of operation, stage of cracking, environmental corrosivity, steel metallurgy, and operation history.

The report will start with simulations of hydrotests under various conditions. The results of simulation will be analyzed to determine the fundamental natures of materials, environments and mechanical conditions that are responsible for achieving maximum crack remediation effect from hydrostatic loading. At the end, recommendations will be made for the purpose of optimized hydrostatic testing to achieve maximum crack remediation effect, pipeline safety and lifetime extensions. Accordingly, the report is structured with the following topic sections. 
- Simulation of Crack Growth during Hydrostatic Testing of Pipeline Steel in Near-neutral pH Environment

- Understanding of crack growth in near-neutral pH Environments

- Development of hydrostatic test guidelines

- Recommendation

\section{SIMULATION OF CRACK GROWTH DURING HYDROSTATIC TESTING OF PIPELINE STEEL IN NEAR-NEUTRAL PH ENVIRONMENT}

\subsection{Introduction}

This section will primarily focus on experimental simulation of hydrostatic tests to determine how various variables in hydrostatic tests will affect crack growth induced by hydrostatic loading. The variables being studied are as follows:

- Effect of crack dimensions

- Effect of loading rate

- Effect of pressure hold

- Effect of hydrostatic test on post hydrostatic test crack growth

\subsection{Experimental Approach}

Hydrostatic simulations were performed on X-65 pipeline steel (Grade $448 \mathrm{MPa}$ ) with a ferritepearlite microstructure. Standard compact tension (CT) specimens were machined from X-65 pipe with the machined notch perpendicular to the pipe hoop direction. The thickness of the CT specimens was $9 \pm 0.2 \mathrm{~mm}$. The X-65 pipe was removed from SPECTRA ENERGY transmission system and was identified to have developed near-neutral $\mathrm{pH}$ stress corrosion cracks after service for 15 years.

Fatigue pre-cracking was performed to produce a sharp crack tip from the machined notch, according to the procedures described in ASTM E647-08. The length of pre-crack on both sides of the CT specimen surface was controlled to $\sim 2.5 \mathrm{~mm}$ with the actual difference less than 0.1 $\mathrm{mm}$. To achieve an accurate measurement, the surfaces of the CT specimens were polished to 600 grit finish prior to pre-fatigue cracking in air and the crack length was measured using an optical microscope.

As shown in Fig. 3-1, the pre-fatigue cracked CT specimen was coated in two different ways to generate different scenarios of hydrogen sources for crack growth. Fig. 3-1a was defined as Type I, which is for the so-called "internal-hydrogen assisted cracking", for which the region of the specimen surface with cracks was coated so that hydrogen is only allowed to be generated on the specimen surface and to diffuse to the crack tip through thickness. The distance between 
the edge of the coating strip and the center of the specimen was less than a half of the thickness $(4.5 \mathrm{~mm})$ of the specimen. Before hydrotesting simulation, the specimen was exposed to a near-neutral $\mathrm{pH}$ environment under a very low load (approximately $0.5 \mathrm{kN}$ ) for about $300 \mathrm{~h}$, which was determined based on the diffusivity of hydrogen in steel $\left(2 \times 10^{-7} \mathrm{~cm}^{2} / \mathrm{s}[1]\right.$ and would be required for hydrogen to reach to the center of the specimen. The hydrogen concentration in the steel is less than $1 \mathrm{ppm}$ after $300 \mathrm{~h}$ immersion in near-neutral pH environment [1, 2].

(a)

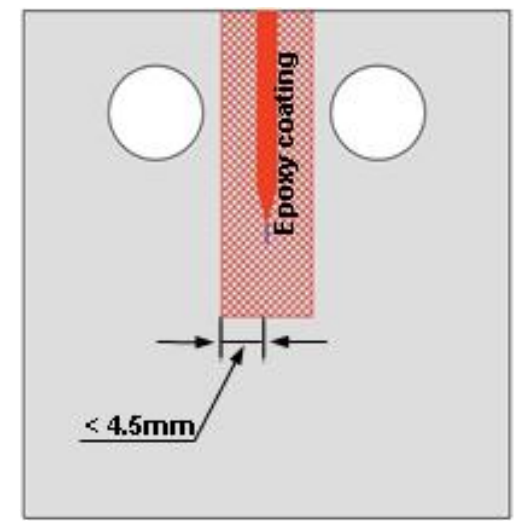

(b)

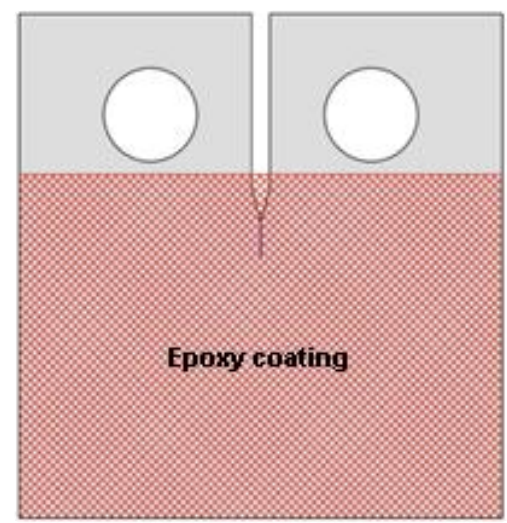

Fig. 3-1 Schematic showing (a) Type I specimen for internal-hydrogen-assisted cracking; (b) Type II specimen for hydrogen-environment-assisted cracking.

Type II specimen (Fig. 3-1b) was designed to study the hydrogen-environment-assisted cracking, for which hydrogen is generated at the crack tip and within the crack crevice. For this purpose, the specimen surface was completed covered with epoxy coating except for the mouth of the specimen. The entire specimen will be pre-exposed to near-neutral $\mathrm{pH}$ solution just for $0.5 \mathrm{~h}$ before hydrostatic simulation to stabilize the potential system. With the setup, only the crack crevice and the crack tip will be exposed to the aqueous solution used.

Some of the hydrostatic simulations were also carried out after a period of static hold at about $75 \%$ minimum yield strength (SMYS) for $24 \mathrm{~h}$ in air. This was done to introduce roomtemperature creep at the crack tip. The room temperature creep can blunt the crack tip and reduce the stress intensity factor at the crack tip.

The specimens for hydrostatic simulation were exposed to a synthetic soil solution (C2 solution [3]) with the following chemical composition: $274 \mathrm{mg} / \mathrm{L}$ magnesium sulfate $\left(\mathrm{MgSO}_{4}\right), 255 \mathrm{mg} / \mathrm{L}$ calcium chloride $\left(\mathrm{CaCl}_{2}\right), 606 \mathrm{mg} / \mathrm{L}$ calcium carbonate $\left(\mathrm{CaCO}_{3}\right), 195 \mathrm{mg} / \mathrm{L}$ sodium bicarbonate $\left(\mathrm{NaHCO}_{3}\right)$ and $35 \mathrm{mg} / \mathrm{L}$ potassium chloride $(\mathrm{KCl})$. The solution was purged with $5 \% \mathrm{CO}_{2}$ balanced by $\mathrm{N}_{2}$, before and during the testing to achieve a near-neutral $\mathrm{pH}$ value of about 6.29. The temperature of the solution and environment was controlled to $30 \pm 0.1{ }^{\circ} \mathrm{C}$.

The laboratory simulations of hydrostatic testing were performed using a horizontal pneumatic loading machine with the CT specimens pin-hole loaded and sealed in test cell filled with the solution. A self-assembled potential drop system was used to measure the crack size during the 
simulation experiments, which was described in Reference [4]. The hydrostatic pressure (stress) scheme is given in Fig. 3-2. The maximum stress of $110 \%$ SMYS was maintained for $1 \mathrm{~h}$ for strength test. After the strength test, the loading was decreased to $100 \%$ SMYS and held at the stress level for $4 \mathrm{~h}$, which was termed as leaking test. Thereafter, the specimens were unloaded to $0.5 \mathrm{KN}$ again and maintained for about $6 \mathrm{~h}$ to achieve stable readings of potential drops. Two loading procedures, named as 1-step and 2-step sequence, were used during the loading to $110 \%$ SMYS in the first $3.5 \mathrm{~h}$ to study the effect of loading rate on crack growth.

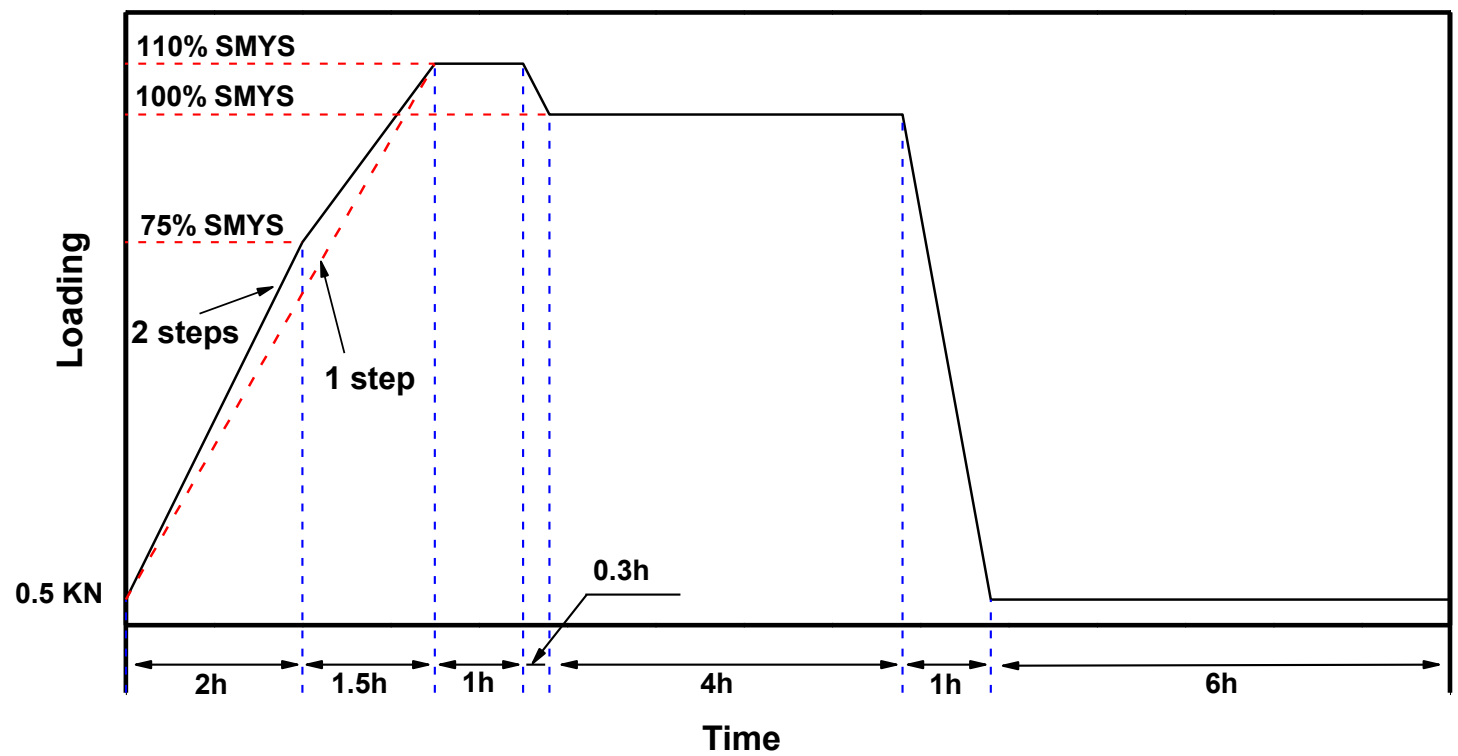

Fig. 3-2 Simulated loading procedure for hydrostatic testing.

In 1-step loading, the same loading rate was maintained during the loading to $110 \%$ SMYS, while in the 2-step loading, different loading rates were used before and after the load was reached to $75 \%$ SMYS, as illustrated in Fig. 3-3, in which two categories of loading procedures are defined: the $1^{\text {st }}$ stage up to $75 \%$ SMYS (specified minimum yield strength), category I in Fig. $3-3$, and the $2^{\text {nd }}$ stage from $75 \%$ to $110 \%$ SMYS, category II in Fig. 3-3.

In this research, the level of stress used during hydrostatic testing was determined based on typical dimensions of surface cracks developed in the pipelines in the field. From characteristics of cracks found in the field, a semi-elliptical shaped crack with a length/depth of $10(2 \mathrm{c} / \mathrm{a}=10.2 \mathrm{c}$ : surface length of crack; a: crack depth) in a pipe with a thickness of $9.88 \mathrm{~mm}$ was assumed and used to calculate the stress intensity factor. From the calculation based on the above assumption, a stress intensity factor of $33.7 \mathrm{MPa} \cdot \mathrm{m}^{1 / 2}, 55.1 \mathrm{MPa} \cdot \mathrm{m}^{1 / 2}$ and $68.7 \mathrm{MPa} \cdot \mathrm{m}^{1 / 2}$ at the crack tip in the depth direction can be achieved when a semi-elliptical crack with a depth of 1.5 $\mathrm{mm}, 3.22 \mathrm{~mm}$ and $4.22 \mathrm{~mm}$, respectively, is loaded to $100 \%$ SMYS. With the stress intensity factor as the bridge, the surface cracks with different depth could be converted to the CT specimens (same pre-crack length: $\sim 2.5 \mathrm{~mm}$ ) with different loading in lab simulation. A total of 18 specimens were investigated including two samples tested in lab air. Table 3-1 lists the test conditions of all the specimens used in this investigation. 

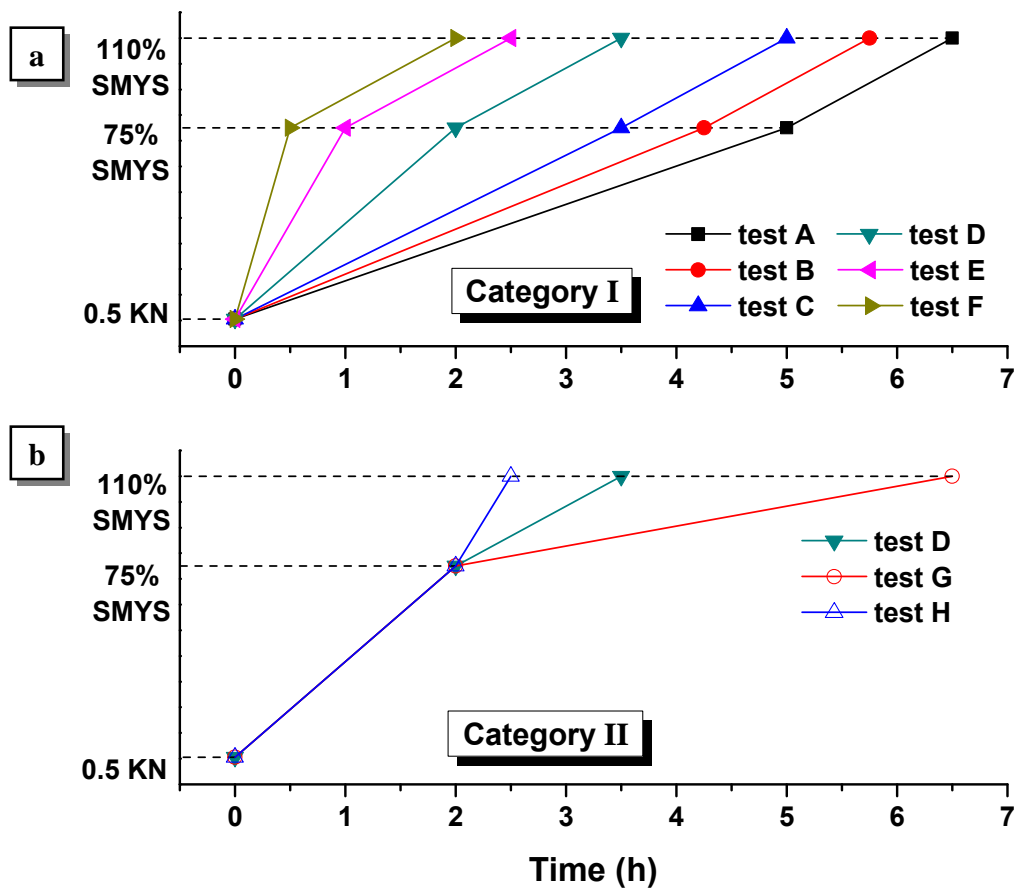

Fig. 3-3 Different loading rates used during hydrostatic loading in Stage I a) and Stage II b).

Table 3.1 Matrix of experiment conditions

\begin{tabular}{cccccc}
\hline Sample No. $\begin{array}{c}\text { Assumed } \\
\text { crack depth } \\
(\mathrm{mm})\end{array}$ & $\begin{array}{c}\text { Hydrogen } \\
\text { condition }\end{array}$ & $\begin{array}{c}\text { Creep } \\
\text { conditio } \\
\text { n }\end{array}$ & $\begin{array}{c}\text { Loading } \\
\text { type }\end{array}$ & $\begin{array}{c}\text { Testing } \\
\text { environme } \\
\text { nt }\end{array}$ \\
\hline CT-01 & 1.5 & Type I (IHAC) & No & 2-step & C2 \\
CT-02 & 1.5 & Type I & Yes & 2-step & C2 \\
CT-03 & 1.5 & Type II (HEAC) & No & 2-step & C2 \\
CT-04 & 1.5 & Type II & Yes & 2-step & C2 \\
CT-05 & 3.22 & Type I & No & 2-step & C2 \\
CT-06 & 3.22 & Type I & Yes & 2-step & C2 \\
CT-12 & 3.22 & Type II & No & 2-step & C2 \\
CT-07 & 3.22 & Type II & Yes & 2-step & C2 \\
CT-13 & 3.22 & Type I & No & 1-step & C2 \\
CT-10 & 3.22 & Type I & Yes & 1-step & C2 \\
CT-14 & 3.22 & Type II & No & 1-step & C2 \\
CT-15 & 3.22 & Type II & Yes & 1-step & C2 \\
CT-17 & 3.22 & & No & 2-step & Air \\
CT-18 & 3.22 & & Yes & 2-step & Air \\
CT-21 & 4.22 & Type I & No & 2-step & C2 \\
CT-22 & 4.22 & Type I & Yes & 2-step & C2 \\
CT-19 & 4.22 & Type II & No & 2-step & C2 \\
CT-20 & 4.22 & Type II & Yes & 2-step & C2 \\
\hline
\end{tabular}


After the test was finished, the specimen was removed immediately from the solution and cleaned with acetone and dried to prevent any corrosion. Some of the specimens were sectioned to observe the crack tip morphologies and crack growth paths. All the specimens were fractured in liquid nitrogen and the fractured surfaces were examined on scanning electron microscope (SEM).

\subsection{Results}

\subsubsection{Effect of crack dimension}

\section{Crack growth behaviour of $1.5 \mathrm{~mm}$ deep crack}

Fig. 3-4 shows the change of measured potential with the hydrostatic simulation time for the four CT specimens (CT-01, CT-02, CT-03, CT-04) corresponding to a crack depth of $1.5 \mathrm{~mm}$. Details of the testing condition for the four samples are given in Table 3-1. The potential curves were normalized to the same beginning potential value. The general trend of the potential drop curves of all the 4 tests is similar, which features with an increase in potential with loading and a decrease in potential with unloading. However, the final level of potentials of the four tests was quite different. The final potential was usually lower than the potential recorded before hydrostatic test. It is known that the potential changes are related to the electric resistance between the two measuring points, which can be affected by several factors in the current system, such as the crack length, the degree of crack closure during unloading, the width of crack mouth and stress level applied to the samples. Therefore, the variation of potential cannot be solely related to the increase of electric resistance arisen from crack propagation.

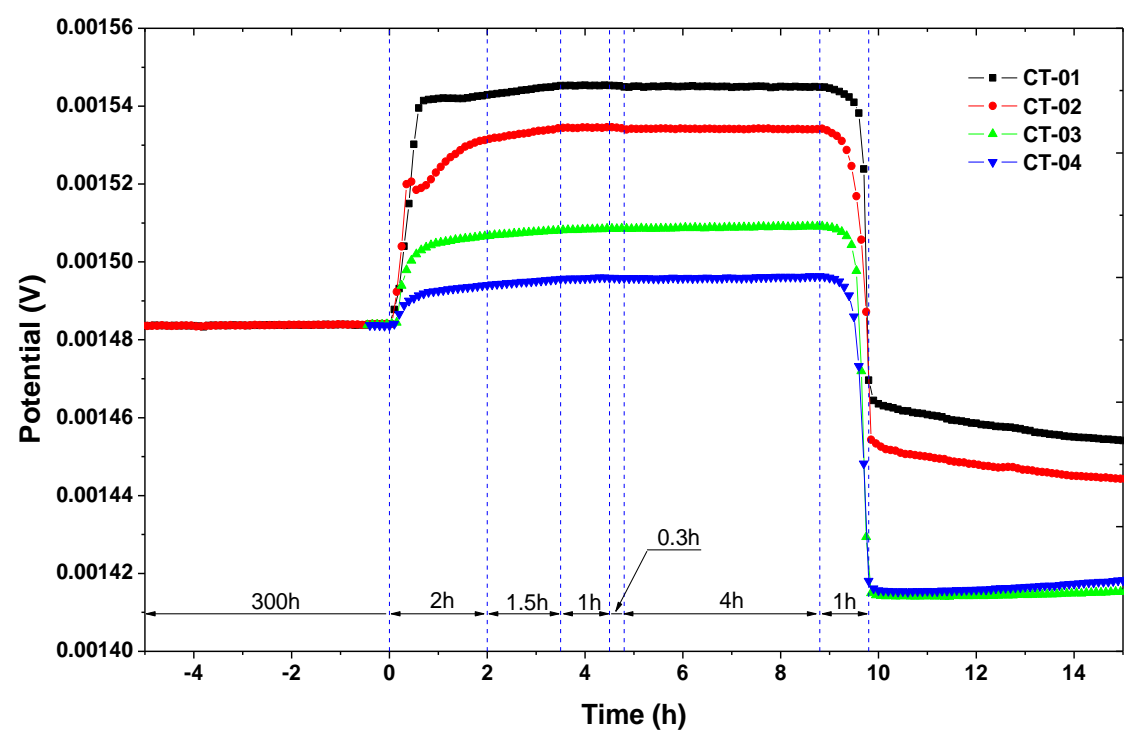

Fig. 3-4 Potential changes during hydrostatic test simulation for the cracks with assumed depth of $1.5 \mathrm{~mm}$. 
The actual crack growth during hydrostatic testing was determined on the fractured Surface examined on SEM. Fig. 3-5 shows the fracture surface morphology of the above four samples after hydrostatic test. Two distinct regions on the fracture surface can be identified in Fig. 3-5: a region with cleavage morphology corresponding to the fracture in liquid nitrogen and the region adjacent to the cleavage morphology, which must be formed by pre-fatigue cracking in air prior to the hydrostatic testing. These SEM observations suggest that crack growth of the $1.5 \mathrm{~mm}$ deep-cracks has not occurred during hydrostatic tests.

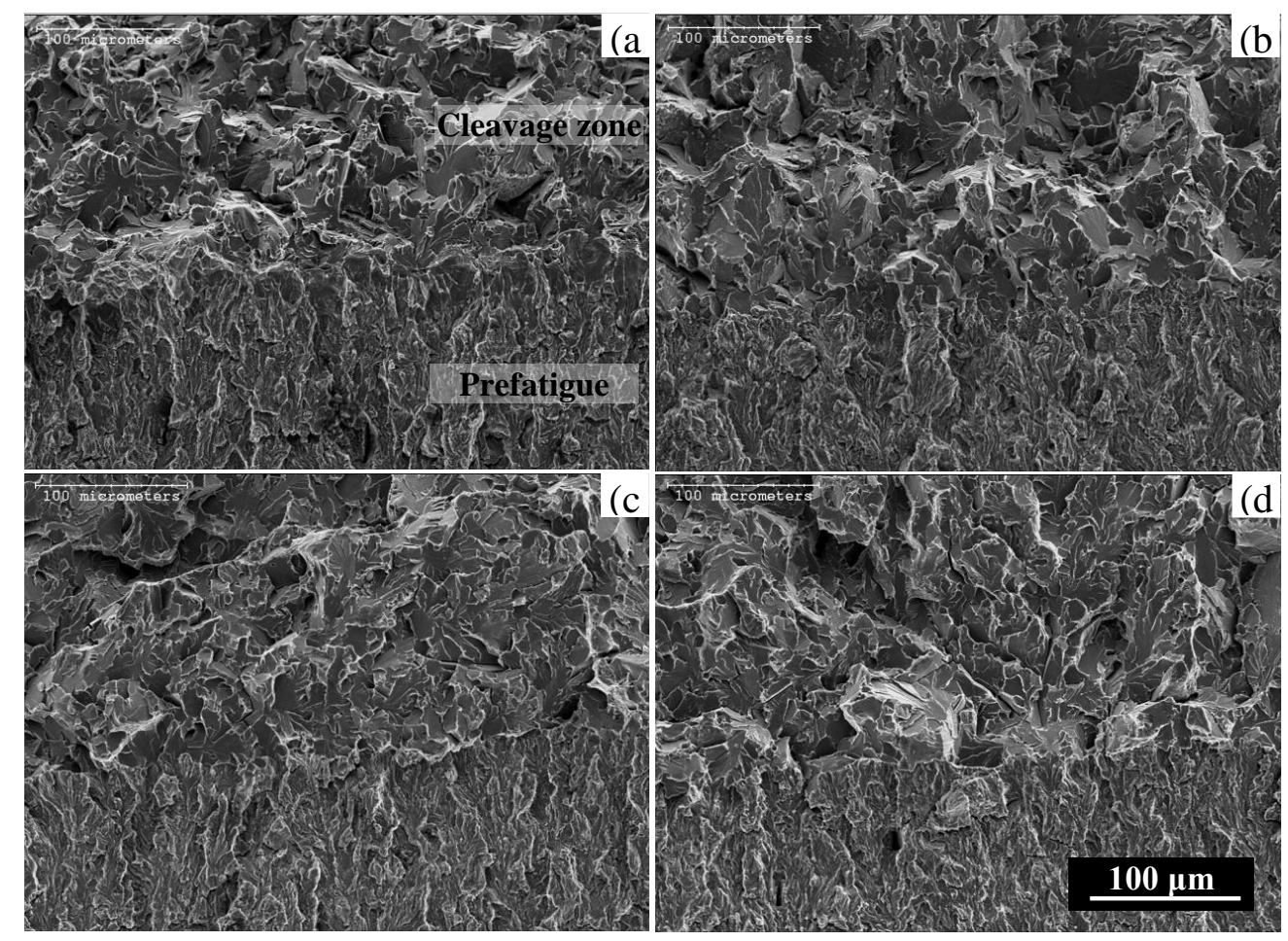

Fig. 3-5 SEM photographs showing fracture surface morphology of specimen (a) CT-01, (b) CT-02, (c) CT-03 and (d) CT-04 after hydrostatic testing.

\section{Crack growth behavior of $3.22 \mathrm{~mm}$ deep crack}

Since no growth was measured for the $1.5 \mathrm{~mm}$ deep crack, the load was increased to simulate hydrostatic test on cracks with larger depths. According to the Reference [5], the crack with a depth of $3.22 \mathrm{~mm}$ would propagate, which was the reason that we selected the $3.22 \mathrm{~mm}$ deep crack.

Fig. 3-6 compares the measured potentials of the specimens for the cracks with a depth of 3.22 $\mathrm{mm}$ before and after hydrotest simulation in $\mathrm{C} 2$ solution. As shown in Fig. 3-6, the final potentials recorded on type I specimens that were tested with 2-step loading (CT-05, CT-06) were higher than the potentials measured prior to the hydrostatic test. For type II specimens (CT-12, CT-07) tested with 2-step loading, the potentials decreased after the simulation. For all 
specimens with 1-step loading, the final potentials recorded were lower than those recorded before hydrotest.

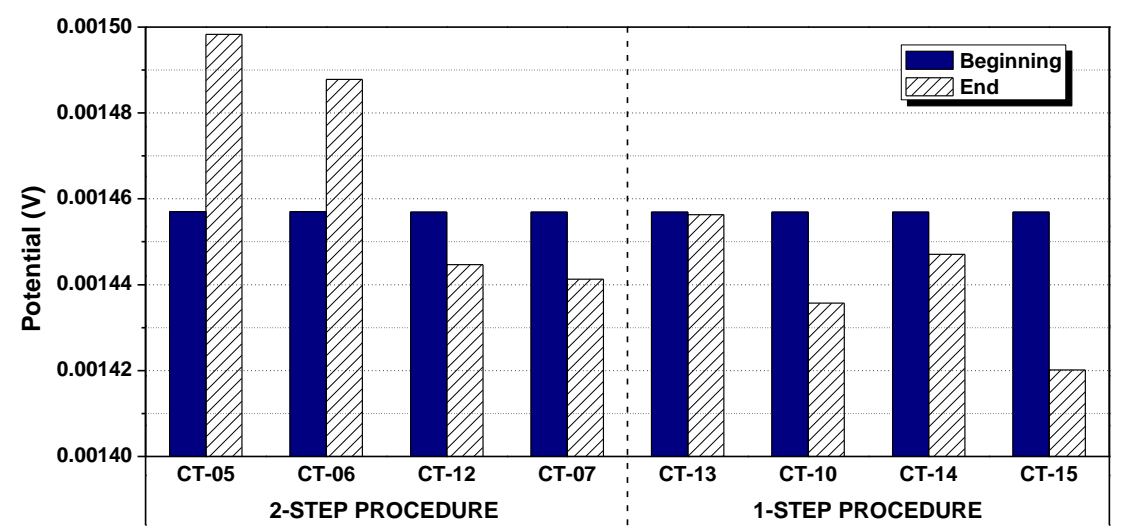

Fig. 3-6 The measured potentials of the specimens corresponding to crack with assumed depth of $3.22 \mathrm{~mm}$ before and after hydrostatic testing simulation with different procedure in $\mathrm{C} 2$ solution.
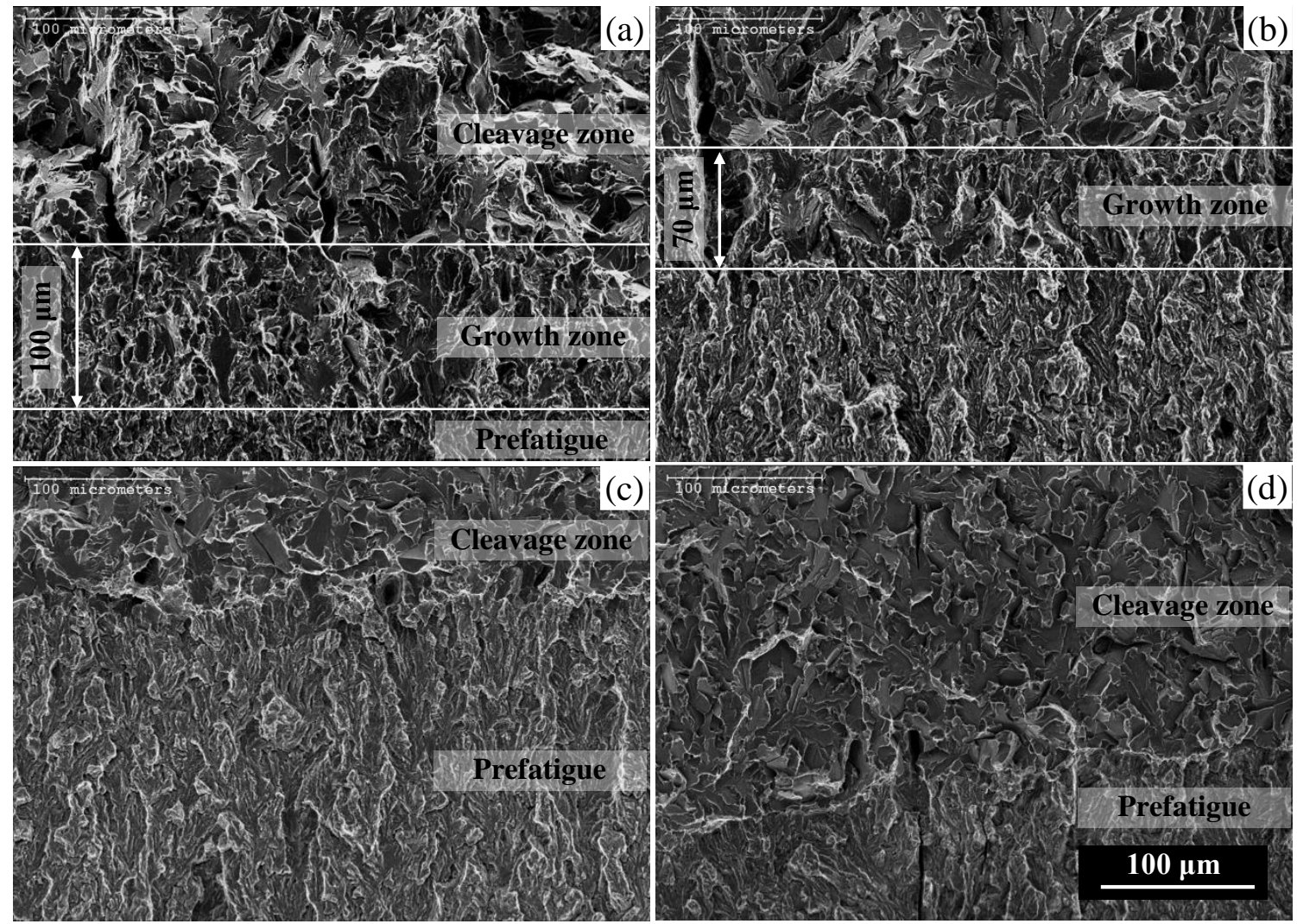

Fig. 3-7 SEM photographs showing fracture surfaces of specimens (a) CT-05, (b) CT-06, (c) CT-12 and (d) CT-07 tested in 2-step procedure hydrostatic testing simulation. 
Fig. 3-7 shows the fracture surfaces of the specimens with 2-step loading. Three characteristic zones, instead of two as observed in Fig. 3-5, can be identified on the fracture surface shown in Fig. 3-7a and 3-7b. A separate zone is found to be located between the cleavage zone formed after fracture in liquid nitrogen and the zone that was created by pre-fatigue in air. This zone appears transgranular and much rougher in morphology than the pre-fatigue zone. Its quasicleavage morphology seems consistent with that arisen from hydrogen embrittlement [6]. This zone was obviously formed by the hydrostatic loading. The length of the hydrotest cracking zone was measured on the SEM image shown in Fig. $7 \mathrm{a}$ and $7 \mathrm{~b}$ to be about $\sim 100 \mu \mathrm{m}$ and $\sim 70$ $\mu \mathrm{m}$ for the un-crept and the crept specimen, respectively, during the 2-step-hydrostatic loading of type I specimens. For type II specimens, however, there just existed two distinct zones corresponding to the pre-fatigue zone and the cleavage zone on the fractured surface, which indicates that no crack growth had occurred regardless whether these specimens were crept or not prior to the hydrostatic loading, Fig. 3-7c and 3-7d.
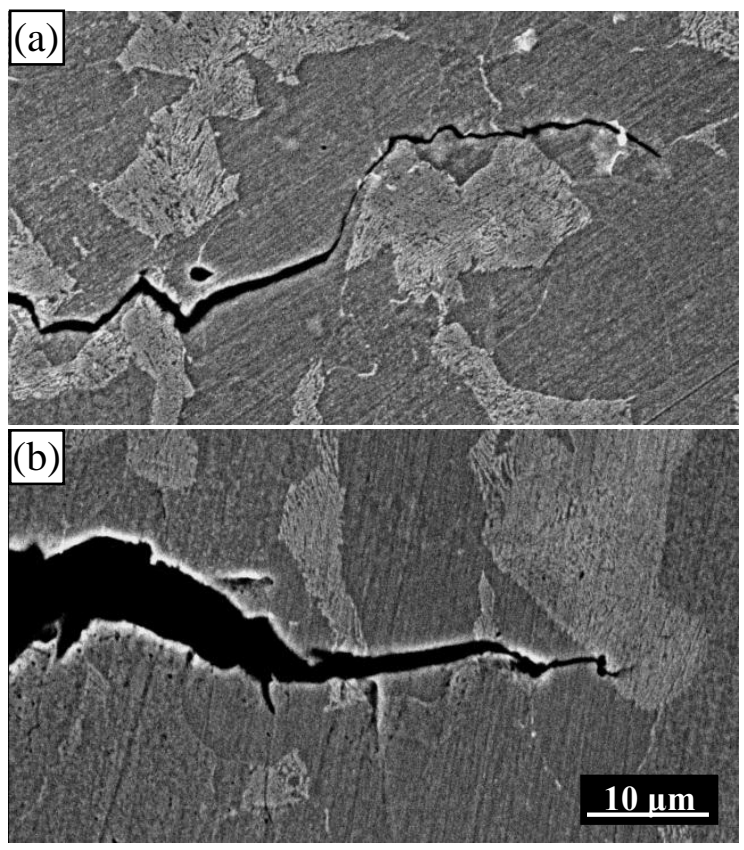

Fig. 3-8 Cross sections of specimens (a) CT-05 and (b) CT-06 after 2-step procedure hydrostatic testing simulation.

Fig. 3-8 shows the crack tip morphology of Type I specimens. A very sharp crack tip is clearly seen, which is consistent with the observations previously reported [6]. Comparing Fig. 3-8a with Fig. 3-8b, the crack tip of the un-crept sample appears sharper than that of the crept specimen. In both cases, cracks were found to propagate across the grains, indicating its transgranular nature, which is also consistent with the morphologies found on the fractured surface.

Fig. 3-9 shows the morphology on the fractured surface of the specimens with 1-step loading. The morphology of the un-crept type I specimen (Fig. 3-9a) was seen to be similar to that in 
Fig. 3-7a, except that the hydrostatic crack zone was shorter, about $\sim 45 \mu \mathrm{m}$. In contrast, no hydrostatic crack zone was found on the fracture surface of type I specimen with creep loading prior to the hydrotest. For Type II specimens, no crack growth was observed during hydrostatic testing.
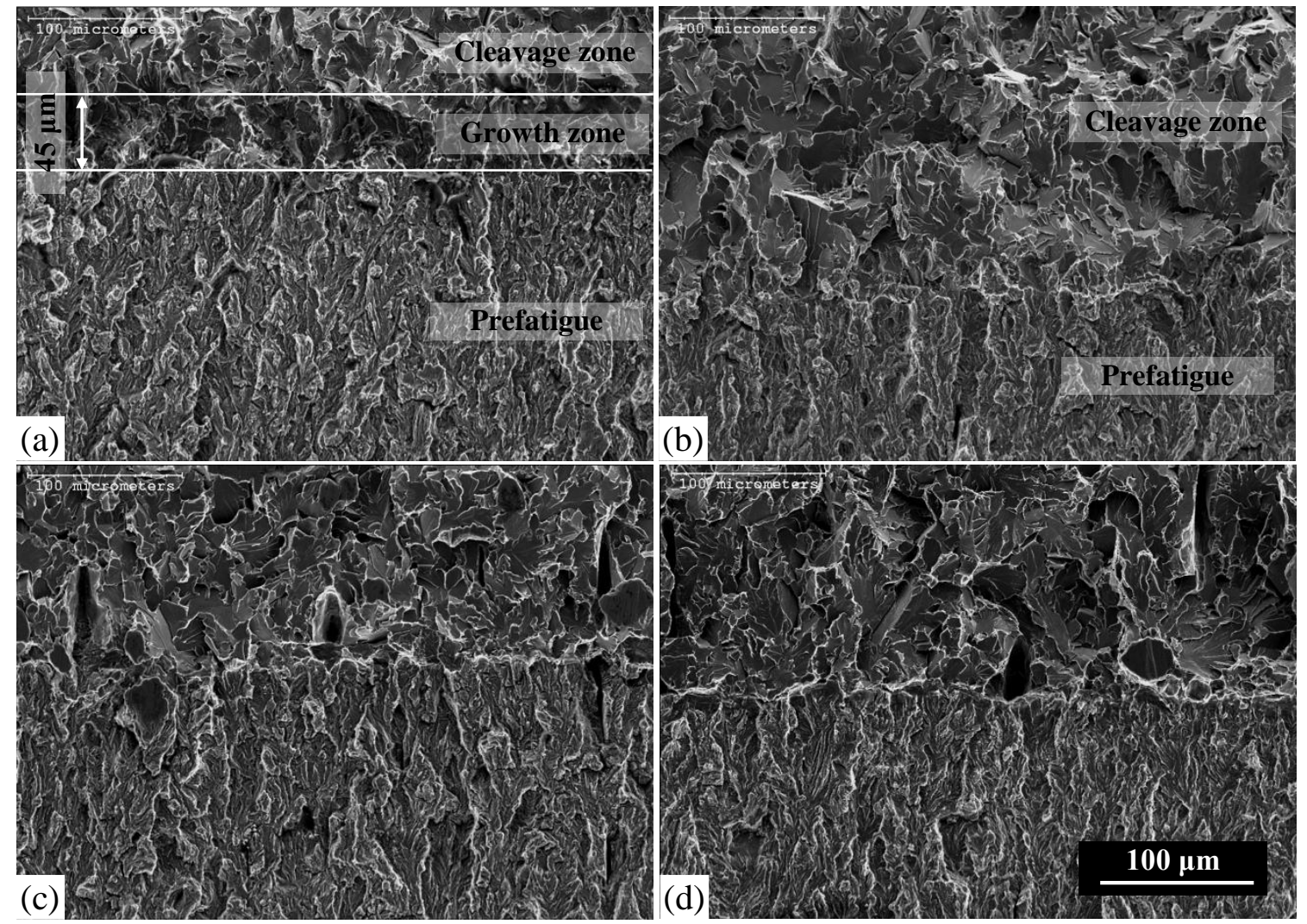

Fig. 3-9 SEM photographs showing fracture surfaces of specimens (a) CT-13, (b) CT-10, (c) CT-14 and (d) CT-15 after 1-step procedure hydrostatic testing simulation.

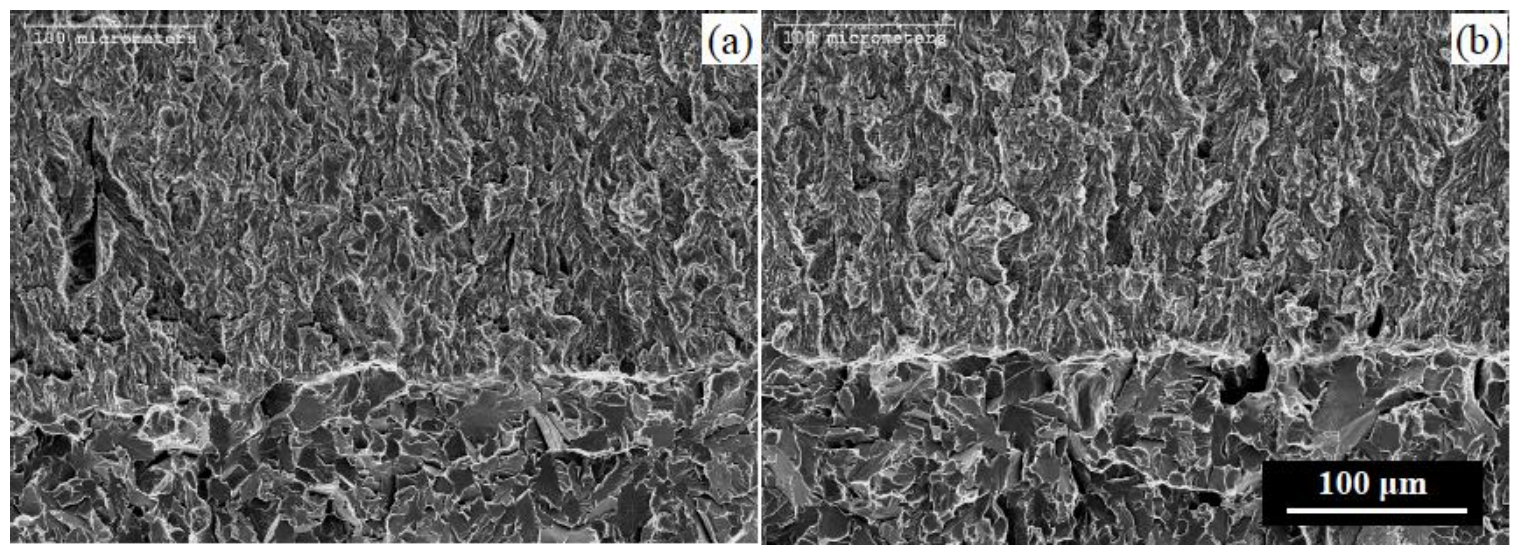

Fig. 3-10 SEM photographs showing fracture surfaces of specimens (a) CT-17, (b) CT-18 tested in air. 
In order to further validate the results of hydrostatic tests in near-neutral $\mathrm{pH}$ environments, the hydrostatic simulation with 2-step loading procedure was performed in air using specimens with and without creep deformation prior to hydrostatic simulation. The measured potentials after hydrostatic tests for the two bare specimens were lower than those recorded prior to the tests. There were only the pre-fatigue zone and the brittle cleavage zone found on the fractured surface (Fig. 3-10).

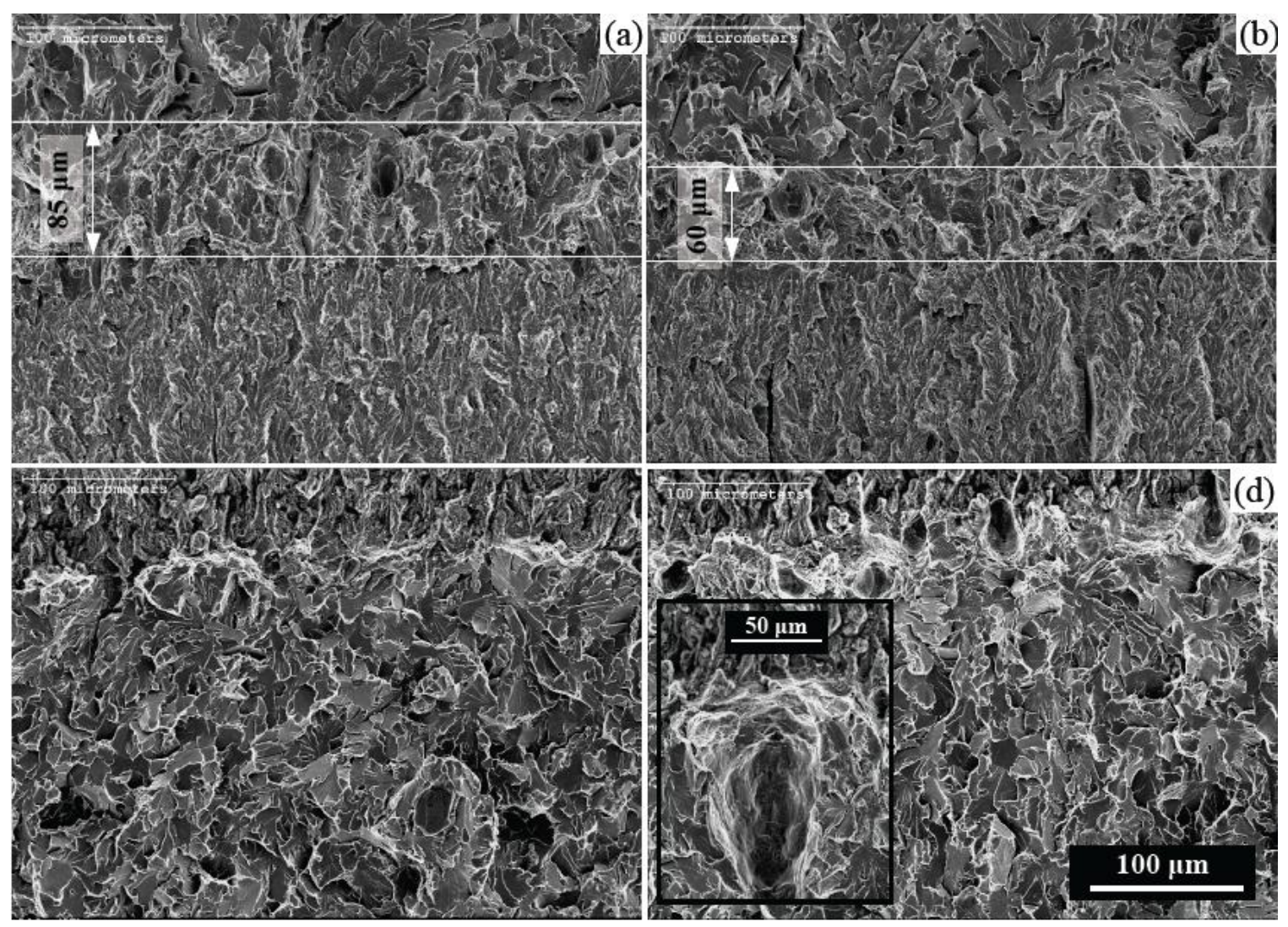

Fig. 3-11 Fracture surface morphology of specimen (a) CT-21, (b) CT-22, (c) CT-19, (d) CT-20.

\section{Crack growth behavior of $4.22 \mathrm{~mm}$ deep crack}

With an increase of crack depth, the stress intensity factor at the crack tip under the same hydrostatic testing will be higher. SEM observations made on the fractured surface indicated that the cracks had advanced for about $85 \mu \mathrm{m}$ for the non-crept- and $60 \mu \mathrm{m}$ for the crept-Type I specimen, as shown in Fig. 3-11a and 3-11b, respectively. However, no crack growth was observed for all Type II specimens (Fig. 11c and 11d). Interestingly, ductile dimples were found either within the hydrostatic growth zone of Type I specimens or at the boundary between the cleavage zone and the pre-fatigue zone of Type II specimens. These ductile fracture features were absent in hydrostatic simulation of the $1.5 \mathrm{~mm}$ cracks and the $3.22 \mathrm{~mm}$ cracks. 


\section{Discussion}

Crack growth of pipeline steels in near neutral $\mathrm{pH}$ environments has been recently characterized [7]. It is believed that crack growth in near neutral $\mathrm{pH}$ environments is related to two competitive processes at the crack tip: the intrinsic blunting and the extrinsic sharpening. The former originates from the low temperature creep at the crack tip due to either near-static loading or fatigue loading at very low frequency, and the active dissolution over the deformed crack tip without passivating the crack surface [8]. The extrinsic sharpening is governed by the mechanisms of fatigue and the hydrogen effects. A balance of both the intrinsic and extrinsic processes determines whether cracks will experience dormancy or active growth. It has further been determined from previous study that hydrogen produced by corrosion at the crack tip is secondary in terms of crack growth, as compared with the amount of hydrogen generated from pipeline surface either resulted from general corrosion or cathodic reaction.

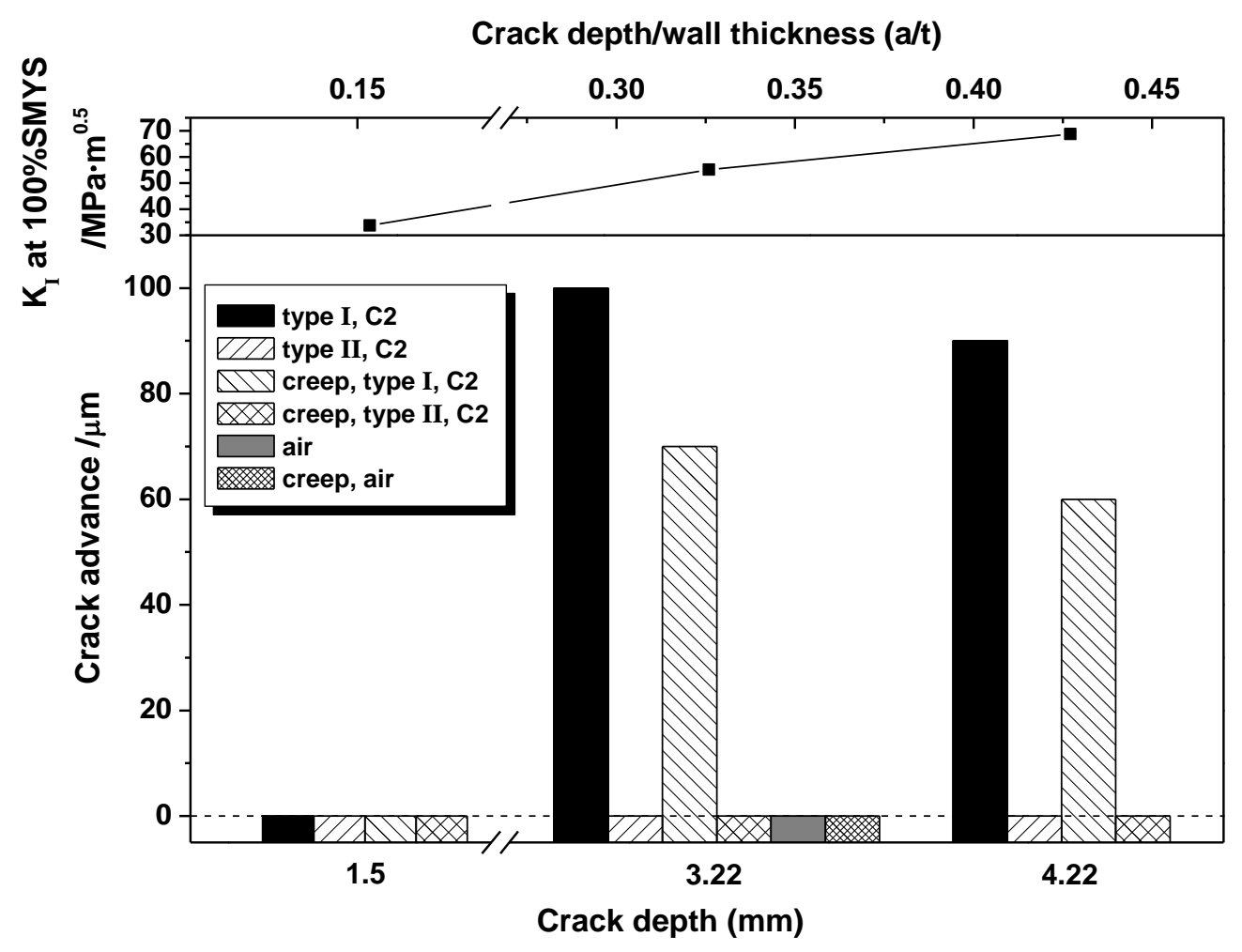

Fig. 3-12 Crack advance vs. crack depth or the ratio of crack depth/wall thickness with different experiment conditions. 
Hydrostatic test is a fatigue loading with only one cycle. The crack growth mechanisms previous proposed should be applicable to the crack growth occurring during hydrostatic tests [7-10]. As a matter of fact, the current investigation has further validated the mechanism of crack growth in near-neutral $\mathrm{pH}$ environment as previously proposed.

1) Effects of hydrogen: crack growth during hydrostatic test was found to occur only when Type I specimen was pre-exposed to near-neutral $\mathrm{pH}$ environment for adequate time, as summarized in Fig. 3-12. This suggests that internal-hydrogen assisted cracking should be the predominant mechanism governing pipeline cracking in near neutral $\mathrm{pH}$ environments. Since the crack tip of Type I specimen is not in direct contact with the near-neutral $\mathrm{pH}$ environment during pre-exposure, corrosion or hydrogen effects from corrosion at the crack tip, the so-called hydrogen-environment-assisted cracking, should play a minor role in nearneutral $\mathrm{pH}$ cracking, at least in the stage of crack growth. This is also consistent with the results of Type II specimens for which no crack growth has been observed in all hydrostatic simulations. All these suggest that the hydrogen sources on the pipe surface surrounding existing cracks, a scenario similar to that of Type I specimen, are the key to the crack growth.

2) Effect of loading procedure/Loading rate: Less crack growth was observed in 1-step loading. The difference of these two procedures in nature is the loading rate. The loading rate in 1step process, which is kept constant, is slower than the initial loading rate but higher than the $2^{\text {nd }} /$ final loading rate of 2-step loading. It has been well studied that lower loading rate in near-neutral $\mathrm{pH}$ environments would yield higher crack growth per cycle. Based on this, it can be concluded that loading rate in the $2^{\text {nd }}$ stage of 2-step loading is most important in terms of crack growth.

3) Effect of room temperature creep: Crack growth induced by hydrostatic loading was consistently found to be smaller when Type I specimens were held at $75 \%$ SMYS for $24 \mathrm{~h}$ prior to the hydrostatic tests. This static hold allows the occurrence of creep deformation that can blunt the crack tip and reduce the stress intensity for crack growth.

In addition to the above findings, some new insights about crack growth during hydrostatic testing were obtained. A surprising finding is the non-linear relation between the crack advance induced by hydrostatic loading and the maximum stress intensity factor at the crack tip. As shown in Fig. 3-12, less crack growth during hydrostatic loading was seen at the highest stress intensity factor corresponding to a crack with longer depth being loaded to the same stress level. Under the circumstances, the crack growth behavior can still be rationalized with a consideration of the competition between crack tip sharpening and crack tip blunting, as indicated earlier $[8,10]$. However, some additional considerations must be made to rationalize the abnormal trend. First of all, ductile dimples have been observed on the surface that was fractured by hydrostatic loading. The observation of ductile dimples indicates the large degree of plastic deformation in the plastic zone ahead of the crack tip. It is well known that the formation of micro-cracks or dimples may lead to micro-crack toughening, which can relax the stresses in the material $[19,20]$. This might explain partly why less crack growth was measured when cracks were loaded to higher stress intensity factor. When material at the crack tip is heavily deformed, the K-singularity may not exist and elastic-plastic fracture mechanics concept like $\mathrm{J}$ - 
integral should be used to quantify the stress state at the crack tip. This will be fully considered in future investigation.

\section{Conclusions}

1) Crack growth was found to occur during hydrostatic loading, but was not linearly related to the stress intensity factor at the crack tip.

2) Crack growth is mainly driven through the internal-hydrogen-assisted cracking mechanism, instead of the hydrogen-environmental-assisted cracking mechanism.

3) Room temperature creep prior to hydrostatic testing can reduce the crack growth during hydrostatic loading. Excessive plastic deformation leads to the formation of ductile dimples in the plastic zone and reduces crack advance during hydrostatic loading.

4) Lower loading rate generally induces larger crack growth by hydrostatic loading. More crack growth occurs during loading in the high stress regime.

\subsubsection{Effect of loading rate}

It has been determined recently that cyclic loading frequency/loading rate can be an independent driving force, like $\Delta \mathrm{K}$ and $\mathrm{K}_{\max }$, during fatigue crack growth, especially in low cyclic loading frequency regime. A dormant state or threshold condition can be achieved by reducing loading frequency to a critical value. This low frequency effect was attributed to the crack tip blunting by low temperature creep, a phenomenon commonly observed at temperatures below 0.4 to $0.5 \mathrm{Tm}$ ( $\mathrm{T}_{\mathrm{m}}$ being the melting points) in any ductile metallic materials. Such a low temperature creep effect on crack growth has been ignored as past studies on fatigue crack growth were overwhelmingly performed at high loading frequencies, normally well above $1 \mathrm{~Hz}$, such that a fatigue threshold condition requiring a crack growth rate at a magnitude of $10^{-7}$ $\mathrm{mm} /$ cycle can be determined in a couple of days.

Low temperature creep effects become significant when loading frequency is reduced well below $0.1 \mathrm{~Hz}$. This range of cyclic loading frequency is occasionally studied in environments in which corrosion can occur, but are rarely addressed when test environments are inert. Such a low cyclic loading frequency is very typical for pipelines used for high pressure oil and gas transmission. Pressure fluctuations can be just a few times in a day or a change of pressure occurs over a period from a few minutes to a few hours [6, 9].

The pipelines often develop cracks on the external surface, for example, due to corrosion in ground water with a near neutral $\mathrm{pH}$ after protective coatings are damaged. These cracks, although often termed as near neutral $\mathrm{pH}$ stress corrosion cracks (SCC) $[10,11]$, are found to be able to propagate only under cyclic loading, instead of a static loading as a condition of SCC and thus this phenomenon is actually corrosion fatigue $[12,13]$. The crack growth rate was 
determined to be inversely sensitive to $1 / f^{\alpha}$, where $f$ is the cyclic loading frequency, $\alpha$ is constant with a value around 0.1 [13].

The above inverse dependence of crack growth rate on loading frequency was related to the diffusion of hydrogen and mechanisms of hydrogen embrittlement. Lower frequency enhances crack growth since it allows more time for hydrogen diffusion. However, the $d a / d N \propto 1 / f^{\alpha}$ relation predicts an infinitely high crack growth per cycle as $f$ approaches to a very small value, which seems contrary to the engineering common senses.

Recent studies of crack growth of pipeline steel in air reveals an intrinsic cyclic crack growth rate in proportional to $d a / d N \propto f^{\gamma}$, where $\gamma$ is a material constant (please refer to Section 4.3). This predicts a decrease of crack growth rate per cycle with decreasing loading frequency, which is opposite to the prediction made based on the above corrosion fatigue model. Now one may wonder how these two opposite trends of crack growth rate dependence of loading frequency are synergistically related during corrosion fatigue over a wide range of loading frequency.

This investigation is designed to resolve the above dilemma. In particular, the above dilemma will be demonstrated using hydrostatic loading at various loading frequencies. In order to improve the reliability or to avoid the unexpected failure of the pipelines, hydrostatic testing as one of the most important methods for pipeline integrity management has been widely used to detect cracks with critical size in the pipelines before failure occurs. During hydrostatic tests, the pipes are filled with water and loaded to a pressure higher than the design pressure. A maximum size of crack in the pipeline can be assumed if the pipeline has survived the test. $A$ safe operation time can then be determined at the operating pressure after hydrostatic tests as long as the rate of crack growth is known.

This investigation will perform hydrostatic testing at various loading rates to demonstrate the synergistic interactions of the two competitive mechanisms, that is, low temperature creep and hydrogen embrittlement, in controlling crack growth during hydrostatic loading. These results are believed to be extremely important in terms of achieving maximum crack remediation effect from optimized hydrotesting. In addition, the role of loading rate to crack growth behavior has been never been clearly defined in any standards for pipelines, such as CSA Z662-07.

Fig. 3-13 summarizes all the crack advances induced by hydrostatic loading at different loading rates during Stage I loading up to $75 \%$ SMYS. In these experiments, the loading rate in Stage 2 was kept the same (see Fig. 3.3). As shown in Fig. 3-13, there exists a critical loading rate at which crack growth caused by hydrostatic loading was the highest, beyond which the amount of crack growth induced by hydrostatic loading was seen to decrease either with increasing the loading rate in the high loading rate regime or with decreasing the loading rate in the low loading regime. Surprisingly, zero crack growth was found when loading rate was reduced to a critical value, which was to be about $0.2 \mathrm{~h}^{-1}$ (about 5 hour for loading up to 75\% SMYS) for the current material. 
The above findings extend our understanding on the crack growth behaviour of pipeline steels in near-neutral $\mathrm{pH}$ environments. It has been well determined from our previous investigations that crack growth rate in near neutral $\mathrm{pH}$ environment is hydrogen controlled and can be correlated to $(\Delta K)^{\alpha} K_{\max }{ }^{\beta} / f^{\gamma}$ with $\alpha+\beta=1$. The relation $d a / d N \propto f^{\gamma}$ reflects the process of hydrogen diffusion for its segregation to the crack tip as stresses increase, and slower loading rate allows more time for hydrogen diffusion to the hydrogen processing zone. This hydrogen dependent growth behavior results in an increase of crack growth with decreasing loading rate as shown in Fig. 3-13. However, with a further decrease in loading rate, low temperature creep can occur to a large extend. This would blunt the crack tip so that a "crack-like" morphology, which usually defines as a flaw with the radius approaching the dimension of several 10's or 100's of atoms, according to fracture mechanics, will turn into a "notch-like" morphology (see Fig. 1-3). The latter is usually treated using "stress concentration factor", instead of stress intensity factor for sharp cracks. The notch-like flaws should have much lower stress intensity at the crack tip and would reduce hydrogen concentration at least at the surface of notch root, where a plane stress state exists and the highest stress would be at the level of the yield strength of the material and therefore would not induce stress enhanced hydrogen segregation. This scenario would result in a decrease of crack growth induced by hydrostatic loading as shown in the low loading rate regime of Fig. 3-13, provided that the blunt tip will not be re-sharpened during hydrostatic loading, which is to further discussed later.

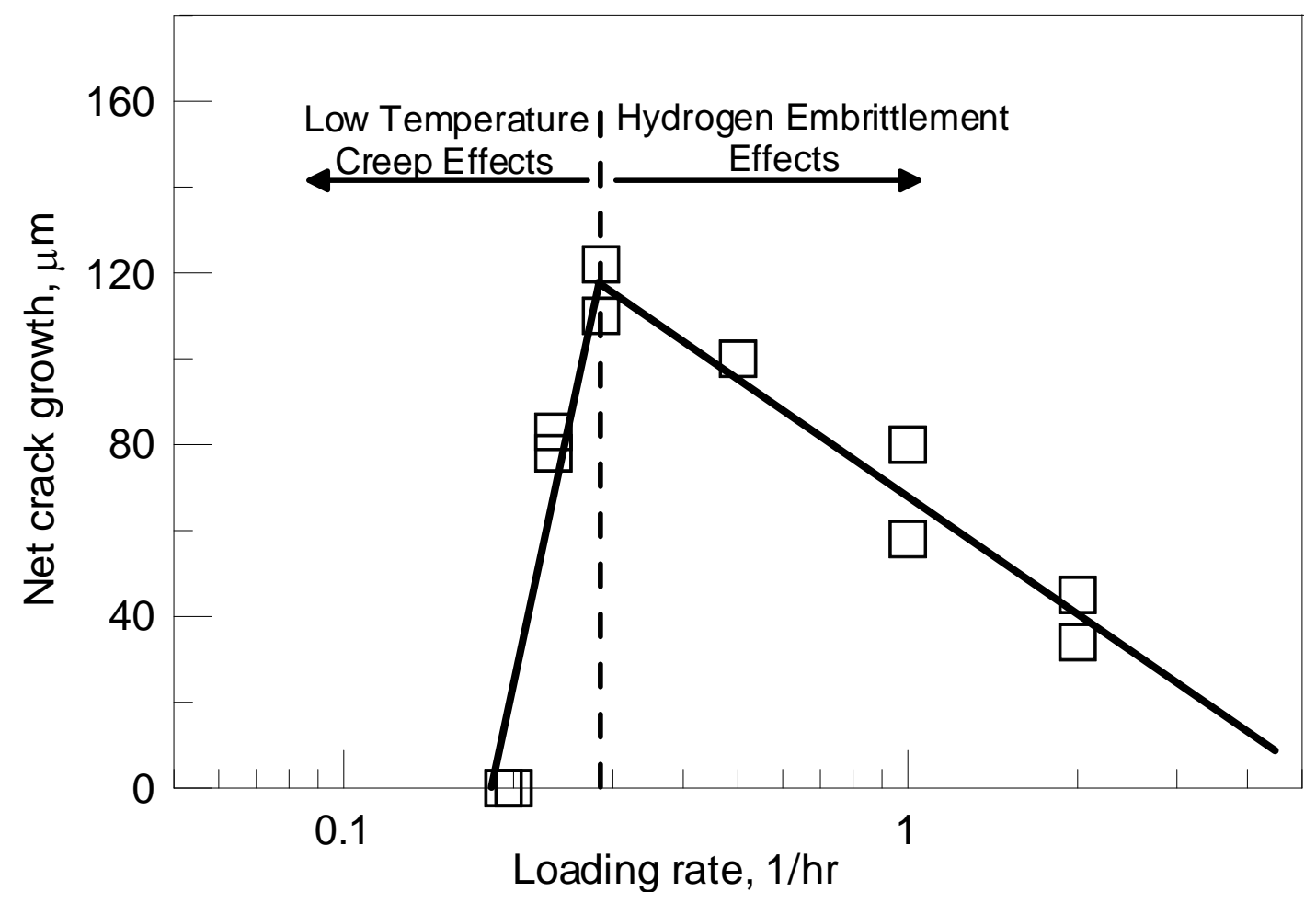

Fig. 3-13 Net crack growth measured as a function of loading rate in Stage I 
The results of crack growth at three different rates in Stage II (see Fig. 3-3 for experimental details) are summarized in Fig. 3-14. For these tests, the loading rate in Stage I was kept the same, which was $0.5 \mathrm{~h}^{-1}$. It is clear that crack growth had occurred in all different loading rates in Stage II. The crack growth determined at different Stage II loading rates does not seem very sensitive to the stage II loading rate. This suggests that the crack growth should have taken place primarily during stage I loading or the conditions at the crack tip achieved during Stage I loading are crucial to the subsequent crack growth during loading beyond $75 \%$ SMYS.

It is believed that the above two situations are equally important depending on the relative loading rates in each stage of loading. The following are some possible scenarios that may yield different crack growth during the entire stage of hydrostatic loading.

1) When the loading rate in Stage I is high, crack tip blunting is minimum and crack growth will occur in both Stage I and Stage II and the amount of crack growth increases with decreasing loading rate

2) When loading rate in Stage I is relatively low, this would yield high crack growth during stage I because of hydrogen effects but crack growth in Stage II can be reduced because of some degree of crack tip blunting in stage I loading.

3) When loading rate in Stage I is very slow, crack growth in Stage I will be small or not take place at all, and crack growth in Stage II will be also small because of crack tip blunting achieved in Stage I loading.

4) When crack tip has been blunted prior to hydrostatic loading, no crack growth or minimum crack growth will occur during hydrostatic loading, as demonstrated in Fig. 3-12.

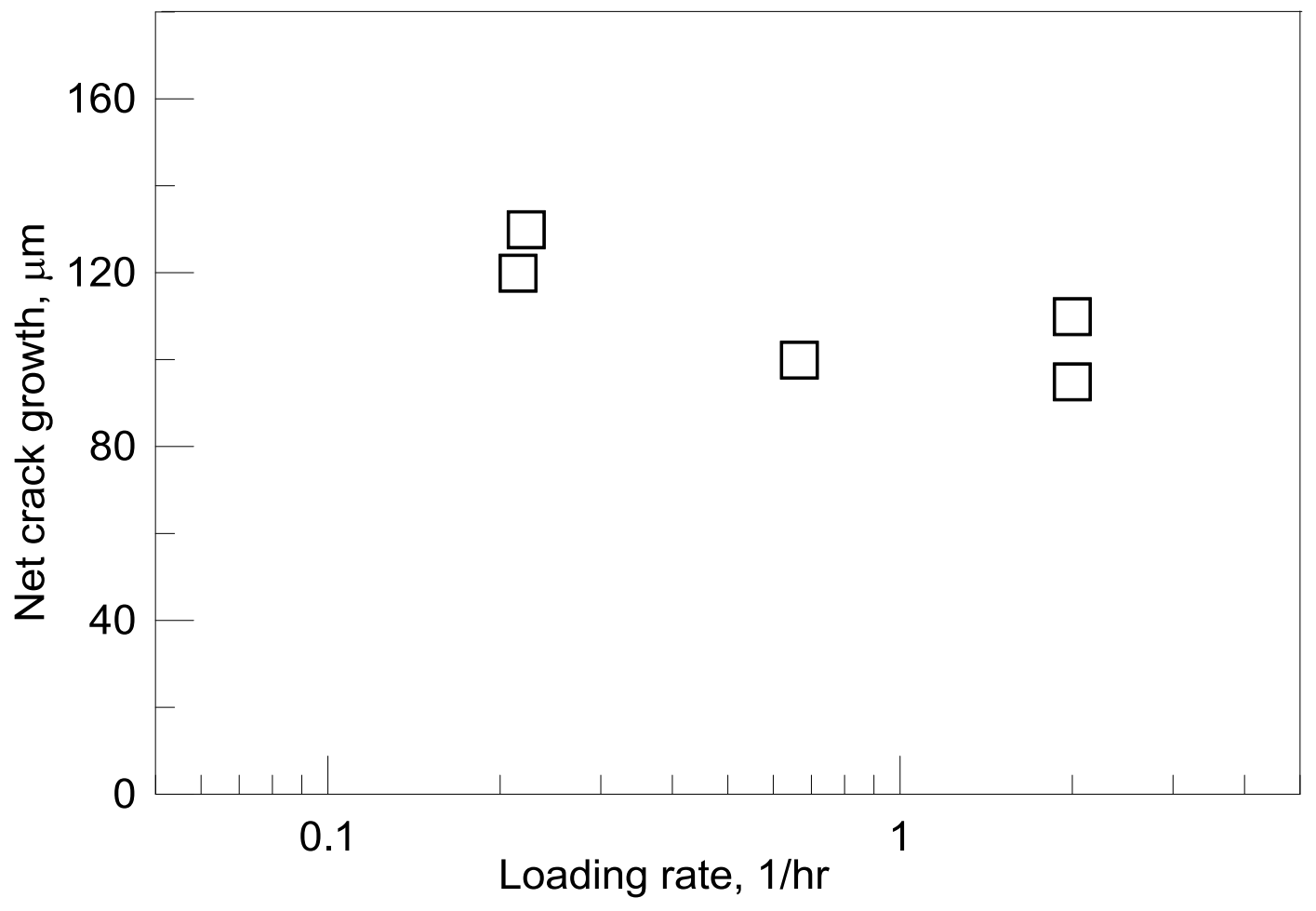

Fig. 3-14 Net crack growth as a function of loading rate in Stage II. 
Scenario 1 and Scenario 2 will yield a mild dependence of total crack growth during the entire stage of hydrostatic loading on loading rate. This is the situation reported in Fig. 3-13. Scenario 3 and Scenario 4 would be ideal for hydrostatic testing as they yield minimum crack growth.

For the situation described in Scenario 4), there is always a risk of re-initiating a sharp microcrack within the tri-axial/hydrostatic zone ahead of a blunt crack tip during hydrostatic loading. This would not only lead to crack growth during hydrostatic loading as the sharp crack may propagate to the notch root, but also will re-sharpen the crack tip, risking higher crack growth rate after hydrostatic testing if the sharp crack will not be re-blunted. The risk of initiating a sharp micro-crack may increase when the following conditions are met:

1) High lattice diffusible hydrogen content in the pipeline steel, for example, steels exposed to low pH soil solutions, or pipeline steels experiencing internal sour corrosion.

2) Steels with large amounts of metallurgical weakest links, for example, steels with large grain sizes, old "dirty" steels having large amounts of inclusions, or steels with heterogeneous microstructures such as pearlite/ferrite steels.

3) Crack tip blunting produced by low temperature creep as compared with blunting caused by general corrosion at the crack tip. The latter situation may occur when cracks in the pipeline steel are shallow. Low temperature creep blunting work-hardens the material in the hydrogen processing zone which could lead to a higher buildup of tensile stresses in the material ahead of the crack tip during hydrostatic loading.

\subsubsection{Effect of pressure hold}

Static hold at a given stress can be performed prior to hydrostatic testing either toward the end of regular service before hydrostatic testing or as a separate loading procedure before hydrostatic loading. The Static hold will lead to the occurrence of low temperature creep at the crack tip, which blunts the crack tip if it has a sharp morphology. To achieve the best results, the static hold can be performed at the maximum operating pressure for a period of time.

Static hold can also be performed at the end of Stage I loading, which will minimize crack growth in Stage II loading. However, slow loading to the maximum pressure in Stage I is also important in terms of minimizing crack growth during Stage I loading.

Static hold is normally performed at maximum pressure in Stage II loading. This would also yield crack tip-blunting effect if the crack tip is sharp before pressure holding.

The above static hold is somehow equivalent to the overload effect/retardation effect extensively studied in the field of fracture mechanics, in which the crack tip is subjected to an increased stress, resulting in an increased plastic deformation/plastic zone size and larger compressive stresses in the plastic zone that reduces the effective tensile stresses/stress intensity factor responsible for crack growth. 
All the above approaches involve a hold at a given pressure. One may wonder what would be the ideal time of hold to achieve the maximum retardation effect. To determine this, a CT specimen was repeatedly applied with a small overload, about $10 \%$ of maximum cyclic load, and held at the overload for different periods of time ranging from 0 to 24 hours, as shown in Fig. 3-15. After each hold, the specimen was tested for about one week under regular cyclic loading to determine base line crack growth rate. Such an assessment was performed in two soil environments.

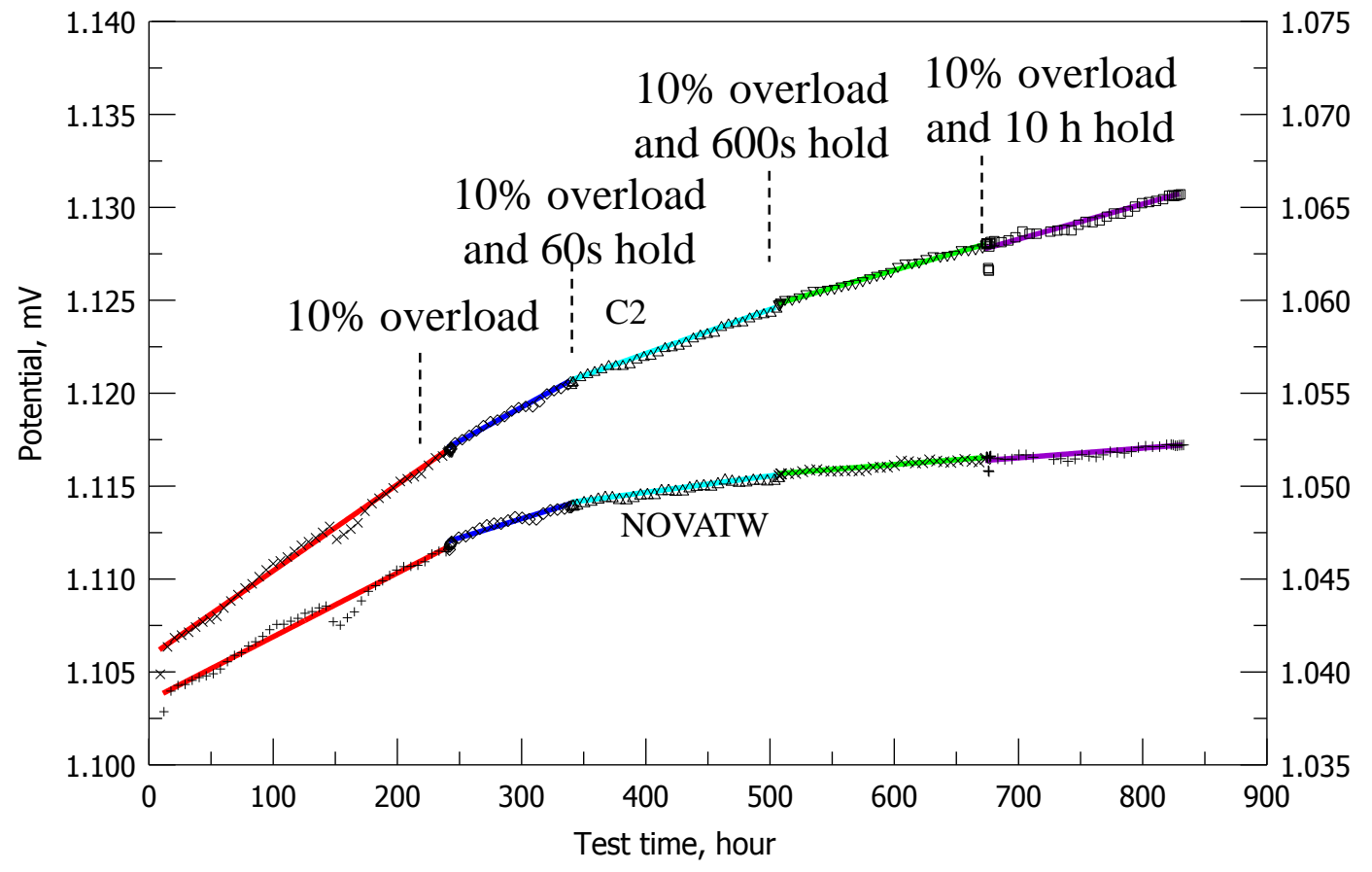

Fig. 3-15 Change of potential drop recorded in a test with different hold times at the same overload stress.

Comparative tests in two different soil environments were conducted to understand the effect of hold time on the subsequent crack growth rate. The results obtained are shown in Figure 3-15 and Figure 3-16. As is seen in both Figures 15 and 16, the growth rate can be reduced by a single overload without any hold. However, further reduction in growth rate can be obtained by increasing the hold time at the same level of overload. A hold time beyond one hour has little effect on the crack growth rate. This observation is consistent with the fact that room temperature creep is generally exhausted within one hour of static hold [14-16].

The observations in Fig. 3-15 and 3-16 indicate the overwhelming effects of hold time related to low temperature creep as compared with overload alone that is responsible for the occurrence of instantaneous plastic deformation. The maximum effect of hold time is the same for two different environments. However, the reduction in crack growth rate is more significant in NOVATW than C2 solution. The latter solution has been proven to be more susceptible to nearneutral $\mathrm{pH}$ cracking. 


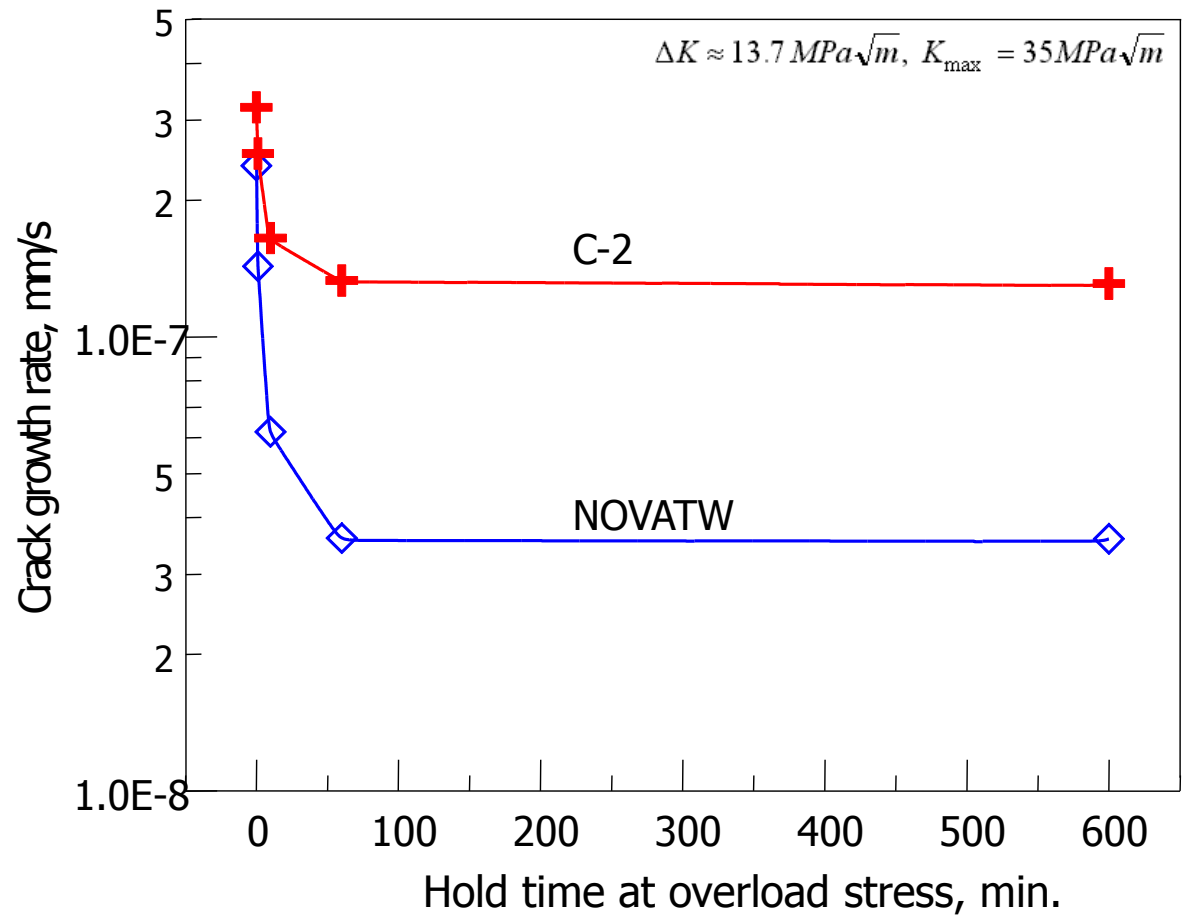

Fig. 3-16 Effect of overload hold time on the crack growth rate after the overload.

A hold at the maximum cyclic stress without overloading can also create similar effect. Fig. 3-17 is an example of hold at maximum cyclic stress without overloading for X65 pipeline in two soil environments. As shown in Fig. ss, the initial cyclic test was conducted at $\Delta \mathrm{K}=12 \mathrm{MPa} \mathrm{m}^{1 / 2}$ and $\mathrm{K}_{\max }=35 \mathrm{MPa} \mathrm{m} \mathrm{m}^{1 / 2}$. It is seen in the figure that there was little crack growth during hold in both the solutions. However, crack growth started only in C2 solution as soon as cyclic loading was resumed after the hold. Hold at $\Delta \mathrm{K}=16 \mathrm{MPa} \mathrm{m}{ }^{1 / 2}$ and $\mathrm{K}_{\max }=47 \mathrm{MPa} \mathrm{m}^{1 / 2}$ was also conducted. In this case, crack growth was initiated in both the solutions after cyclic loading was resumed.

One may naturally raise the following two questions on the results presented in Fig. 3-17.

1) Since the crack tip was exposed to aqueous environment and no passivating will be achieved in near-neutral $\mathrm{pH}$ environments, dissolution will occur at the crack tip and may also lead to crack tip blunting. Between the blunting by dissolution and that by low temperature creep, which one of them is truly responsible for the occurrence of blunting? This has been extensively studied by present investigator and it has been concluded that the blunting effect is mainly related to low temperature creep.

2) In Fig. 3-17, crack growth was observed after cyclic loading was resumed, indicating the reactivation of crack growth of a blunt crack. What determines this re-activation process? Would the reactivation of crack growth occur during hydrostatic loading? This issue has also been dealt with in our previous research and will be further discussed in Section 3.4. According to our previous research, whether crack growth can be reactivated depends on the critical value of the combined factor $(\Delta K)^{\alpha} K_{\max }^{\beta} / f^{v}$. 


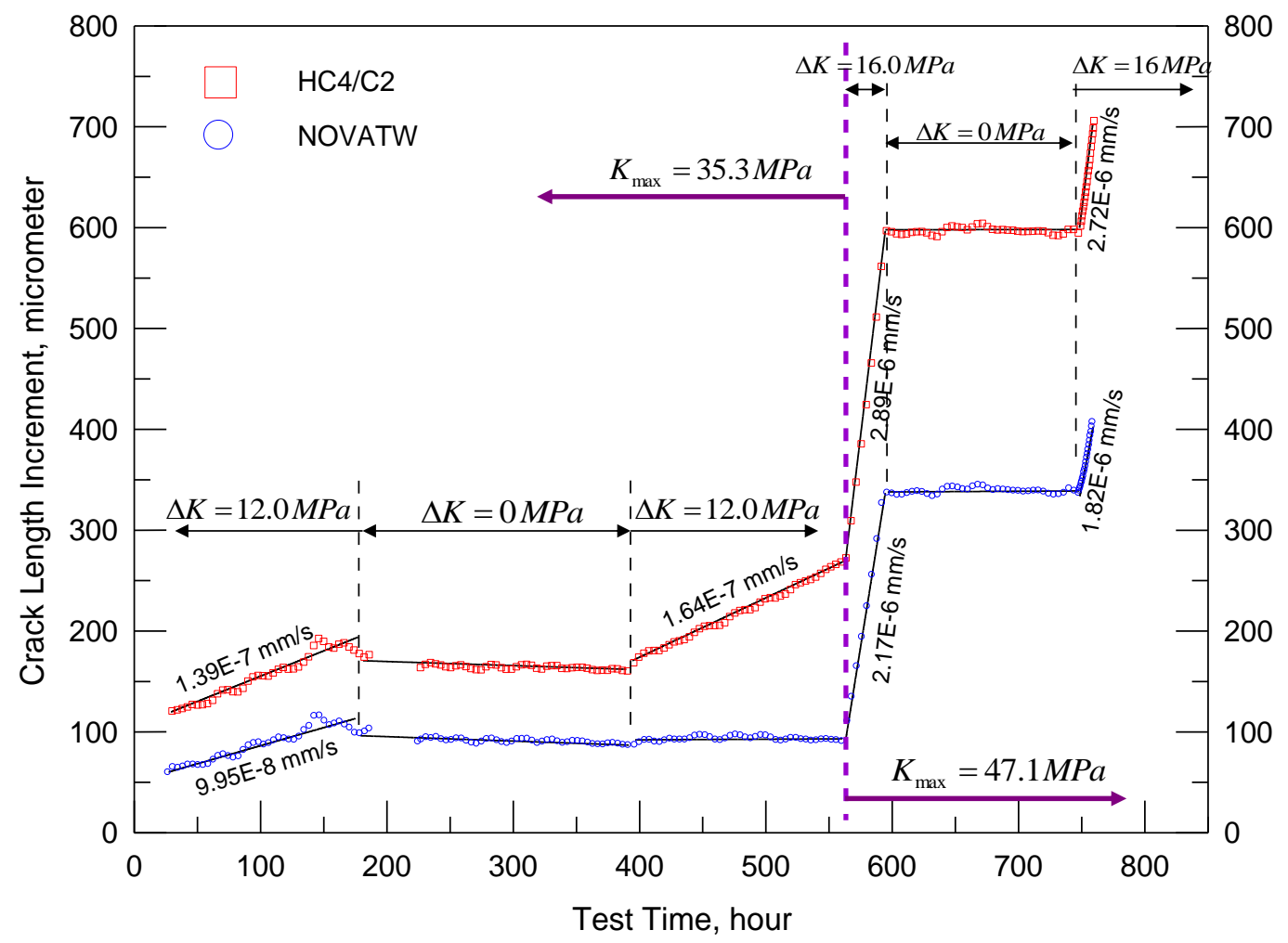

Fig. 3-17 Crack length increment as a function of test time in two different soil solutions [17]

Lastly, one may wonder if there is any adverse effect if the period of hold is very long. The hold at a given stress level for a long time represents the loading condition of stress corrosion cracking. That is, whether stress corrosion cracking is a mechanism. A clear answer to this question has been extensively addressed Section 4.4.3.5.

\subsubsection{Effect of hydrostatic test on post hydrostatic test crack growth}

An interesting argument would be whether hydrostatic testing, a process of controlled overloading, would retard the crack growth after the hydrostatic test, as is generally believed [4]. This has been addressed in our previous research [10]. It was found that the degree of retardation depends on the stress intensity factor range used during the cyclic loading after hydrostatic testing, $\Delta K_{c}$. Figure 3-18 compare the crack growth rate as a function of $\Delta \mathrm{K}_{\mathrm{c}}$ before and after hydrostatic loading. Due to the occurrence of crack growth during the hydrostatic testing, the $\Delta \mathrm{K}_{\mathrm{c}}$ acting at the crack tip before and after the hydrostatic testing is slightly different. This effect was considered in the data shown in Figure 3-18. In addition, only the average rate within the first 48 hours of cyclic loading was plotted in Figure 3-18 in order to avoid the effect of increasing $\Delta \mathrm{K}_{\mathrm{c}}$. As is seen in Fig. 3-18, the growth rate after hydrostatic test is reduced in both the soil solutions. The level of reduction strongly depends on the stress intensity factor range 
applied in the cyclic loading with larger reduction found at lower stress intensity factor range. Given the short duration of testing before and after the hydrostatic test loading it is not clear, however, whether the change in growth rates will be long-lived.

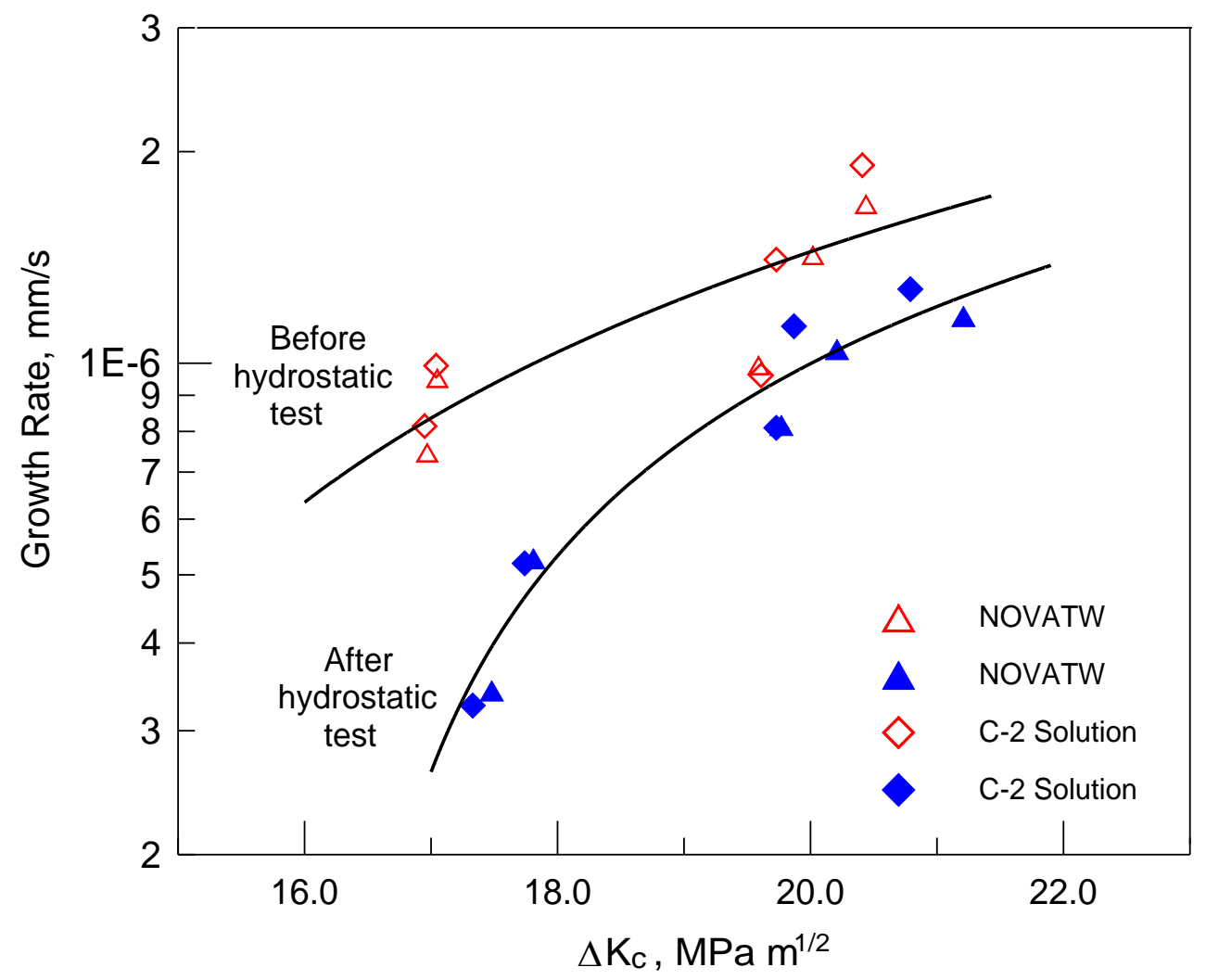

Figure 3-18 Crack growth rate before and after hydrostatic test as a function of $\Delta K_{C}[10]$.

Similar tests have also been repeated in the current investigation for an increased period. Fig. 3-19 shows the loading scheme used. Two types of specimen as defined previously were used. Both the tests have yielded similar results, which are presented in Fig. 3-20. It was found after the tests that the coating covering the crack propagating path on Type II specimen was delaminated and this might be reason why crack growth rate was not very different between Type I and Type II specimen. In addition, the mechanical loading used in both case was relatively aggressive which will result in a predominant mechanical effect but a reduced hydrogen effect, which has been extensively discussed in Ref [ 17]. Despite the above inconsistency, the crack growth retardation is very obvious. As shown in Fig. 3-20, crack growth rate after hydrotest was reduced to about half of the crack growth rate measured before hydrotest. 


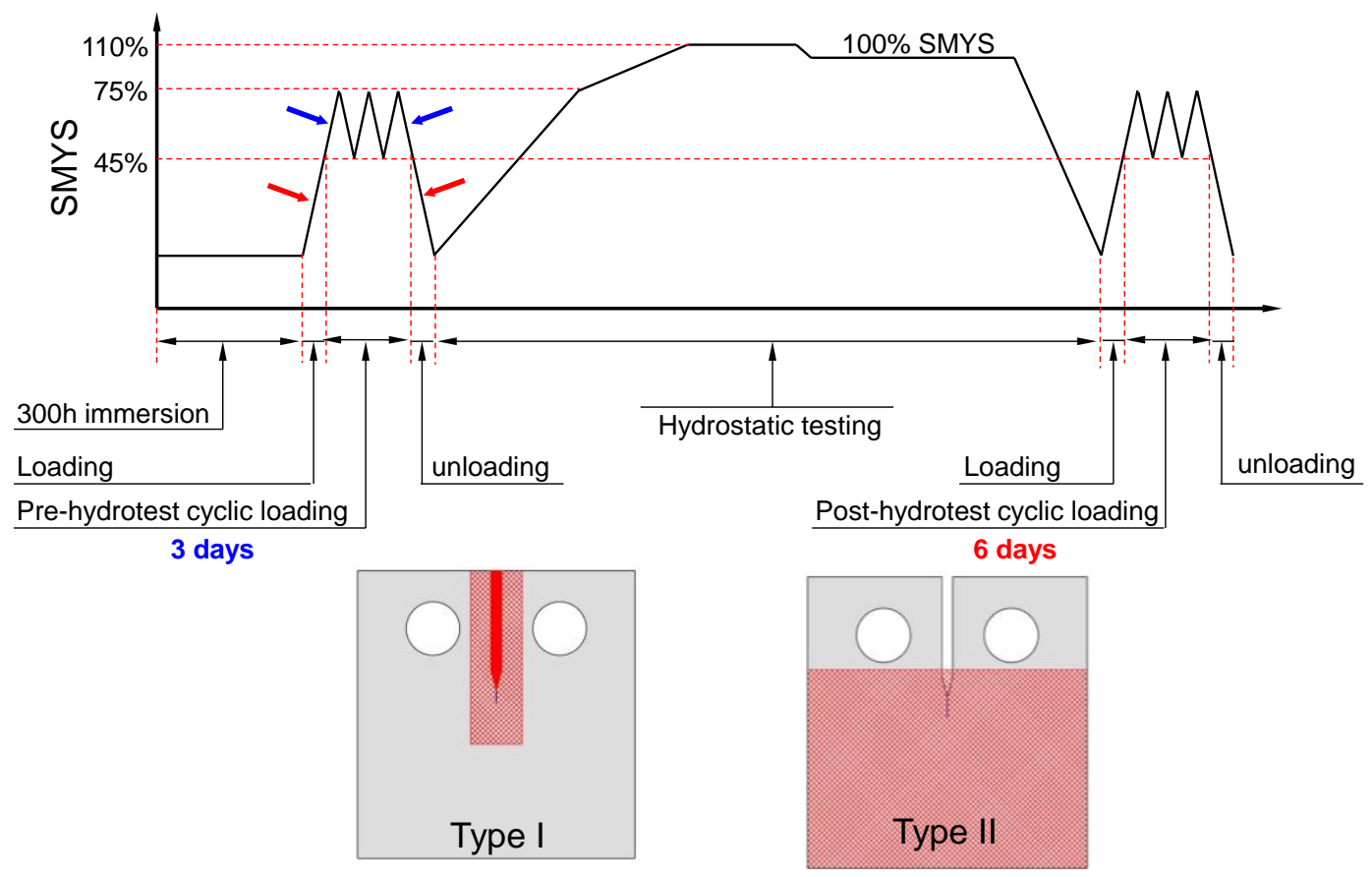

Fig. 3-19 Loading schemes used for determining crack growth rate before and after hydrotest.
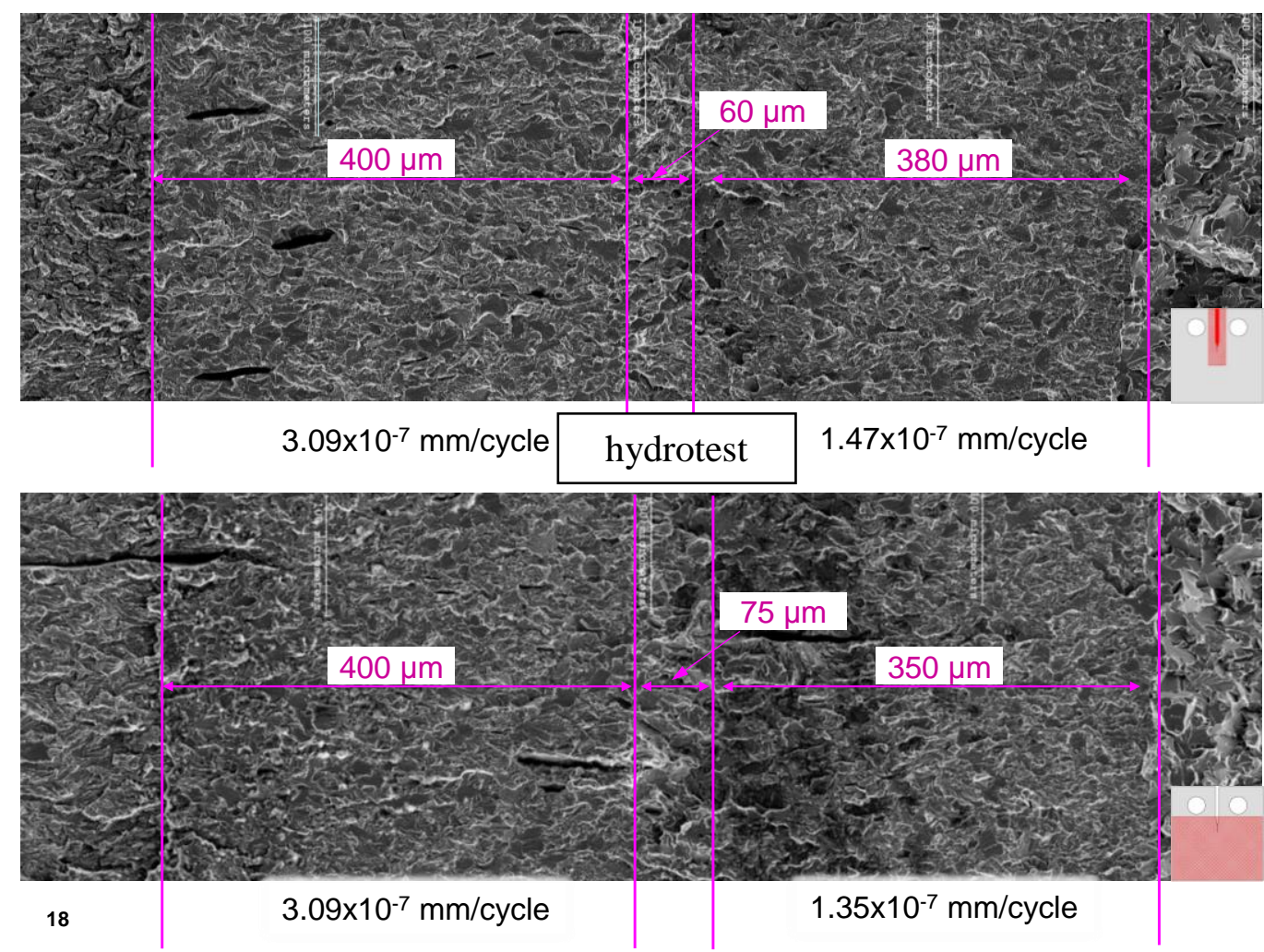

Fig. 3-20 Crack growth determined on the fracture surface of CT specimen after the loading schemes shown in Fig. 3-19 


\section{References}

1. E. Hörnlund, J.K.T. Fossen, S. Hauger, C. Haugen, T. Havn and T. Hemmingsen, Hydrogen diffusivities and concentrations in $520 \mathrm{~m}$ carbon steel under cathodic protection in $0.5 \mathrm{~m} \mathrm{NaCl}$ and the effect of added sulphite, dithionite, thiosulphate, and sulphide, International Journal of Electrochemical Science 2 (2007), 82-92.

2. W. Chen, T.R. Jack, F. King, M.J. Wilmott, Hydrogen permeation behavior of X-70 piperline steel in a near-neutral $\mathrm{pH}$ soil environment, International Pipeline Conference 2000, Calgary, Canada, pp. 953-960.

3. D.X. He, W. Chen, and J.L. Luo, Effect of cathodic potential on hydrogen content in a pipeline steel exposed to NS4 near-neutral pH soil solution, Corrosion, 60 (2004), 778-786.

4. W. Chen, R.L. Eadie, and R.L. Sutherby, Environmental effects on near-neutral pH stress corrosion cracking in pipelines, Second International Conference on Environment-induced Cracking of Metals, 2004, The Banff Centre, Banff, Alberta, Canada, pp. 211-220.

5. W. Chen, R. Sutherby, Environmental effect of crack growth rate of pipelines steel in nearneutral pH soil environments, International Pipeline conference 2004, Calgary, Canada, pp. 123-132.

6. ['] M.P.H. Brongers, J.A. Beavers, C.E. Jaske, and B.S. Delanty, Effect of hydrostatic testing on ductile tearing of X-65 line pipe steel with stress corrosion cracks, Corrosion, 56 (2000), 1050-1058.

7. W. Chen, R.L. Sutherby, Crack growth behavior of pipeline steel in near-neutral pH soil environment, Met. Mater. Trans. A 38 (2007) 1260-1268.

8. W. Chen, G. Van Boven, R. Rogge, The role of residual stress in neutral pH stress corrosion cracking of pipeline steels - Part II: Crack dormancy, Acta Mater., 55 (2007) 43-53.

9. B.N. Leis, F.W. Brust, , NG-18 Report No\#194, 1992.

10. W. Chen, R. Sutherby, International Pipeline Conference 2006, Calgary, Canada, pp. 2529.

11. Y.W. Kang, W. Chen, R. Kania, G.V. Boven, R. Worthingham,, Corrosion Sci. 53 (2011), 968-975.

12. R.P. Gangloff, Hydrogen-assisted cracking, in: I. Milne, R.O. Ritchie, B. Karihaloo (Eds), Comprehensive Structure Integrity, volume 6: Environmentally-Assisted Fracture. Elsevier, Oxiford, 2003, vol. 6, pp.31-34.

13. I. Meletis, J. Mech. Behavior of Mater., 7(1996)1-14.

14. S. Wang, W. Chen, Mater. Sci. Eng. A325 (2002) 144-151.

15. S. Wang, Y.G. Zhang, W. Chen, J. Mater. Sci. 36 (8) (2001) 1931-1938.

16. S.Wang,W. Chen, Mater. Sci. Eng.AA301 (2001) 147-153.

17. W. Chen, R. Kania, R. Worthingham, G.V. Boven, Tansgranular crack growth in the pipeline steels exposed to near-neutral $\mathrm{pH}$ soil aqueous solutions: the role of hydrogen, Acta Mater., 57 (2009), 6200-6214. 


\section{UNDERSTANDING OF CRACK GROWTH IN NEAR NEUTRAL pH ENVIRONMENTS}

\subsection{Introduction}

It is well established that transgranular stress corrosion cracking (SCC) requires a simultaneous condition for film formation on the crack walls and corrosion at the crack tip. This scenario can be achieved usually when a susceptible material is exposed to a transition zone in the polarization curve that demarcates active dissolution and passivating [1]. The above cracking prerequisite, however, is not necessary for intergranular SCC, which can occur over a wider range of potentials because chemical inhomogeneities at the grain boundary produce a different electro-chemical response relative to grain material [2].

When transgranular cracking is observed in a corrosion environment that strongly passivates the materials being exposed, film rupture by localized plastic deformation from a static stress (condition of stress corrosion cracking) becomes insignificant and crack growth would be too slow to cause any engineering concerns. Under the circumstances, cyclic loading becomes important, which can enhance the process of film rupture to make the crack to grow at a rate that is of engineering significance [3,4]. This would be the case of corrosion fatigue [4].

Now considering an environment that does not produce passivation on the material being exposed, transgranular cracking under constant stress (condition of stress corrosion cracking) would be less possible as corrosion will occur at the crack tip and on the crack walls as well. This could gradually turn a crack characteristic of a sharp tip into a pit (blunting) if the crack could be formed initially, for example, by a different mechanism. As a result, transgranular cracking in the environment that does not passivate the material being exposed could occur only if there exists a mechanism that could maintain the crack tip at a sharp state (for example, at high growth rates at which crack tip blunting is negligible), or could constantly re-sharpen the crack tip to counterpart the blunting.

Near neutral $\mathrm{pH}$ ground water that has been found to be responsible for the rupture of buried pipeline steels is such an environment that causes pipeline steels to crack transgranularly and to corrode the pipeline steels without passivating them [5-9]. Fig. 1 shows the cross section of a typical near neutral $\mathrm{pH}$ transgranular crack in the pipeline steel developed in the field. It has been found from statistic analysis of thousands of crack colonies that $95 \%$ of crack population has a blunt tip as shown in Fig. 1 [10-11]. Cracks with such a crack tip morphology are considered to be dormant. However, the remaining $5 \%$ of total crack population can grow continuously or repeatedly, leading to pipeline rupture. This investigation is aimed to provide some insights on the mechanisms that govern the growth of those growing cracks that take up of about $5 \%$ of total crack population.

Crack dormancy is an unique feature of the cracks in pipeline steels exposed to near-neutral pH environments. Field studies have revealed that more $95 \%$ of cracks are in a dormant state and only less than $5 \%$ of them are able to grow and potentially lead to the final failure. Crack dormancy in the field occurs primarily in the stage of crack initiation and early short/shallow 
crack growth. The cracks formed can be better characterized as shallow notches, instead of cracks, for which fracture mechanics principles, such as stress intensity factor, cannot be applied for analysis. These defects are usually less than $1 \mathrm{~mm}$ deep and have very small depth/length aspect ratios, around 0.1 to 0.2 .

Details on the initiation of the shallow cracks and early crack propagation are not the subject of this investigation. However, a brief summary is made here for the purpose of better understanding the growth behavior of cracks beyond the dormant stage that is to be focused in this investigation. It is generally believed that the initiation can be caused by many different mechanisms [12-26], such as preferential dissolution at physical and metallurgical discontinuities such as scratches [12] , inclusions [13], grain boundaries, pearlitic colonies, banded structures [14-16] in the steel, corrosion along persistent slip bands induced by cyclic loading prior to corrosion exposure [14, 17], crack initiation at stress raisers such as corrosion pits [18, 19], and localized corrosion through millscale-steel galvanic effects [20]. The initiation of the microstructurally short cracks, usually less than $100 \square \mathrm{m}$, can occur under a constant stress loading. The early crack growth is generally believed due to the presence of high tensile residual stresses at the pipe sub-surface [11, 21, 22], which adds to the applied stress. However, these cracks generally go to dormancy for reasons yet to be determined.

Pipeline ruptures in the environments that can develop the above features are usually caused by the propagation of sharp cracks (those $5 \%$ of crack population). Therefore, special conditions must exist at some locations of pipe surface or during certain periods of service that could either make the defects maintain a relatively sharp tip or could re-sharpen the tip after blunting. Such competitive conditions are briefly considered below based on the nature of synergistic interactions between neutral $\mathrm{pH}$ soil environments and the mechanical loading encountered by the pipeline steels.

\section{$\underline{\text { Under constant stress loading -- scenario of stress corrosion cracking }}$}

Pipeline cracking in near-neutral $\mathrm{pH}$ ground water was initially termed as stress corrosion cracking [5-7], implying that crack can initiate and grow under a static load/stress. This was believed probably due to the fact that steel pipelines, particularly those for high-pressure gas transmission, are operated under a near static loading condition, and of the fact that high $\mathrm{pH}$ SCC in the steel pipelines that can be reproduced in the laboratory under static loading [27-29]. However, the growth of crack in the pipeline steels exposed to near-neutral pH environment has never been observed under static loading. This observation, however, does not exclude possible crack initiation as outlined previously on the formation of short cracks mostly at a dormant state through various processes in which fracture mechanics principles are not applicable [14, 15, 23, 24]. Nevertheless, a pre-existed axial crack would come to a dormant state under a static loading in near-neutral $\mathrm{pH}$ environments. In fact, mild mechanical cycling in near-neutral pH environments would also lead to crack dormancy as is demonstrated in Ref [30]. This coincides with the fact that $95 \%$ of crack population come to a dormant state, once they reached to about $0.5 \mathrm{~mm}$ in depth [10-11]. 


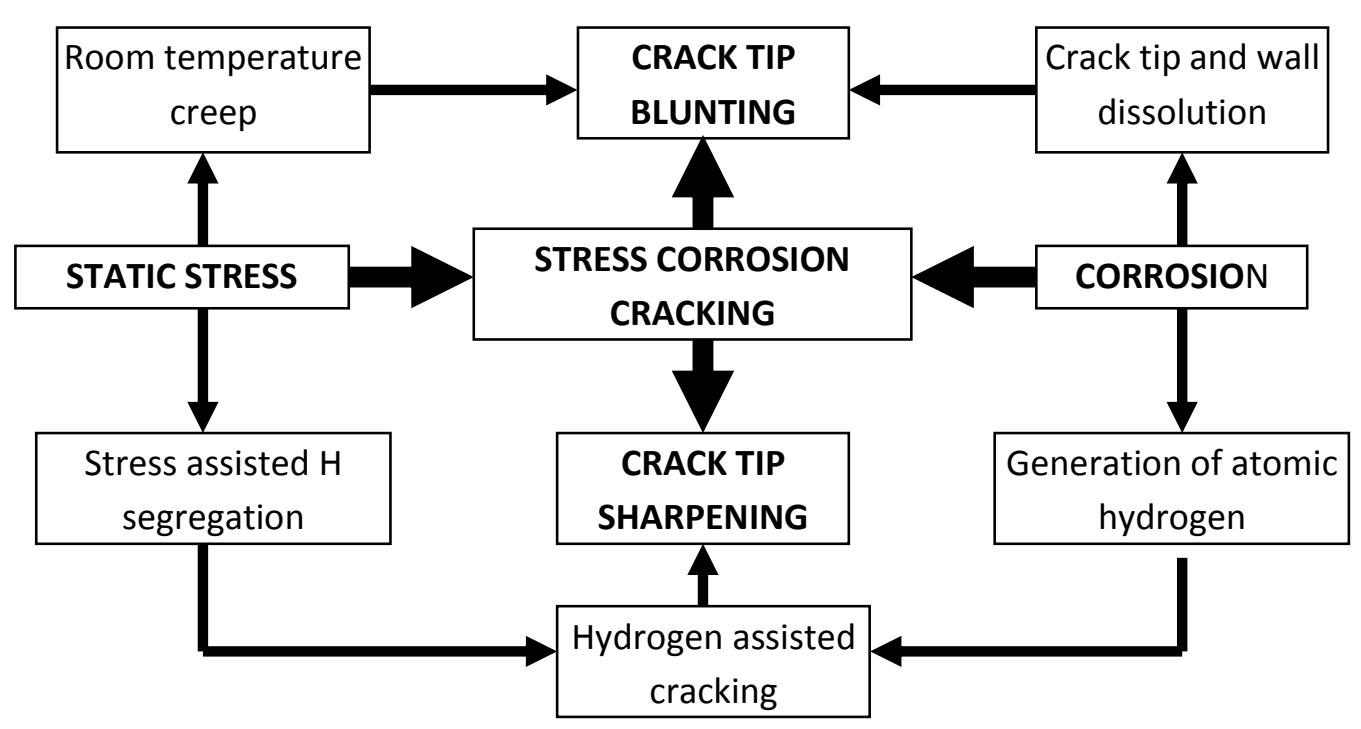

Figure 4-1 A schematic showing the competition between crack tip blunting and crack tip sharpening in the pipeline steels exposed to near neutral $\mathrm{pH}$ environments under constant stresses (situation of stress corrosion cracking).

Fig. 4-1 has considered various competitive factors both for crack sharpening prerequisite to active crack growth and for blunting leading to crack dormancy. A predominant factor in near neutral $\mathrm{pH}$ soil environments that causes crack tip to blunt is the general corrosion occurring at the crack tip and on crack walls since the current near neutral $\mathrm{pH}$ environments do not cause pipeline steels to passivate [8]. The second factor that can contribute to the crack tip blunting is room temperature creep, which is unique to pipeline steels and can be very excessive depending on the type of pipeline steels and prior loading history of the pipeline steels [31-34]. Room temperature creep will occur at the tip of crack when the crack tip is stressed.

Opposite to the process of blunting, segregation of atomic hydrogen to the hydrostatic zone and the highly deformed areas ahead of the crack tip can be the main reason of crack sharpening [35]. Under the circumstances, hydrogen induced micro-cracks (HIC) may be initiated under the combined effect of high hydrostatic stresses in the plastic zone, increased hydrogen segregation, and the weakest link sites, such as grain boundaries and inclusions, in the plastic zone ahead of the crack tip. The micro-cracks that from in the plastic zone link up with the main crack, resulting in crack extension [36, 37] and re-sharpening the blunt tip. On the other hand, hydrogen adsorption induced cleavage (also called stress-sorption cracking), originally proposed by Uhlig, may also take place to produce direct sharpening of the blunt tip [38]. 
The above sharpening process is unlikely to occur under static loading as cracks are mostly dormant, and at least when cracks are around $1.0 \mathrm{~mm}$ deep. A proof to the above competition is the observation of sharp micro-cracks in the plastic zone ahead of the tip of a dormant crack/notch of about $0.8 \mathrm{~mm}$ deep [9]. However, the micro-cracks did not link up with the main crack, indicating that initiation of such micro-cracks is possible, but its propagation to the root of the main crack to re-sharpen it has not occurred.

\section{Under cyclic stress loading - scenario of corrosion fatigue}

When cyclic loading is present in the loading scheme, the blunting mechanisms as discussed previously in SCC type of loading scenario are still applicable, except for an attenuation of low temperature creep related blunting process as low temperature creep increases with an increase of the applied stress and creep time. Therefore, this type of blunting would be more profound at lower loading frequency and slower crack growth rate, both of which allows more time for creep to proceed at the crack tip. An analysis of competitive processes for crack tip blunting and sharpening in the case of cyclic loading is shown in Fig. 4-2.

Recently, we have analyzed crack growth data both from laboratory tests using compact tension (CT) specimen and from full scale tests of shallow cracks [30, 39]. It has been found that the crack growth rate per cycle $(\mathrm{da} / \mathrm{dN})$ can be correlated by $\Delta K^{2} K_{\max } / f^{\alpha}$, where $\Delta \mathrm{K}$ is the stress intensity factor range; $K_{\max }$ is the maximum stress intensity factor; $f$ is the loading frequency; and $\alpha$ is a factor related to corrosivity of soil environments. This correlation enables the determination of threshold $\Delta K^{2} K_{\max } / f^{0.1}$ values for long cracks such as in a test using CT specimen. The above growth correlation appears also true for small/shallow cracks in full scale tests except that small/shallow cracks were found to grow at appreciable rates below the threshold of long cracks [39], a well understood phenomenon in fatigue [40, 41].

The fact that crack growth is possible under cyclic loading but not under SCC loading implies the effectiveness of crack sharpening by fatigue in near-neutral $\mathrm{pH}$ soil environments, a wellunderstood phenomenon in the field of fatigue. However, $95 \%$ cracks in the field remained dormant, suggesting that sharpening and/or re-sharpening of crack by the type of fatigue loading encountered in the field is not predominant, at least not the sole factor, as the dormant cracks, representing $95 \%$ of total crack population, are subjected to the same loading schemes as those $5 \%$ of total cracks that can grow.

Hydrogen related sharpening should also exist under fatigue loading. However, this sharpening mechanism should be most influential under the SCC loading in terms of hydrogen segregation in comparing with the fatigue loading. Despite that, crack growth can not be incurred under the SCC loading, indicating that hydrogen related sharpening can not act alone to re-sharpen the crack as discussed previously. 


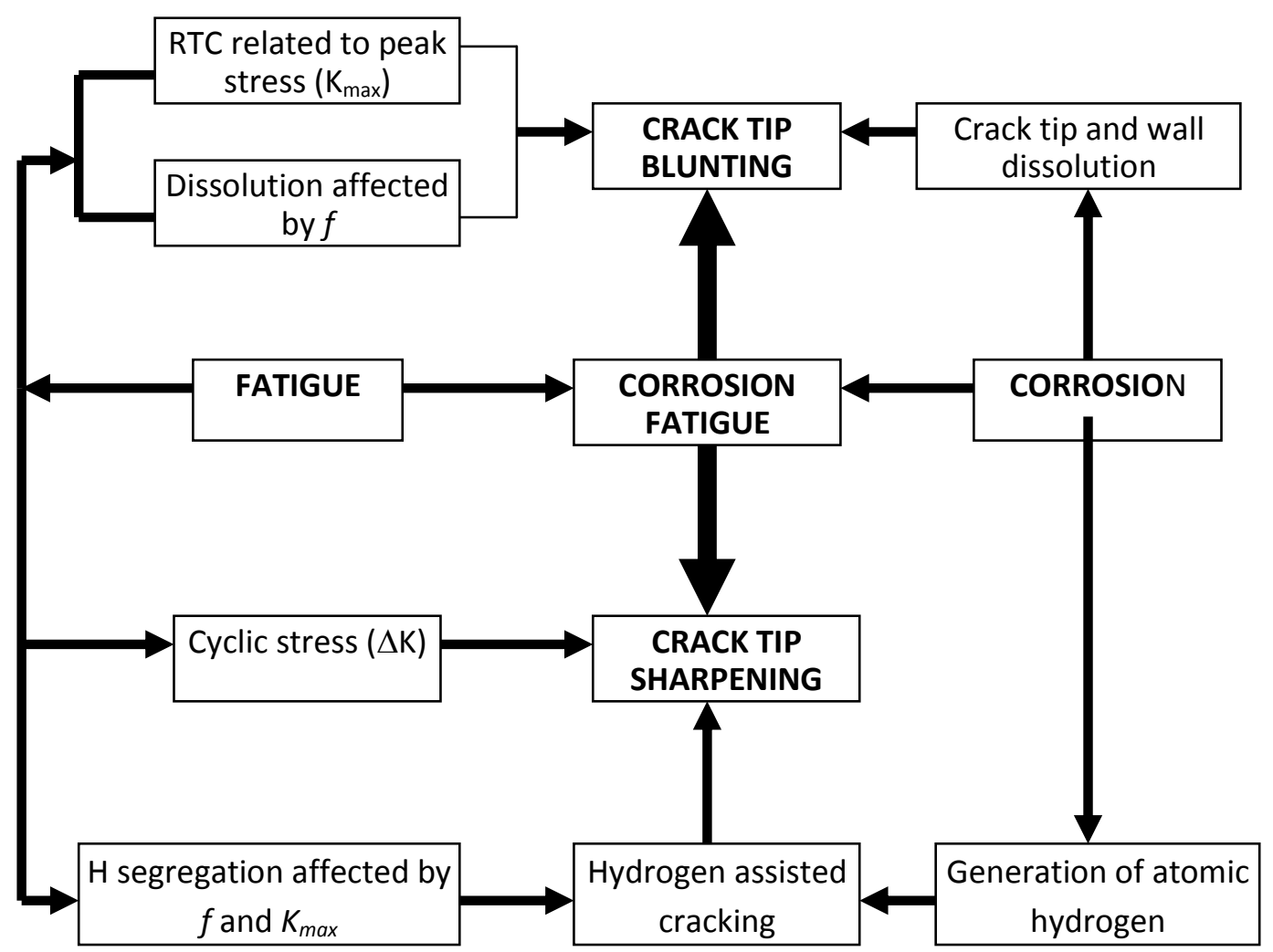

Figure 4-2 A schematic showing the competition between crack tip blunting and crack tip sharpening in the pipeline steels exposed to near neutral pH environments under cyclic loading condition (scenario of corrosion fatigue).

As a result, the mechanism(s) governing crack re-sharpening in the field cannot be either purely fatigue- or hydrogen-related. Instead, a synergistic interaction of both is most likely the case. The former factor is common to all the cracks in the system, the latter would be very location dependent and could interact with the former factor to make some of the cracks, typically $5 \%$ of the total population, to grow continuously or repeatedly. This investigation is aimed primarily to determine the location specific conditions involving synergistic interactions of realistic fatigue loading (characteristic of high stress ratio and very low loading frequency [42]) and hydrogen assisted crack tip sharpening and re-sharpening in the pipeline steels exposed to typical near neutral $\mathrm{pH}$ soil environments.

It should be noted that the above considerations are only limited to two of the three essential factors on corrosion cracking, i.e., stress and environments. The third factor, materials, is important when discussing the susceptibility of different materials or microstructures. For a given pipeline steel, the fabrication condition can be considered to be similar. Variation in microstructural features are usually at micrometer levels (such as inclusions and grain boundaries), which may affect the growth for a short period, such as crack initiation, except for the effect of residual stresses and banded microstructures. The effect of residual stress is also very location specific and may play a decisive role in the process of continuous or repeated 
growth of those $5 \%$ of total cracks responsible for pipeline rupture. This factor of residual stresses has been considered in detail in previous research [11, 21-22], and will be discussed as it is needed when considerations for stress and environmental factors are made. The banded microstructures are normally seen in the central region of pipe wall, and the bands are oriented along the pipeline length direction. Its effect on crack growth into pipe thickness direction, particularly in the early and intermediate stage of crack growth, would be limited.

Efforts in this section will be made in understanding how crack blunting and crack tip sharpening occur in pipeline steel exposed to near neutral pH environments and how these two competing processes determine the growth of crack.

\section{References}

1. Staehle RW, Stress corrosion cracking and hydrogen embrittlement of Iron base Alloys, R. W. Staehle et al, eds, NACE-5, NACE, Houston, 1977, p.193.

2. Jones DA. Principles and Prevention of Corrosion, $2^{\text {nd }}$ ed., Prentice Hall, Upper Saddle River, 1996, p.291.

3. Evans JT, Parkins RN. Acta Metall 1976;24:511

4. Revie RW, Uhlig HH. Corrosion and Corrosion Control, John Wiley \& Sons Inc., 2008, p.173.

5. Parkins RN. "A Review of Stress Corrosion Cracking of High Pressure Gas Pipelines" Proceedings of Corrosion 2000, NACE International. Houston, Texas, 2000, Paper 00363

6. Parkins RN, Blanchard WK Jr, Delanty BS. Corrosion 1993;50:395

7. Parkins RN, Blanchard WK, Delanty BS. Corrosion 1994;50:394

8. Liu X, Mao X. Scripta Metall. et Mater 1995;33:145.

9. Chen W, King F, Vokes ED. Corrosion 2002;58:267

10. King F, Given R, Chen W. "Detailed Characterization of SCC Cracks from the Nordegg Rupture Site and Their Mechanistic Implications" Internal Report \#01442, Nova Research \& Technology Corp., November 2000.

11. Chen W, Bovan GV, Rogge R. Acta Mater 2007;55:43-53

12. He D, Jack TR, King F, Chen W. "Effect of surface scratch roughness and orientation on SCC of line pipe steel in neutral pH environment", 2000 Int. Pipeline Conf., Vol. 2, 2002. p.997.

13. Elboujdaini M, Wang YZ, Revie RW, Parkins RN, Shehata MT. "Stress Corrosion Crack Initiation Processes: Pitting and Microcrack Coalescence". NACE International Corrosion 2000. Paper No. 00379.

14. Chen W, Wang SH, Chu R, King F, Jack TR, Fessler RR. Metall. and Mater. Trans 2003;34A:2601

15. Chu R, Chen W, Wang SH, King F, Jack TR, Fessler RR. Corrosion 2004;60(3):275

16. Kushida T, Nose K, Asahi H, Kimura M, Yamane Y, Endo S, Kawano H. "Effects of Metallurgical Factors and Test Conditions on Near-Neutral pH SCC of Pipeline Steels", Corrosion 2001, 2001. paper No. 01213.

17. Wang S, Chen W. Corrosion, 2002;58(6):526

18. Fang BY, Eadie RL, Chen W, Elboujdaini M. Corrosion Engineering, Science and Technology 2009;44(1):32 
19. Fang BY, Eadie RL, Chen W, Elboujdaini M. Corrosion Engineering, Science and Technology , in press, 2009.

20. Qin Z, Demko B, Noel J, Shoesmith D, King F. Corrosion, 2004;60(10):906

21. Beavers JA, Johnson JT, Sutherby RL. "Materials Factors Influencing the Initiation of nearneutral pH SCC on Underground Pipelines", Proceedings of 3th International Pipeline Conference, Oct 1-5, 2000, Calgary, Canada, Vol 2, 2000. p.979.

22. Bovan GV, Chen W, Rogge R. Acta Mater 2007;55:29

23. Lu BT, Luo JL. Corrosion 2006;62(8):723.

24. Zheng W, Bibby D, Li J, Bowker JT, Gianetto JA, Revie RW, Williams G. "Near-neutral pH SCC of two line pipe steels under quasi-static stressing conditions", IPC 2006, vol. 2. 2006. p.95.

25. Fang B, Han EH, Wang J, Ke W. Corrosion 2007;63:419

26. King F, Jack T, Chen W, Wang SH. "Development of a Predictive Model for the Initiation and Early-stage Growth of Near-neutral pH SCC of Pipeline Steels" Corrosion 2001, paper \#214.

27. Sutcliffe JM, Fessler RR, Boyd WK, Parkins RN. Corrosion 1972;28:313

28. E. I. Meletis, J. Mech. Behavior of Mater 1996;7:1

29. Leis N, Parkins RN, Fatigue \& Fract. Enging. Mater. \& Struc 1998;21:583

30. Chen W, Sutherby RL. Met. \& Mater. Trans A, 2007;38A:1260

31. Wang S, Chen W. Mater. Sci. Eng 2002;A325:144

32. Wang S, Zhang YG, Chen W. J. of Maters. Sci 2001;36(8):1931

33. Wang S, Chen W. Mater. Sci. Eng A 2001;A301:147

34. Zhao J, Mo T, Nie DF, Ren M, Guo X, Chen W. J. Mater. Sci 2006;41:6431

35. Sofronis P, McMeeking RM. Journal of the Mechanics and Physics of Solids 1989;37(3):317

36. Troiano AR. "The role of hydrogen and other interstitials in the mechanical behavior of metals;" (1959 Edward De Mille Campbell Memorial Lecture), Transactions of the ASM; vol $52,1960$.

37. Gangloff RP. Hydrogen-assisted cracking in high-strength alloys. Comprehensive Structural Integrity, Vol. 6: Environmentally-Assisted Fracture, 2003. Elsevier, Oxford

38. Uhlig HH. Physical Metallurgy of Stress Corrosion Fracture, Rhodin TN. ed. Interscience, 1959. p. 1.

39. Chen W, Kania R, Worthingham R, Kariyawasam S. "Crack growth model of pipeline steels in near-neutral pH soil environments", International Pipeline Conference 2008, Calgary, Sep 29-Oct 3, 2008. paper \# IPC08 64475,

40. Torng TY, McClung RC. "Probabilistic Fatigue Life Prediction Methods for Small and Large Fatigue Cracks", Proc. 35th Structures, Structural Dynamics, and Materials Conf., April 1994. p.1514.

41. McClung RC, Sehitoglu H. ASME J. Engng Mater. Technol 1992;114:1

42. Wang SH, Chen W, King F, Jack TR, Fessler RR. Corrosion 2002;56(6):526 


\subsection{Hydrogen effects in near-neutral pH environments}

Hydrogen effects are associated with the process of sharpening. The mechanism of and the conditions leading to hydrogen sharpening for pipelines exposure to near neutral $\mathrm{pH}$ environments have been addressed in Ref. [1]. Conclusions of the research are given below:

1) Crack growth in near neutral $\mathrm{pH}$ environments was related to two competitive processes at the crack tip: the intrinsic blunting and the extrinsic sharpening. The former originates from the low temperature creep at the crack tip due to either near-static loading or fatigue loading at very low frequency, and the active dissolution over the deformed crack tip without passivating the crack surface. The extrinsic sharpening is governed by the mechanisms of fatigue and the hydrogen effects. Balance of both the intrinsic and extrinsic processes determines whether cracks will experience dormancy or active growth.

2) Under static loading (scenario of stress corrosion cracking), crack tip blunting is predominant and thus cracks would always stay dormant. When cracks are subjected to cyclic loading (a situation of corrosion fatigue), the blunting process is attenuated but the sharpening process is enhanced such that the two processes can be very comparable depending on variations of service conditions including alteration of environments, cathodic protection and pressure fluctuations.

3) Since pipelines, particularly those for high pressure gas transmission, are operated under a near static condition most of time, crack growth proceeds normally by repeated cycles of dormancy and active growth with a growth rate substantially higher than generally estimated in the field.

4) For a given pipeline system, the presence of near neutral $\mathrm{pH}$ environments and high residual stresses on pipe surface determines whether a crack colony can be developed, while the presence of high diffusible hydrogen at special locations within some crack colonies is thought to determine whether repeated crack growth is possible to occur. Hydrogen produced by corrosion at the crack tip is secondary in terms of crack growth, as compared with the amount of hydrogen generated from pipeline surface either resulted from general corrosion or cathodic reaction.

5) There exist many situations in the field that could enhance the generation of diffusible hydrogen at the pipe surface within a crack colony. This is believed to be a key reason that a small fraction of cracks, typically $5 \%$ of total population, can grow repeatedly to cause pipeline rupture.

\section{Reference:}

1. W. Chen, R. Kania, R. Worthingham, G.V. Boven, Tansgranular crack growth in the pipeline steels exposed to near-neutral pH soil aqueous solutions: the role of hydrogen, Acta Mater., 57 (2009), 6200-6214. 


\subsection{Low temperature creep behavior of pipeline steels}

\subsubsection{Introduction}

Low temperature creep has been considered to be responsible for crack tip blunting. The occurrence of low temperature creep at the crack tip is largely dependent of slow loading frequencies characteristic of pipeline operating. The following is a fundamental study of low temperature creep of two pipeline steels.

The frequency effects on fatigue crack growth rate can be strongly environmental dependent. When crack growth occurs in the environments that can cause corrosion, fatigue crack growth rates are generally observed to increase with decreasing loading frequency ${ }^{[1-3]}$. In the environments where corrosion effects are negligible, the effects of frequency on fatigue crack growth rate are sensitive to the type of materials and the range of frequency. For materials with an fcc structure, cyclic loading frequency generally exhibits negligible effect both on fatigue life and fatigue crack growth rate, primarily because of low activation energy for dislocation motion ${ }^{[4-7]}$. For metals with a bcc and hcp structure, crack growth rate is more sensitive to loading frequency, especially in the very high loading frequency regime where motion of dislocations is difficult to activate ${ }^{[8,9]}$. For steel alloys, the effect of frequency on crack growth rate is more complicated. Crack growth rate is more sensitive to the loading frequency for materials that exhibit cyclic softening, but less sensitive for materials that show cyclic hardening ${ }^{[10]}$. The other factor which we will introduce into consideration is low temperature creep ${ }^{[11-15]}$ which has been shown to be important in many pipeline steels.

This investigation is aimed at understanding the frequency dependence of fatigue crack growth of pipeline steels under very low loading frequency when tested in laboratory air. This is useful in understanding corrosion fatigue, for example, in pipeline steels. Sometimes the corrosion fatigue rate at low frequencies is compared to the fatigue in air at high frequencies and this may be misleading as we will see. The frequency to be examined is in the range of 0.1 to $0.001 \mathrm{~Hz}$. This range of cyclic loading frequency is occasionally studied in environments in which corrosion can occur, but are rarely addressed when test environments are inert. Such a low cyclic loading frequency is very typical for pipelines used for high pressure oil and gas transmission. Pressure fluctuations can be just a few times in a day or a change of pressure occurs over a period from a few minutes to a few hours ${ }^{[16,17]}$.

These pipelines often develop cracks on the external surface, for example, due to corrosion in ground water with a near neutral $\mathrm{pH}$ after protective coatings are damaged. These cracks, although often termed as near neutral pH stress corrosion cracks (SCC) ${ }^{[18,19]}$, are found to be able to propagate only under cyclic loading, instead of a static loading as a condition of SCC and thus this phenomenon is actually corrosion fatigue ${ }^{[3,20]}$. The crack growth rate was determined to be inversely sensitive to $1 / f^{\alpha}$, where $f$ is the cyclic loading frequency, $\square$ is constant with a value around $0.1^{[3]}$. 
Three factors are usually considered on how loading frequency may influence crack growth in the near-neutral $\mathrm{pH}$ corrosion system ${ }^{[20]}$ : 1) it has been suggested that this inverse dependence of crack growth rate on frequency is related to the diffusion of hydrogen and mechanisms of hydrogen embrittlement. Lower frequency enhances crack growth since it allows more time for hydrogen diffusion. 2) on the other hand, low frequency also promotes low temperature creep which may blunt the crack tip and, therefore, reduces the driving force for crack growth due to reduced stress intensity at the crack tip. 3) low frequency allows more time of corrosion at the crack tip, particularly when cracks are loaded to the high stress portion of the cycle, which may also blunt the crack tip in the current system in which passivation will not take place. To sort this out it is necessary to see how fatigue varies in the absence of corrosion.

In reality, the above three considerations interact synergistically to result in some unique features of NNPHSCC: less than $5 \%$ of cracks are able to propagate and potentially cause pipeline rupture, but over $95 \%$ of cracks remains dormant and give no indication of growth during their lifetime ${ }^{[20]}$. In a previous communication ${ }^{[20]}$, the growth of this $5 \%$ of cracks was attributed to hydrogen effects. For a given pipeline system, the presence of near neutral $\mathrm{pH}$ environments and high residual stresses on pipe surface determines whether a crack colony can be developed, while the presence of high diffusible hydrogen at special locations within some crack colonies is thought to determine whether ongoing crack growth can occur. The dormancy is believed to occur at locations where hydrogen effects are benign and the other two factors as defined above are responsible for crack dormancy. However, it has been never determined which of the above two factors, corrosion or room temperature creep or both at the crack tip, is truly responsible for the occurrence of dormancy.

This investigation was initiated to answer the above questions. In particular, it will aim to study crack growth behaviour at extremely low loading frequencies in a lab air environment. For this investigation, the dormancy at low loading frequency was found to be an intrinsic characteristic of pipeline steels. The cyclic loading frequency acts together with $\Delta \mathrm{K}$ and $\mathrm{K}_{\max }$ as a driving force governing the process of fatigue crack growth.

\subsubsection{Experimental}

Two grades of pipeline steels, X52 and X80, were used in this study representing the low and high strength pipeline steels commonly used today. Their chemical compositions and tensile properties are listed in Tables 4-1 and 4-2, respectively. Compact tension (CT) specimens were machined from the pipe with the notch perpendicular to the circumferential direction of the pipe. The specimens were polished to 600 grit abrasive paper and then pre-cracked by fatigue in air according to ASTM E647-93. The sharp crack initiated from the machined notch was controlled to be between 2 and $3 \mathrm{~mm}$ long with the difference of less than $0.1 \mathrm{~mm}$ on the sides of the sample.

Fatigue tests were performed in a laboratory environment with room temperature at $22^{\circ} \mathrm{C}$. Cyclic loads were applied to CT specimens at different frequencies including 0.5, 0.05, 0.005 and 
$0.001 \mathrm{~Hz}$ using an Instron fatigue hydraulic loading frame. Each test started from the highest frequency $(0.5 \mathrm{~Hz})$ for 1800 cycles to the lowest frequency $(0.001)$. The starting $\mathrm{K}_{\max }, \Delta \mathrm{K}$ and $\mathrm{R}$ ratio for each test are listed in Table 4-3. Since crack growth at each frequency was very small, the entire test with varied frequencies can be considered to be a test with constant $\mathrm{K}_{\max }$ and $\Delta \mathrm{K}$. Crack growths after a certain number of cycles (Table 4-4) were measured directly with on optical microscope. Average growth rate was measured over the test period for a given loading frequency.

TABLE 4-1 Chemical composition of X52 and X-80.

\begin{tabular}{|c|c|c|c|c|c|c|c|c|c|c|c|}
\hline STEELS & $\mathrm{C}$ & $\mathrm{Mn}$ & $\mathrm{Cu}$ & $\mathrm{Nb}$ & $\mathrm{Cr}$ & $\mathrm{Mo}$ & $\mathrm{V}$ & $\mathrm{Ni}$ & $\mathrm{Al}$ & $\mathrm{Ti}$ & $\mathrm{N}$ \\
\hline $\mathrm{X} 52$ & 0.07 & 0.8 & 0.28 & 0.09 & 0.05 & 0.01 & 0.002 & 0.01 & 0.031 & 0.019 & 0.001 \\
\hline $\mathrm{X} 80$ & 0.06 & 1.75 & 0.27 & 0.31 & 0.04 & 0.03 & 0.005 & 0.08 & 0.026 & 0.011 & 0.003 \\
\hline
\end{tabular}

TABLE 4-2 Mechanical properties of X52 and X80.

\begin{tabular}{|c|c|c|c|}
\hline Steel & Yield Strength (MPa) & Tensile Strength (MPa) & Total Elongation (\%) \\
\hline X52 & 382.2 & 485.3 & 32.2 \\
\hline X80 & 619.5 & 705.1 & 20.6 \\
\hline
\end{tabular}

TABLE 4-3 Mechanical loading conditions

\begin{tabular}{|c|c|c|c|c|}
\hline Test No. & $\mathrm{K}_{\max }, \mathrm{MPa} \sqrt{\mathrm{m}}$ & $\square \mathrm{K}, \mathrm{MPa} \sqrt{\mathrm{m}}$ & $\mathrm{R}$ & $\square \mathrm{K}^{0.67} \mathrm{~K}_{\max }^{0.33}, \mathrm{MPa} \sqrt{\mathrm{m}}$ \\
\hline 1 & 33 & 15.3 & 0.53 & 19.7 \\
\hline 2 & 40 & 15.3 & 0.62 & 21.0 \\
\hline 3 & 33 & 16.8 & 0.489 & 21.0 \\
\hline
\end{tabular}

TABLE 4-4 Cyclic loading frequency

\begin{tabular}{|c|c|c|}
\hline Frequency $(\mathrm{Hz})$ & Cycles $(\mathrm{N})$ & Time (hour) \\
\hline 0.5 & 1800 & 1 \\
\hline 0.05 & 1800 & 10 \\
\hline 0.005 & 3600 & 200 \\
\hline 0.001 & 1800 & 500 \\
\hline
\end{tabular}

\subsubsection{Results and Discussion}

\section{Experimental observations}

Figure 4-3 shows crack growth rates plotted as a function of cyclic frequency. Three tests were performed with different starting $\mathrm{K}_{\max }$ and $\Delta \mathrm{K}$ as indicated in the figure. Crack growth rate is seen to decrease significantly with decreasing cyclic frequency. In X-52 steel for example the crack rate decreased by $1 / 15$ between $0.5 \mathrm{~Hz}$ and $0.001 \mathrm{~Hz}$ for a $\mathrm{K}_{\max }$ of $33 \mathrm{MPa} \sqrt{\mathrm{m}}$. The 
trend of growth rate reduction is strongly dependent of both $\mathrm{K}_{\max }$ and $\Delta \mathrm{K}$ values. Under the same $\mathrm{K}_{\max }$ and $f$, higher $\Delta \mathrm{K}$ yielded higher crack growth rate and slower decrease in growth rate with decreasing loading frequency. Under the same $\Delta \mathrm{K}$ and $f$, higher $\mathrm{K}_{\max }$ leads to higher growth rate and less dependence of growth rate on frequency.

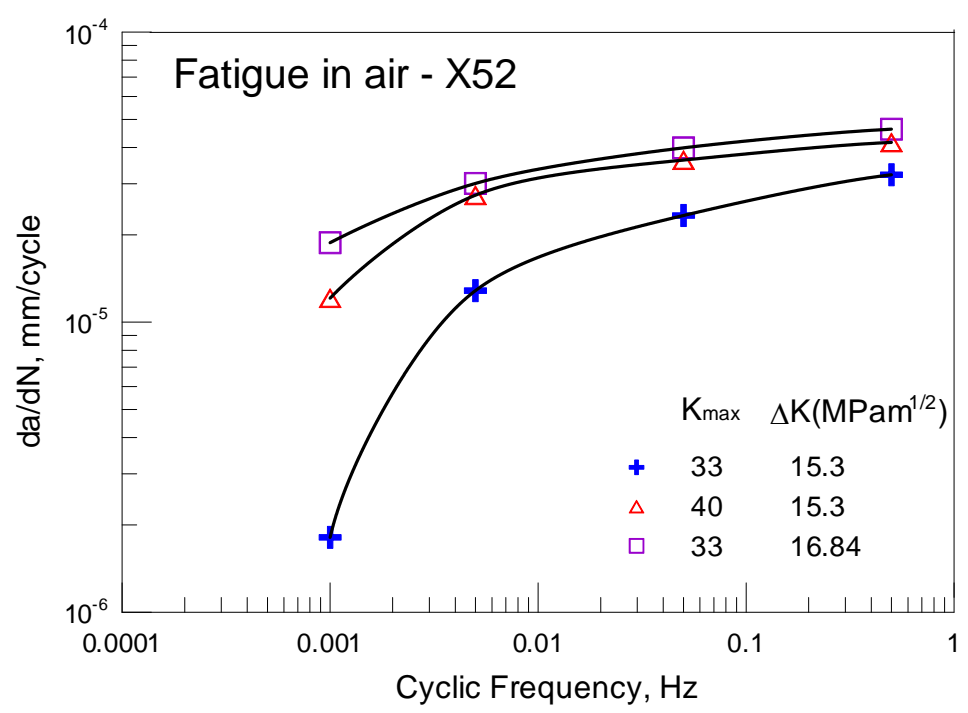

a)

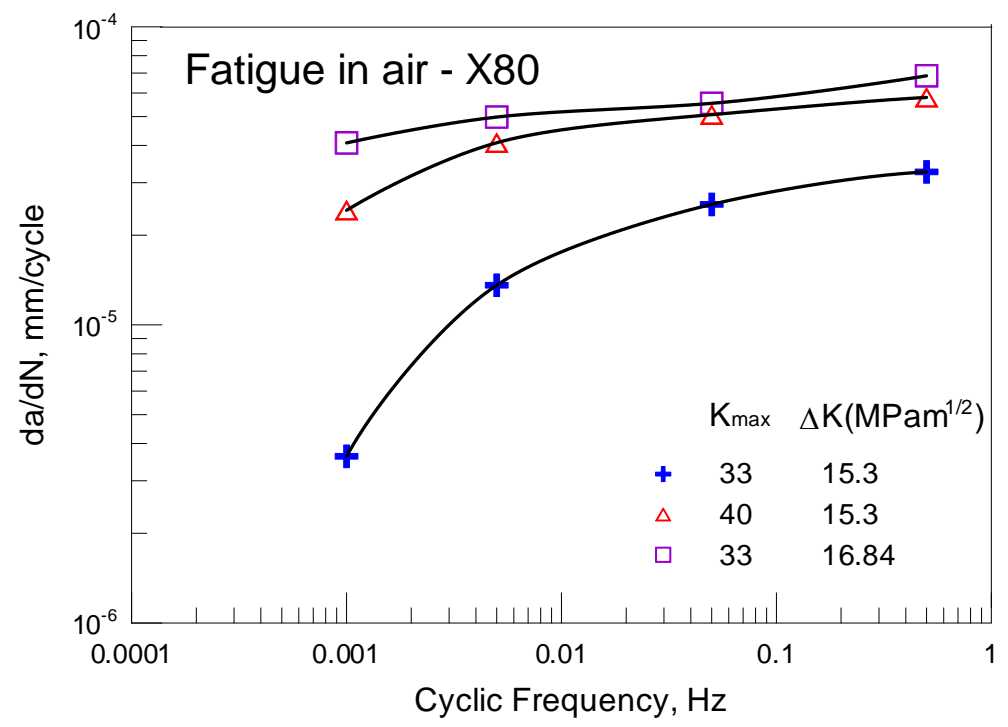

b)

Figure 4-3 Variation of da/dN with loading frequency for tests with different starting $\mathrm{K}_{\max }$ and $\Delta \mathrm{K}$ values, a) X52 pipeline steel, b) X80 pipeline steel.

It should be noted that the total crack growth for the entire test was usually less than $0.1 \mathrm{~mm}$, which yields a change in $\mathrm{K}_{\max }$ and $\Delta \mathrm{K}$ to be less than 0.3 and $0.1 \mathrm{MPam}^{1 / 2}$, respectively. Therefore, each test in air with varied frequency can be considered to be performed under constant $\mathrm{K}_{\max }$ and $\Delta \mathrm{K}$. 
As is shown in Fig. 4-3b), similar crack growth rate-frequency dependence is also observed in X80 pipeline steel, although X-80 exhibit less crack growth rate dependence on frequency in the low frequency regime. The comparable change was only $1 / 7$ as opposed to $1 / 15$.

It is also seen from Fig. 4-3 that the lowest crack growth rate at a frequency of 0.001 (less than 20 minute per cycle) is around $2 \times 10^{-6} \mathrm{~mm} /$ cycle, which is about $2 \times 10^{-9} \mathrm{~mm} /$ second. The value of $\mathrm{K}_{\max }$ used in the loading was about $33 \mathrm{MPam}^{1 / 2}$, which can be achieved at the depth tip of a semi-elliptical crack with a depth of $25 \%$ wall thickness in a X-65 steel line pipe of $9.88 \mathrm{~mm}$ thick that is loaded to a hoop stress of $75 \%$ SMYS (specified minimum yield strength), assuming a crack aspect ratio of $\mathrm{c} / \mathrm{a}=5$ ( $2 \mathrm{c}$ being the surface length of the crack, $a$ the depth). SCC cracks in the field with a growth rate of $1 \sim 2 \times 10^{-9} \mathrm{~mm} / \mathrm{second}$ are generally considered to be dormant for a line pipe of $9.88 \mathrm{~mm}$ thick (it needs almost 16 years to grow $1 \mathrm{~mm}$ at a growth rate of $2 \times 10^{-}$ $\left.{ }^{9} \mathrm{~mm} / \mathrm{s}\right)^{[21]}$.

By referring to the above calculation, one can conclude that the mechanical loading conditions encountered by both oil and gas pipelines should generally yield a situation of "mechanical dormancy", which exist well beyond the size of dormant cracks found in the field, which was usually below 1 2 $\mathrm{mm}$ in depth ${ }^{[20]}$. It is believed that this reduced crack growth rate/mechanical dormancy is primarily caused by the increased low creep deformation at the tip of crack that can blunt the crack tip. This means that these cracks are benign in the absence of a corrosive environment.

\section{Nature of the frequency effects}

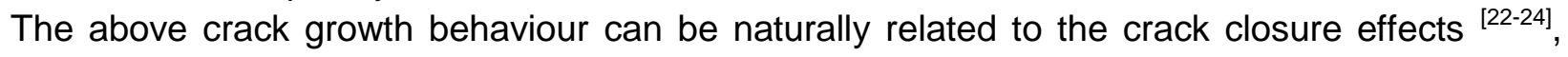
more specifically, the plasticity-induced crack closure, as extensively studied in the last 40 years. However, an analysis of the experimental results indicates that the experimental results are not consistent with the concept of crack closure effects.

1) The plasticity at the crack tip can be considered to be the same when cracks are loaded at the same loading rate (the same frequency) to the same $\mathrm{K}_{\max }$. Under the circumstances, the same crack growth rate can be expected if crack closure occurs at a $R$ ratio higher than the R-ratios used; or the crack growth rate at lower R-ratio would be higher if crack closure occurs at a R-ratio lower than the R-ratios used. Comparing results from Test 1 and 3 (see Table 4-3), it is obvious that the above predictions based on the concept of crack closure is contrary to the experimental results obtained.

2) Under the same $\Delta \mathrm{K}$ loading, however, higher $\mathrm{K}_{\max }$ would induce higher plasticity at the crack tip and stronger crack closure effects. This would predict a lower crack growth rate in Test 2 as compared with Test 1 , if effects of crack closure are present, which is also inconsistent with the experimental results.

A possible explanation for the observations would be the two threshold driving forces concept originally proposed by Vasudevan et al. ${ }^{[25-32]}$. In this concept, both $\mathrm{K}_{\max }$ and $\Delta \mathrm{K}$ will contribute to the crack growth in a way that can be unified through micro-mechanisms of plastic deformation 
at the tip of crack. The concept has been used to model the crack growth of pipeline steels in near-neutral $\mathrm{pH}$ environments ${ }^{[3,20]}$. However, the effect of frequency has never been incorporated into the concept. Since the frequency at the current investigation manifests itself in a way to influence crack growth through low temperature creep, a form of plastic deformation, at the crack tip, it might be reasonable to consider frequency as another independent variable like $\Delta \mathrm{K}$ and $\mathrm{K}_{\max }$ that plays a role in the process of crack growth. As a matter of fact, both $\Delta \mathrm{K}$ and $\mathrm{K}_{\max }$ should also have some influences on the occurrence of room temperature creep irregardless of the change of frequency. For example, higher $\mathrm{K}_{\max }$, on one hand, yields a larger plastic zone at the crack tip, but at the same time would cause more low temperature creep deformation as low temperature creep can be enhanced when the material is more plastically deformed and is under a higher applied stress (or $\mathrm{K}_{\max }$ in the current case). This simply suggests that all the three variables can be interrelated to the micro-plasticity at the crack tip and therefore may govern the crack growth through interconnected micro-plastic mechanisms.

In a previous investigation ${ }^{[3]}$, crack growth rate of pipeline steels was seen to be well correlated to a combined mechanical factor in the form of $\Delta \mathrm{K}^{0.67} \mathrm{~K}_{\max }{ }^{0.33}$ or $\left(\Delta \mathrm{K}^{2} \mathrm{~K}_{\max }\right)$. The same combined factor has also been used in this investigation. The effect of frequency was then determined by curve fitting the experimental data using a new combined factor including the frequency factor: $\Delta \mathrm{K}^{0.67} \mathrm{~K}_{\max }{ }^{0.33} \mathrm{f}^{\gamma}$. The value of $\gamma$ was determined to be 0.02 and 0.01 , respectively, for X52 and $\mathrm{X} 80$. A linear relation seems to exist between da/dN and the new combined term, Fig. 4-4a). When the same data and the linear curve obtained from curve fitting is plotted on a log-log scale (Fig. 4-4b), the threshold behaviour, as often seen in a da/dN- $\Delta \mathrm{K}$ relation, is clearly observed. Similar behaviour was also found for the fatigue crack growth of a X80 pipeline steel, as shown in Fig. 4-5.

The above correlation predicts a positive dependence of crack growth rate on frequency, that is, lower frequency yields lower crack growth rate. Physically, the lower the frequency, the more low temperature creep can occur, which would make the crack tip more blunt and therefore would correspond to a lower crack growth rate. This frequency dependence is opposite to those observed in the fatigue tests where environmental effects become significant. For the latter cases, crack growth rate can be inversely related to cyclic frequency ${ }^{[1-3]}$. In general, a negative frequency dependence can be observed if additional external/internal conditions will produce more damage to the material at the crack tip if more time is available, e.g. anodic dissolution or hydrogen embrittlement ${ }^{[1-3]}$. In contrast, a positive dependence can be produced if the additional variables reduce the driving force for crack growth, such as low temperature creep that can blunt the crack tip and work-harden the material at the crack tip. However, it is not clear whether these two opposite dependencies of crack growth rate can be combined to produce an ultimate condition for material's sensitivity to the effect of environments. That is, in a relatively low frequency regime, a positive dependence of fatigue crack growth rate on frequency is an intrinsic property of the pipeline material, while the negative dependence of fatigue crack growth on frequency is extrinsic behaviour of a material often related to the occurrence of corrosion. For the former situation, the different positive dependence of crack growth rate on frequency relates to the characteristics of microstructures and substructures in 
the material, as the threshold and the frequency dependence of fatigue crack growth rate is seen to be different between X52 and X80.
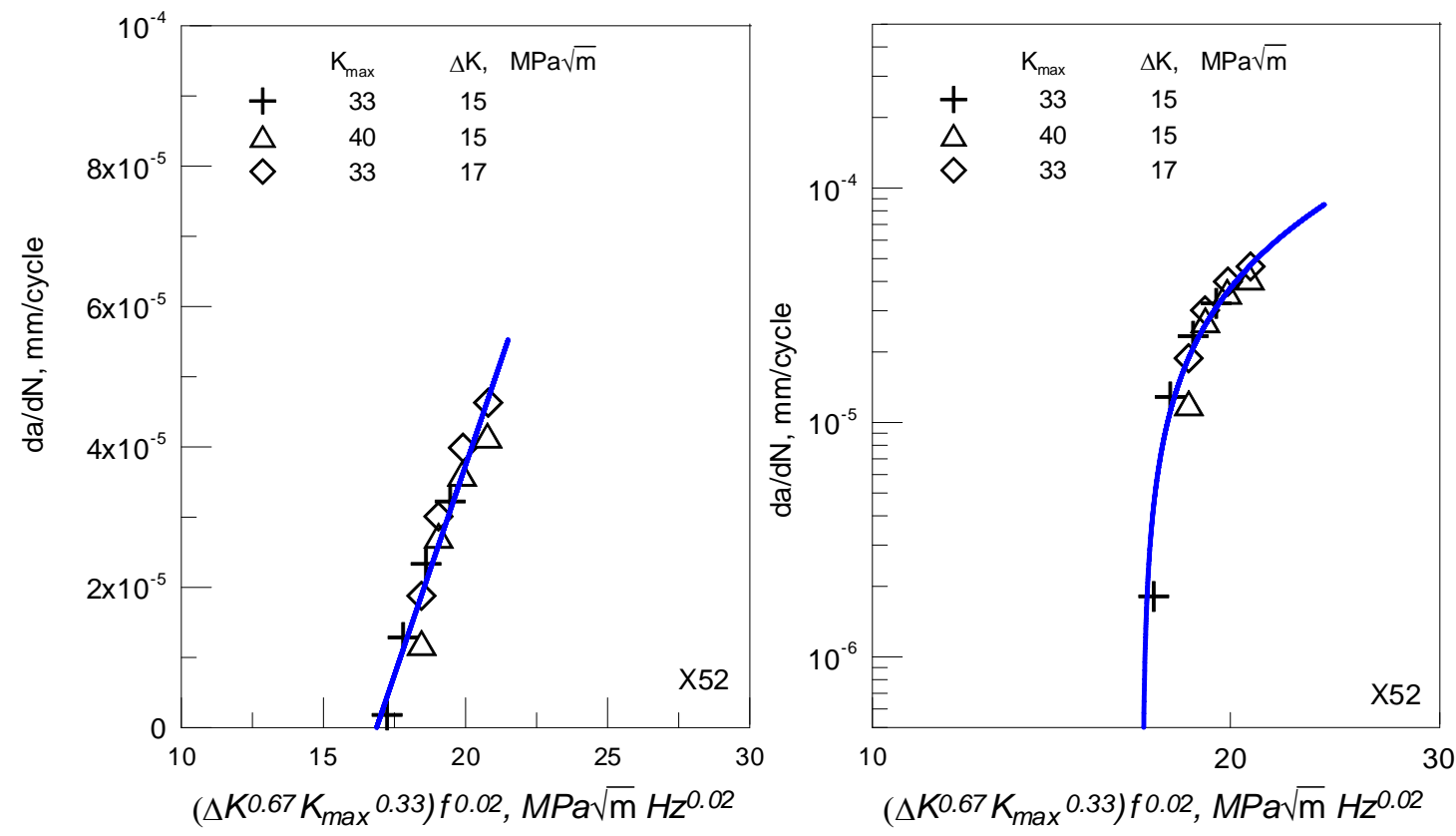

a) b)

Figure 4-4 Fatigue crack growth rate, da/dN, of X52 pipeline steel as a function of new combined driving force, a) linear scale, b) log-log scale.
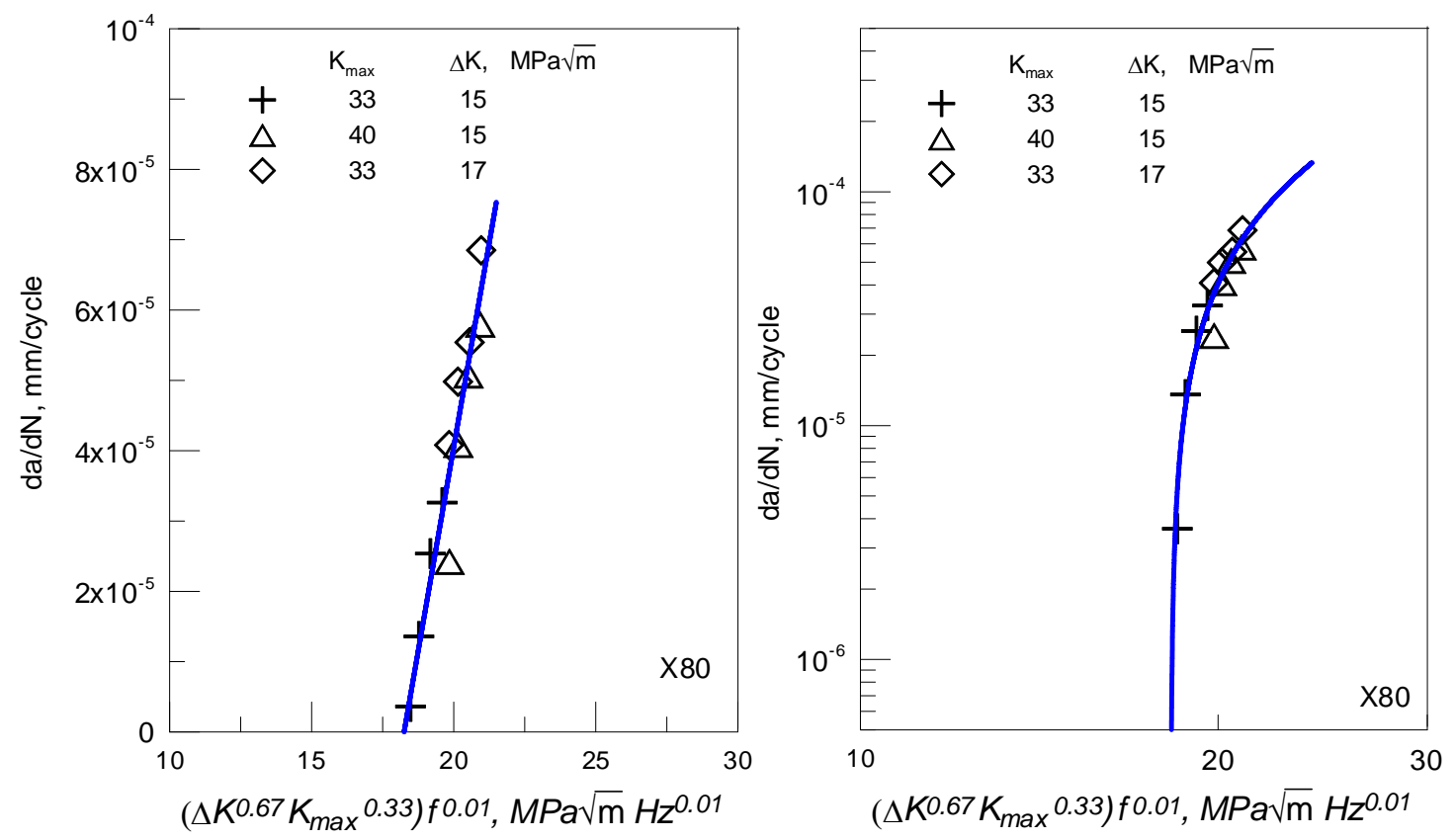

a) b)

Figure 4-5 Fatigue crack growth rate, $\mathrm{da} / \mathrm{dN}$, of $\mathrm{X} 80$ pipeline steel as a function of new combined driving force, a) linear scale, b) log-log scale. 
The findings reported here are believed to be practically useful, for example, for the integrity management of pipeline steels with crack colonies. Because of extremely low loading frequency, cracks with certain depth can be left without grinding during repairing as long as these cracks are covered with high quality of coatings preventing any future exposure to corrosive environments.

\subsubsection{Conclusions}

Frequency can be an independent driving force, like $\Delta \mathrm{K}$ and $\mathrm{K}_{\max }$, in low cyclic loading frequency regime. A dormant state or threshold condition can be achieved by reducing loading frequency. The findings can be utilized to determine whether certain dimensions of cracks are required to be removed by grinding during pipeline repairs.

\section{References:}

1. R. P. Wei and R. P. Gangloff, in Fracture Mechanics: Perspectives and Directions (Twentieth Symposium), ASTM STP 1020, R. P. Wei and R. P. Gangloff, Eds., American Society for Testing and Materials, Philadelphia, 1989, pp. 233-264.

2. R.P. Gangloff, Hydrogen-assisted cracking, in: I. Milne, R.O. Ritchie, B. Karihaloo (Eds), Comprehensive Structure Integrity, volume 6: Environmentally-Assisted Fracture. Elsevier, Oxiford, 2003, vol. 6, pp.31-34.

3. W. Chen and R. L. Sutherby, Met. \& Mater. Trans A, 38A (2007) 1260-1268

4. Laird C, Charsley P. In: Wells J M, Buck O, Roth L D, Tien J K eds., Ultrasonic Fatigue, Proc 1st Int Conf on Fatigue and Corrosion Fatigue up to Ultrasonic Frequencies, Philadelphia: The Metallurgical Society of the American Institute of Mining, Metallurgical and Petroleum Engineers (AIME), 1982: 187

5. Roth L D, Willertz L E, Leax T R. In: Wells J M, Buck O, Roth L D, Tien J K eds., Ultrasonic Fatigue, Proc $1^{\text {st }}$ Int Conf on Fatigue and Corrosion Fatigue up to Ultrasonic Frequencies, Philadelphia: The Metallurgical Society of the American Institute of Mining, Metallurgical and Petroleum Engineers (AIME), 1982: 265

6. Taylor D, Knott JF. In: Proc 6th Int Conf Fracture, New Delhi: Pergamon Press, 1984; 3: 1759

7. Lukas P, Kunz L, Knesl Z, Weiss B, Stickler R. Mater Sci Eng, 70(1985)91

8. Meininger J M, Gibeling J C. Metall Trans, 23A(1992)3077

9. Papakyriacou M, Mayer H, Pypen C, Plenk H Jr, Stanzl-Tschegg S. Mater Sci Eng, A308(2001)143

10. Hong, Youshi, Zhao, Aiguo, Qian, Gui'an, Acta Metall. Sinica, 45(7)(2009)769—780.

11. T. H. Alden, Metall. Trans. A, 18A(1987)811.

12. S. Wang and W. Chen, Mater. Sci. Eng., A325(2002) 144-151.

13. S. Wang, Y. G. Zhang and W. Chen, J. of Maters. Sci., 36(8)(2001)1931-1938.

14. S. Wang, W. Chen, Mater. Sci. Eng A. A301(2001)147-153.

15. W. Chen, H. Zhu and S-H. Wang, Canadian Metallurgical Quarterly, 48(3)(2009)271-284

16. M. J. Wilmott and R. L. Sutherby, "The Role of Pressure and Pressure fluctuations in the Growth of Stress Corrosion Cracks in Line Pipe Steels," Proceedings of the International 
Pipeline Conference (The American Society of Mechanical Engineers, New York, N.Y., 1998): pp. 409-422.

17. S. Wang, W. Chen, Corrosion, 58(6)(2002)526-534.

18. Parkins RN. A review of stress corrosion cracking of high pressure gas pipelines proceedings of corrosion 2000. Paper 00363. Houston, Texas: NACE International; 2000.

19. Parkins RN, Blanchard Jr WK, Delanty BS. Corrosion 50(1993)395.

20. W. Chen, R. Kania, R. Worthingham, G. Boven, Acta mater., 57 (2009)6200-6214

21. W. Chen, F. King, and E. D. Vokes, Corrosion, 58(3)(2002) 267-275.

22. Elber W. Eng. Fract. Mech., 2(1990)37

23. Elber W. ASTM STP-486, American Society of Testing and Materials, Philadelphia PA, 1970, p.230.

24. Suresh S. in Fatigue of Materials, Cambridge University Press, Cambridge, 1991, Ch.7

25. Vasudeven AK, Sadananda K, Louat N. Mater. Sci. Eng. A, A188(1994)1

26. Vasudevana AK, Sadananda K, Holtz RL. International J. of Fatigue, 27(2005)1519-1529

27. Vasudevan AK, Sadananda K. International Journal of Fatigue, 29(2007)1985-1989

28. Sadananda K, Vasudevan AK. Acta Materialia, 52(2004)4239-4249

29. Sadananda K, Vasudevan AK. International Journal of Fatigue, 26(2004)39-47

30. Sadananda K, Vasudevan AK, Kang IW. Acta Materialia, 51(2003)3399-3414

31. Sadananda K, Vasudevan AK. International Journal of Fatigue, 25(2003)899-914

32. Sadananda K, Vasudevan AK. Fatigue Fract Engng Mater Struct, 26(2003)835-845

\subsection{Modelling crack growth of pipeline steels in near-neutral pH environments}

\subsubsection{Introduction}

This section is aimed at providing a modelling approach that could predict crack growth on the basis of crack tip blunting and crack tip sharpening.

In the last a few decades, fatigue experiments have been primarily conducted at high frequencies at which millions of cycles can be performed in a few days, which is necessary especially when threshold conditions with a growth rate at $10^{-7} \mathrm{~mm} /$ cycle level can be accurately determined. The results obtained from such a practice are meaningful if a structure is subjected to stress fluctuations at loading frequencies relevant to those used in laboratory experiments. However, there are many industrial situations where cyclic frequencies are well below the range of frequencies adopted in laboratory evaluations, for example, the reciprocating sucker rods used in oilfields, the pressure variations in steel pipelines for oil and gas transmission [1, 2], cyclic stresses from temperature variations and many other loading scenarios.

Crack growth behavior at low frequency cyclic loading becomes complicated when time dependent mechanisms are to be involved. It is well known that, for example, in the corrosion 
system where passivating films can be formed, low frequency cyclic loading could reduce crack growth rate or even suppress cracking when the rate of film-forming exceeds the rate of film rupture by cyclic stress [3, 4]; In the system where effects of hydrogen embrittlement (HE) can occur, on the other hand, low frequency cyclic loading often results in a negative crack growth rate dependence of loading frequency, which is attributed to the increased time for hydrogen diffusion and segregation to the crack tip [5-7]. To reveal such negative frequency dependences of crack growth rate, low frequency laboratory simulations are often performed. However, these low frequency tests, mostly around $0.01 \mathrm{~Hz}$ or above, often bear no connections to the actual frequencies of loading in the field, which are often operated at even much lower levels, for example, in the $10^{-3}$ to $10^{-4} \mathrm{~Hz}$ range $[1,2]$.

The above consideration of frequency-effects is primarily related to the external operating conditions that can lead to the time-dependent material degradation. The effects of frequency on fatigue crack growth rate (FCGR) are also sensitive to the type of materials and the range of frequency. For materials with an face centered cubic (fcc) structure, cyclic loading frequency generally exhibits negligible effect both on fatigue life and fatigue crack growth rate (FCGR), primarily because of low activation energy for dislocation motion [8-11]. For metals with a bcc and hcp structure, crack growth rate is more sensitive to loading frequency, especially in the very high loading frequency regime where motion of dislocations is difficult to activate $[12,13]$. For steel alloys, the effect of frequency on FCGR is more complicated. FCGR is more sensitive to the loading frequency for materials that exhibit cyclic softening, but less sensitive for materials that show cyclic hardening [14].

One of the essential causes of the frequency-effect on FCGR is the occurrence of low temperature creep (LTC) [15-19], which has been shown to be important in many ductile metallic materials. LTC is plastic deformation occurring at temperatures below $0.4 \sim 0.5 \mathrm{~T}_{\mathrm{m}}\left(\mathrm{T}_{\mathrm{m}}\right.$ : melting point) (in contrast to the thermally activated process at temperatures above $0.4 \sim 0.5 \mathrm{~T}_{\mathrm{m}}$ ) and is caused by motion of existing mobile dislocations under applied stresses. In our previous investigations [7, 20, 21], we have studied crack growth behaviour of pipeline steels at a wide range of loading frequencies of steels exhibiting LTC. The frequencies examined were in the range of 0.1 to $0.001 \mathrm{~Hz}$. This range of cyclic loading frequency is occasionally studied in environments in which corrosion can occur, but are rarely addressed when test environments are inert. Such a low cyclic loading frequency is very typical for pipelines used for high pressure oil and gas transmission. Pressure fluctuations occur over a period from a few minutes to a few hours [1, 2]. It was found that crack dormancy at low loading frequency is an intrinsic characteristic of the steels [21]. Frequency can be an independent driving force, like $\square \mathrm{K}$ and $\mathrm{K}_{\max }$, in the low cyclic loading frequency regime. A dormant state or threshold condition can be achieved by reducing loading frequency.

Cyclic loading at very low frequencies allows adequate time for LTC to occur over the high stress portion of a cycle. However, the occurrence of LTC can also take place during cyclic loading with high stress-ratios (=minimum stress/maximum stress). Under such conditions, the material at the crack tip approaches a near static loading state as stress ratio $\mathrm{R}$ increases. More generally, LTC effects should exist at any cyclic loading at which crack growth proceeds at a 
very low rate. Therefore, the effect of LTC should be fully considered in any cyclic evaluations of ductile materials.

The purpose of this investigation was to develop a compounding approach to predict corrosion fatigue (CF) crack growth based on the intrinsic cyclic behavior of pipeline steels as affected by LTC [21]. Pipeline steels often develop cracks on their external surface after their coating is damaged, for example, due to corrosion in ground water with a near neutral $\mathrm{pH}(\mathrm{NNpH})[7,22$, 23]. These cracks, although often termed near neutral pH (NNpHSCC) stress corrosion cracks (SCC) [22, 23], are found to be able to propagate only under cyclic loading, instead of under static loading which should occur for SCC and thus this phenomenon is actually corrosion fatigue $[7,20]$. The crack growth rate was determined to be inversely sensitive to $1 / f^{\alpha}$, where $f$ is the cyclic loading frequency, $\alpha$ is a constant with a value around 0.1 [20].

Three factors are usually considered on how loading frequency may influence crack growth in the $\mathrm{NNpH}$ corrosion system [7]: 1) it has been suggested that this inverse dependence of crack growth rate on frequency is related to the diffusion of hydrogen and HE mechanisms. Lower frequency enhances crack growth since it allows more time for hydrogen diffusion. 2) On the other hand, low frequency promotes LTC which may blunt the crack tip and, therefore, reduce the driving force for crack growth due to reduced stress intensity at the crack tip. 3) Low frequency allows more time for corrosion at the crack tip, particularly when cracks are loaded to the high stress portion of the cycle, which may also blunt the crack tip in current NNpH system in which passivation will not take place. Our previous investigations have confirmed that crack growth behaviour in $\mathrm{NNpH}$ environments is predominately determined by a synergistic interaction of Factor 1) and Factor 2) as discussed above. Another effect which will be termed Factor 3 contributes to the crack growth through the generation of hydrogen (by-product of corrosion) and the occurrence of HE.

Based on the above introduction, one can now naturally imagine whether there is any connection between the intrinsic cyclic behavior of pipeline steels determined from tests in an inert environment such as lab air for the pipeline steels [21] and the CF crack growth behavior obtained from tests in corrosive environments [20]. More precisely, one may wonder if the threshold in CF is also the threshold found in fatigue loading in air, and how the enhanced crack growth rate in the current corrosive environment can be tied to the intrinsic cyclic behavior in air/inert environments and the hydrogen effects. For the latter situation, would a function reflecting the intrinsic behavior of hydrogen effects exist?

In this investigation, we will use the intrinsic cyclic behavior with an inclusion of frequency factor as a base of modeling and the hydrogen/corrosion as an enhancement factor to fully predict the crack growth behavior obtained over the whole range from more aggressive mechanical loading to the benign loading conditions near the threshold. The modelling efforts made in this investigation will support the rationale of the existing empirical approaches on correlating crack growth rate to various contributing factors. On the other hand, it will also provide new insights into the control of crack growth in pipeline and other structures in field service and on materials design to achieve better resistance to fatigue and corrosion fatigue. 


\subsubsection{Experimental}

X52 pipeline steel was used in this study. Its chemical composition and mechanical properties are shown in Tables 1 and 2, respectively. The X52 pipeline steel had low carbon content with a microstructure consisting of dispersed carbide particles in a ferritic matrix. Compact tension (CT) specimens were used in all the tests, which were machined from the pipes with the notch perpendicular to the circumferential direction of the pipe. The specimens were polished to 600 grit abrasive paper and then pre-cracked by fatigue in air according to ASTM E647-93. The sharp crack initiated from the machined notch was controlled to be between 2- and 3- $\mathrm{mm}$ long with a difference of less than $0.1 \mathrm{~mm}$ on the sides of the specimen.

Table 4-5 List of test conditions for all corrosion fatigue tests performed

\begin{tabular}{|c|c|c|c|c|}
\hline Test No. & $\mathrm{K}_{\max }, \mathrm{MPa} \sqrt{\mathrm{m}}$ & $\Delta \mathrm{K}, \mathrm{MPa} \sqrt{\mathrm{m}}$ & $\mathrm{R}$ & $\mathrm{f}, \mathrm{Hz}$ \\
\hline 2 & 35 & 14 & 0.6 & 0.01 \\
\hline 3 & 38 & 14.8 & 0.6 & 0.005 \\
\hline 7 & 43 & 18 & 0.58 & 0.00125 \\
\hline 8 & 35 & 18 & 0.48 & 0.00125 \\
\hline 10 & 35 & 12 & 0.65 & 0.005 \\
\hline
\end{tabular}

CT specimens were cyclic loaded in a $\mathrm{NNpH}$ synthetic soil solution. They were pin hole loaded in sealed test cells with the solution filled up to the middle of their notches using a horizontal pneumatic cyclic loading frame. Minimum and maximum loads were controlled considering the pre-crack size to achieve $\mathrm{K}_{\max }$ and $\Delta \mathrm{K}$ in the range of 35 to 55 and 10 to $28 \mathrm{MPam}^{0.5}$, respectively. Triangle waveform was used with three different frequencies of $0.01,0.005$ and $0.00125 \mathrm{~Hz}$ and stress ratio (R) of about 0.6 for most of the tests (Table 4-5 for details).

C2 solution was used as the $\mathrm{NNpH}$ synthetic soil solution and its chemical composition was provided in Section 3.2 [24]. The solution was purged with the gas mixture of $5 \% \mathrm{CO}_{2}$ balanced with $\mathrm{N}_{2}$ in a sealed glass container for at least 24 hours before the test to achieve the nearneutral $\mathrm{pH}$ value $(\mathrm{pH}=6.29)$. Gas purging was also continued during the test to keep the $\mathrm{pH}$ of the solution near-neutral (6.29) at all times.

Crack growth was monitored using a DC potential drop system. Details of this system were reported in Ref. [20]. A constant current of $10 \mathrm{~A}$ was applied through the crack crevice and changes of potential due to crack growth were converted to crack length using ASTM E647-05 equations. At least 20 data points were collected for each loading cycle depending on the loading frequency. Each of the data points were the average of ten measurements at positive and ten measurements at negative current polarity. Testing temperature was controlled to be $30^{\circ} \mathrm{C} \pm 0.1^{\circ} \mathrm{C}$, which is an important consideration in making these measurements. 
The microstructure of pipeline steels and the morphology of cracks after corrosion exposure were examined on S-2700 Scanning Electron Microscope (SEM) (HITACHI, Japan).

\subsubsection{Results and Discussions:}

\subsubsection{Crack growth behavior}

Crack growth data were correlated to $\Delta \mathrm{K}$ in many previous $\mathrm{NNpH}$ cracking studies [20]. As indicated in a previous investigation by present researchers, crack growth data in $\mathrm{NNpH}$ environments cannot be related to $\Delta \mathrm{K}$ alone as the growth rate was also found to depend on environmental effects and the other fatigue driving force viz. $K_{\max }$ [20]. Under the same $\Delta \mathrm{K}$ value, higher growth rate corresponds to the test with higher $K_{\max }$. It has been well established in a previous investigation that crack growth rate of a $\mathrm{X} 65$ pipeline steel in $\mathrm{NNpH}$ environments can be correlated by a single combined term, $(\Delta K)^{2} K_{\max } / f^{0.1}$ or $(\Delta K)^{0.67} K_{\max }{ }^{0.33} / f^{0.033}$ after being normalized to $(\Delta K)^{\alpha} K_{\max }^{\beta} / f^{\gamma}$ with $\alpha+\beta=1$ [20]. The same correlative behaviour has also been found in this investigation for X52 pipeline steel, as demonstrated in Fig. 4-6.
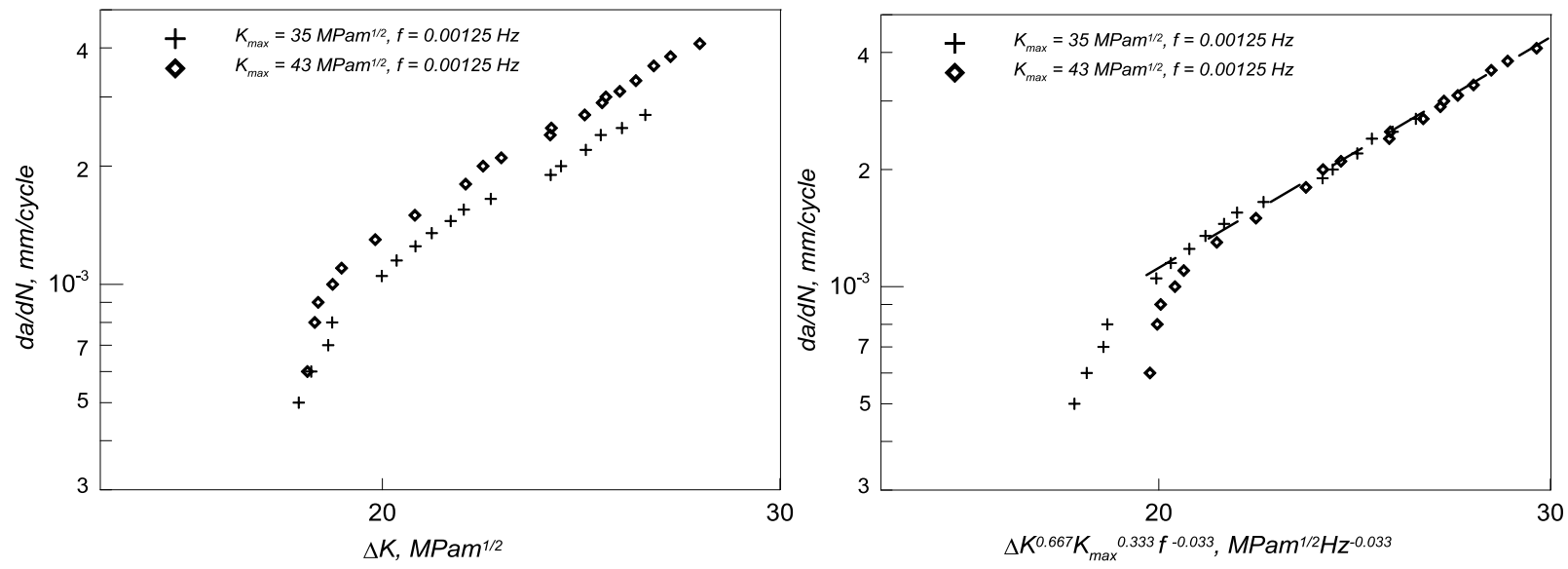

Fig. 4-6 Crack growth rate $\mathrm{da} / \mathrm{dN}$ as a function of $\Delta \mathrm{K}$ a) and $(\Delta \mathrm{K})^{0.667} \mathrm{~K}_{\max }{ }^{0.333} / \mathrm{f}^{0.033}$ b) for $\mathrm{X52}$ pipeline steel.

Various test conditions as summarized in Table 4-5 were applied to the pipeline steel to obtain its crack growth behaviour in $\mathrm{NNpH}$ environments. The crack growth data were correlated using a single factor $(\Delta K)^{0.67} K_{\max }{ }^{0.33} / f^{0.033}$. Figure 4-7 shows the crack growth rate, da/dN, of four individual tests of $\mathrm{X} 52$ as a function of $(\Delta K)^{0.67} K_{\max }{ }^{0.33} / f^{0.033}$. The value of $\Delta K$ and $K_{\max }$ at the beginning of each test and the constant frequency of each test are also included in Fig. 4-7. Each of these tests was at least one month long and some of them lasted over 3 month. Each of the crack growth curves can be roughly divided into two regions: the linear stage at higher $(\Delta K)^{0.67} K_{\max }{ }^{0.33} / f^{0.033}$ values, and the tail portion observed at the beginning of test or when $(\Delta K)^{0.67} K_{\max }{ }^{0.33} / f^{0.03}$ value is low. The tail part observed for a test with high initial $(\Delta K)^{0.67} K_{\max }^{0.33} / f$ 
${ }^{0.03}$ values is short, while it is very long and over a long period when $(\Delta K)^{0.67} K_{\max }{ }^{0.33} / f^{0.03}$ is very low. In the latter case, the tail portion shows a parabolic growth behaviour with increasing $(\Delta K)^{0.67} K_{\max }{ }^{0.33} / f^{0.03}$ and appears $f$-dependent even when the data are normalized by a $f$ containing term, in contrast to the linear relation observed for the tests with high $(\Delta K)^{0.67} K_{\max }^{0.33}$ $/ f^{0.03}$ values. This naturally suggests a division of the entire growth behaviour over the scale of $(\Delta K)^{0.67} K_{\max }^{0.33} / f^{0.03}$ into two main regions: the tail portion and the linear growth region.

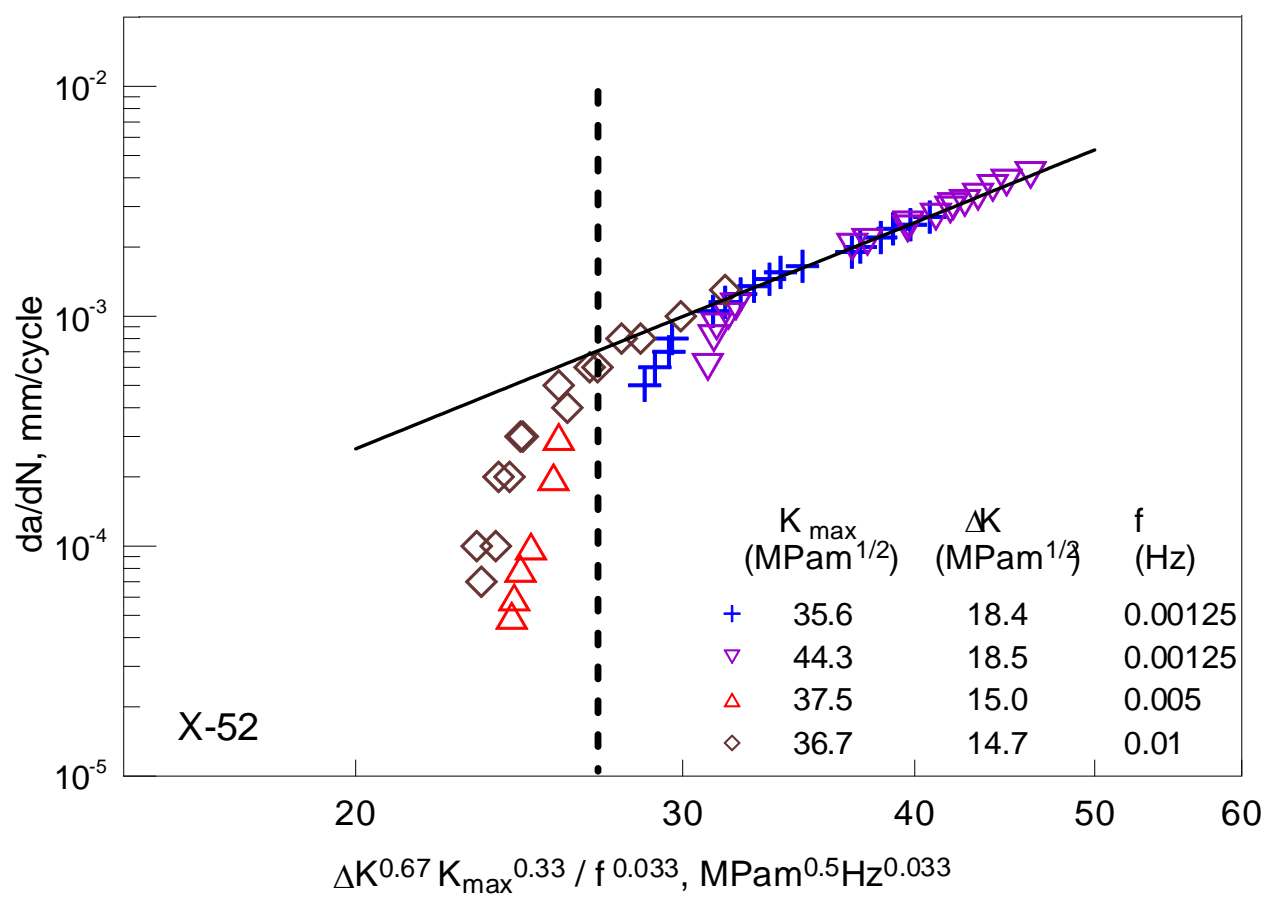

Figure 4-7 Crack growth rate $\mathrm{da} / \mathrm{dN}$ as a function of $\Delta \mathrm{K}$ and $(\Delta \mathrm{K})^{0.667} \mathrm{~K}_{\max }{ }^{0.333 / f^{0.033}}$ for $\mathrm{X} 52$ pipeline steel.

\subsubsection{Crack growth mechanisms}

The linear stage in the region under high $(\Delta K)^{0.67} K_{\max }{ }^{0.33} / f^{0.033}$ loading has been characterized in details in previous investigations [20,7]. The growth is driven by a mechanical process related to micro-plastic mechanism at the crack tip under cyclic loading. The two-parameter driving force, namely $\Delta K$ and $K_{\max }$, has been well established for many metallic materials [25-32]. The inverse dependence of crack growth rate on frequency has been initially observed by Wei and was further categorized by Gangloff $[5,6]$. For the current environment-material system, it has been further determined by the present investigators that the crack growth is enhanced by atomic hydrogen dissolved in the steel, which is a by-product of dissolution of $\mathrm{Fe}$ in $\mathrm{NNpH}$ solutions [7, 33]. The contribution to the crack growth by the direct dissolution of Fe at the crack tip was found to be secondary, while the hydrogen-enhanced cracking at the crack tip or in the plastic zone ahead of the crack tip has been proven to be mainly responsible for crack growth. 
The dependence of crack growth on $1 / f^{0.033}$ is believed to be related to the diffusion of hydrogen to the crack tip during loading and un-loading. Therefore, the linear crack growth can be categorized as a hydrogen-enhanced mechanically driven process (HEMDP).

The crack growth mechanisms in the tail portion can be different depending on the initial $(\Delta K)^{0.67} K_{\max }{ }^{0.33} / f^{0.033}$ value. For a test with high $(\Delta K)^{0.67} K_{\max }{ }^{0.33} / f^{0.03}$ value, the short tail portion has been correlated to the time required for achieving hydrogen equilibrium in the steel [7]. This needs about ten days for the thickness of the specimen used and the low diffusion rate of hydrogen at low hydrogen concentration present in this corrosion-environment-material system. The growth rate in the tail portion was also not reasonably linear, reflecting the predominant role played by mechanical driving forces and relatively minor contribution of $\mathrm{HE}$.

It is certain that the tail portion observed at low $(\Delta K)^{0.67} K_{\max }{ }^{0.33} / f^{0.02}$ values cannot be attributed to the time effects related to the time to achieve the equilibrium state of hydrogen in the specimen, as it lasted over a long period, e.g., over 1 month. Crack growth rate in the tail portion increases slowly with increasing $(\Delta K)^{0.67} K_{\max }^{0.33} / f^{0.033}$, which does not seem to be very consistent with a growth behaviour above or near the threshold as often seen in CF or fatigue curves. In addition, the crack growth rate after normalization was also $f$-dependence with higher growth rate at higher frequencies.

From the above observations, one can logically raise many questions such as,

1) What is the nature of the correlation of growth rate in the regime with $\left(\Delta K^{0.667} K_{\max }^{0.333} / f^{0.033}\right)$ ?

2) Why is there different growth behaviour present at low $(\Delta K)^{0.67} K_{\max }{ }^{0.33} / f^{0.03}$ values, at which crack growth rate is no longer linear but still $f$-dependent after being normalized by $1 / f^{0.033}$ ? Is the exponential value for the $f$-factor intrinsic to a given material-corrosion system?

3) Is the tail portion a near-threshold condition, and what would be the nature of thresholds if present? What would be the physical mechanisms of crack growth in the tail region as compared with those in the linear region?

The next sections will first provide a modelling approach to predict the CFCGR and then elucidate the nature of the modelling, from which the above questions are to be answered.

\subsubsection{Modelling Approach}

To understand the crack growth mechanisms in $\mathrm{NNpH}$ environments, crack growth behaviour under very low frequency in air was studied. The complete results of crack growth behaviour in air at low frequencies has been reported in Ref [21]. The experimental results of LTC behavior of X52 are presented in Figs. 4-3a) and 4-4. Similar behavior was also found for X-80 pipeline steel [21]. It was found that crack dormancy at low loading frequency is an intrinsic characteristic of the pipeline steels. Frequency can be an independent driving force, like $\Delta K$ and 
$K_{\max }$, in low cyclic loading frequency regime. A dormant state or threshold condition can be achieved by reducing the loading frequency.

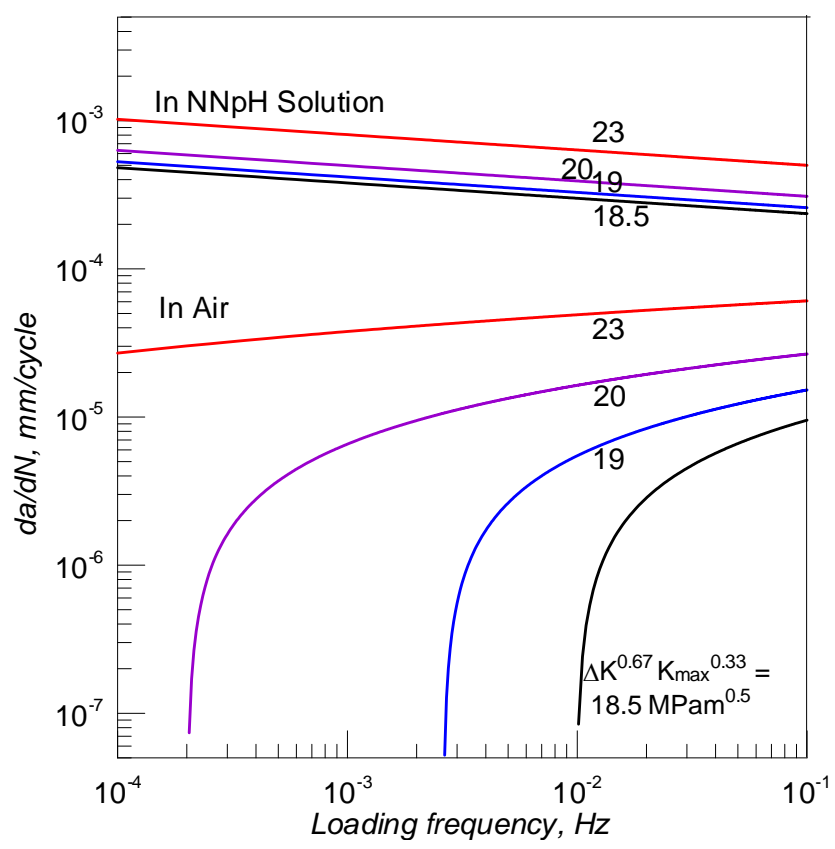

a)

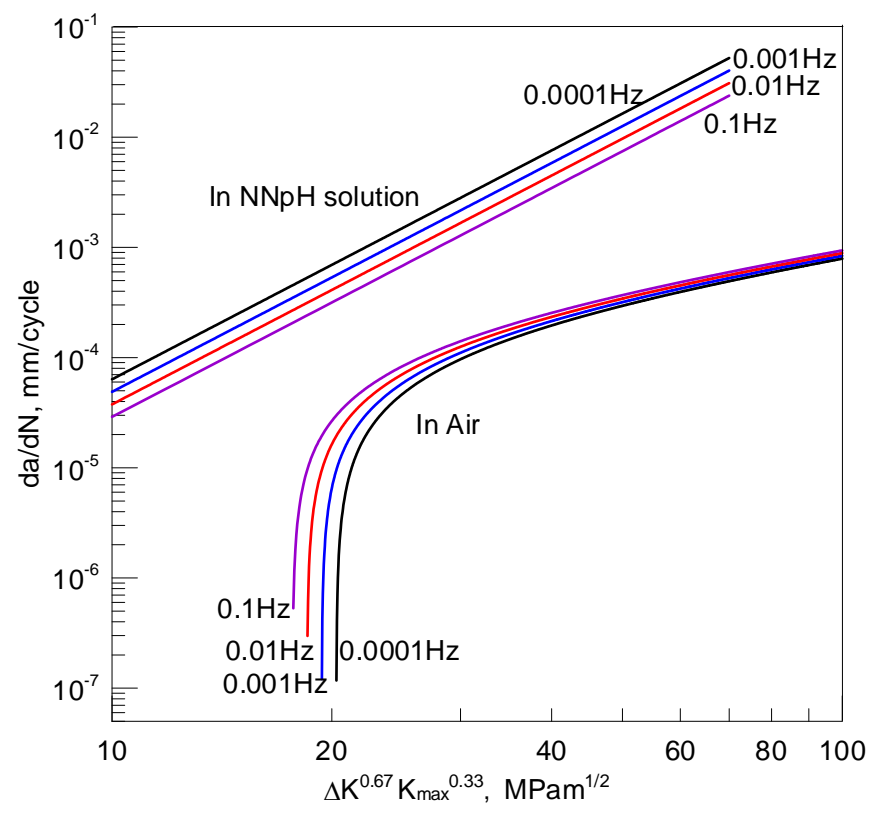

b)

Figure 4-8 Comparison of crack growth rate in air and in near-neutral $\mathrm{pH}$ environment as a function of loading frequency a) as a function of $\left.(\Delta \mathrm{K})^{0.67} \mathrm{~K}_{\max }{ }^{0.33} \mathrm{~b}\right)$. 
To build the CF model, the crack growth curves of the same X52 in air and in NNpH solution at different $(\Delta K)^{0.67} K_{\max }{ }^{0.33}$ values are compared as a function of loading frequency in Fig. 4-8a. The crack growth curves in $\mathrm{NNpH}$ solution were made using the linear growth relation shown in Fig. 4-7. It is clear from Fig. 4-8 that crack growth in $\mathrm{NNpH}$ environment is generally higher by one order of magnitude or more in the $f$-regime relevant to the actual conditions of pipeline operation. The difference becomes progressively smaller with increasing $f$, e.g., over $0.1 \mathrm{~Hz}$, as commonly believed. In addition, the crack growth in air exhibits threshold behaviour at different frequencies depending on the value of $(\Delta K)^{0.67} K_{\max }{ }^{0.33}$.

Similar comparison was also made at different frequencies but using $(\Delta K)^{0.67} K_{\max }{ }^{0.33}$ as a variable, as shown in Fig. 4-8b. This comparison is especially helpful in stimulating the idea of building a CF model based on the intrinsic crack growth behaviour in air. As shown in Fig. 6b, in the region with high $(\Delta K)^{0.67} K_{\max }{ }^{0.33}$ values, the growth rate curves in $\mathrm{NNpH}$ solution and in air are linear or nearly linear in nature, which might be the reason why a linear correlation was observed in the high $(\Delta K)^{0.67} K_{\max }{ }^{0.33} / f^{0.033}$ regime in Fig. 4-7. In contrast, the tail portion in Fig. 47 may be influenced by the curved crack growth behaviour near the thresholds observed in the fatigue tests in air.

With the above considerations, one can derive a predictive model either using a superposition approach that adds the contribution of cyclic growth in air to that of the hydrogen enhanced growth in $\mathrm{NNpH}$ environments, or the compounding approach that would multiply individual contributing factors. The superposition model is often expressed as [5, 6, 34, 35]:

$$
\left(\frac{d a}{d N}\right)_{\text {total }}=\left(\frac{d a}{d N}\right)_{\text {fatigue }}+\frac{1}{f}\left(\frac{d a}{d t}\right)_{S C C}
$$

The superposition approach for pipeline steel-NNpH system has also been attempted and has shown very large scatters (of over several orders of magnitude) [34]. It has been extensively discussed in Ref [20] that superposition approach does not seem applicable to the current corrosion system, which can be attributed to a number of reasons, but predominantly to the fact that loading under a constant stress regardless of its magnitude can only lead to crack dormancy, instead of crack growth. Further discussion on the applicability of superposition approach will be made in Section 4.4.3.5.

The compounding approach is plausible here as the crack growth rate obtained from experiments can be well correlated by a single term as shown in Fig. 4-7. To the simplicity of consideration, one can simply assume the following relation:

$$
\left(\frac{d a}{d N}\right)_{C F}=[H E F] *\left(\frac{d a}{d N}\right)_{A I R}
$$

Where $(d a / d N)_{C F}$ is the CF crack growth rate in $\mathrm{NNpH}$ environment; [HEF] stands for "hydrogenenhanced factor", which represents the hydrogen enhanced crack growth in $\mathrm{NNpH}$ environments as it has been well determined that hydrogen is the key contributing factor to the 
growth while crack growth by corrosion is secondary $[7,33]$ (except at the crack initiation stage where galvanic effects [36] and residual stresses [37, 38] are important); $(d a / d N)_{A I R}$ is the FCGR determined from fatigue tests in air [21]. The later represents the magnitude of crack growth attributed to the mechanical driving forces, and can be mathematically expressed, for X52 based on the experimental results shown in Fig. 4-4a), as,

$\left(\frac{d a}{d N}\right)_{\text {AIR }}=1.194 \times 10^{-5}\left(\Delta K^{0.667} K_{\max }^{0.333} f^{0.02}\right)-2.01 \times 10^{-4}(\mathrm{~mm} /$ cycle $)$

In Eq. 2), $[H E F]$ is unknown but could be determined based on the existing experimental results shown in Fig. 4-7 and some assumptions made as follows. First, [HEF] cannot be a single numerical value and should be both $f$ - and $\left(\Delta \mathrm{K}^{0.67} \mathrm{~K}_{\max }{ }^{0.33}\right)$-dependent, as shown in Fig. 4-8. Second, one can assume that the same [HEF]-function can be used to correct the crack growth rates in air to yield the entire crack growth curve of the steel in $\mathrm{NNpH}$ environments.

The [HEF]-function can be obtained by re-arranging Eq. 2) into the form below:

$$
[H E F]=\left(\frac{d a}{d N}\right)_{C F} /\left(\frac{d a}{d N}\right)_{A I R}
$$

A numerical representation of [HEF]-function based on Fig. 4-8 is shown in Fig. 4-9a, which is obtained by dividing the $(d a / d N)_{C F}$ values shown in Fig. 4-9 by those of $(d a / d N)_{A I R}$ at a given $f$. At high $\left(\triangle K^{0.67} K_{\max }{ }^{0.33}\right)$ values, the $[H E F]$-function is nearly linear on log-log scale for a given $f$. The curved portion within low $\left(\Delta \mathrm{K}^{0.67} \mathrm{~K}_{\max }{ }^{0.33}\right)$ region primarily results from near-threshold nonlinear crack growth behaviour in air, and, therefore, should be excluded for the determination of [HEF]-function.

The nearly-linear region at high $\Delta K^{0.67} K_{\max }{ }^{0.33}$ values in Fig. 4-9a can be further normalized to remove the $f$-effects to obtain the $[H E F]$-function. Since the linear region is also slightly curved, the normalization would yield a perfect linear correlation only over a small region at a given point. This problem actually reflects the nature of linear correlation shown in Fig. 4-7 and will be further discussed in the subsequent sections. To better determine the [HEF]-function that can represent the experimental data shown in Fig. 4-7, the normalization was made at $\left(\Delta K^{0.67} K_{\max }{ }^{0.33}\right) \approx 39 \mathrm{MPa} \vee m$, the highest $\Delta K^{0.67} K_{\max }{ }^{0.33}$ value used in this investigation. The best fit was found when the $[H E F]$-value is normalized by $\Delta K^{0.67} K_{\max }{ }^{0.33} / f^{0.095}$, as shown in Fig. 4-9b. The [HEF]-function, which is the linear dash line in Fig. 4-9b, was then determined to be

$$
[H E F]=0.0252 *\left[\Delta K^{0.667} K_{\max }^{0.333} / f^{0.095}\right]^{1.608}
$$

The above normalization has caused the [HEFl-value at lower $f$ to shift to the right. This agrees well with the effects of low temperature creep: low $f$ allows more LTC to occur and should reduce the $[H E F]$-value or see the LTC-effects at higher $\Delta K^{0.67} K_{\max } 0.33 / f^{0.095}$ values. The purpose of normalization is to remove the $f$-dependant effects from the [HEF]-function. The 
normalization also reveals the physical nature of the normalization, which will be further discussed in Section 4.4.3.4

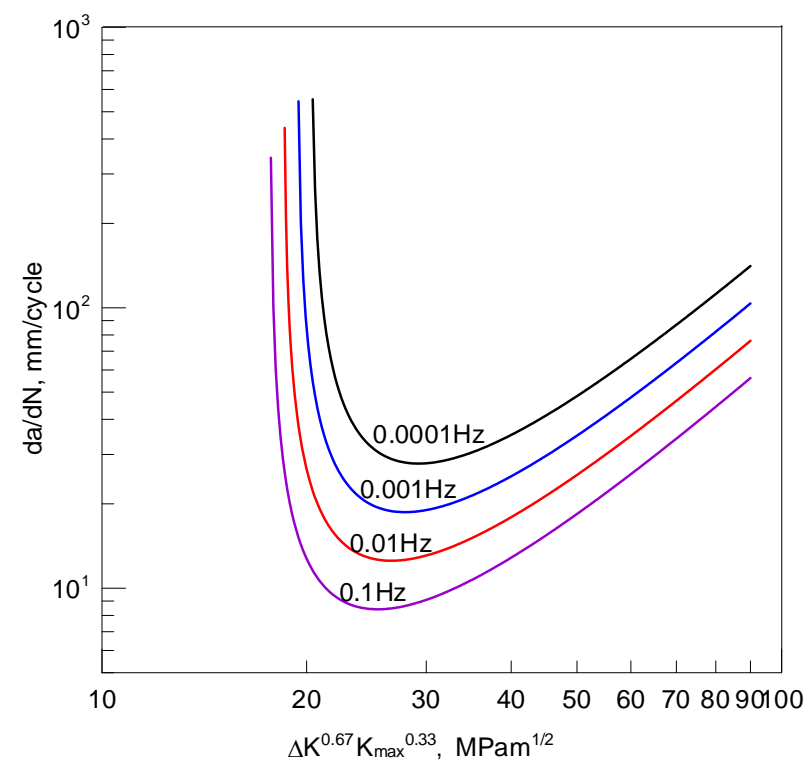

a)

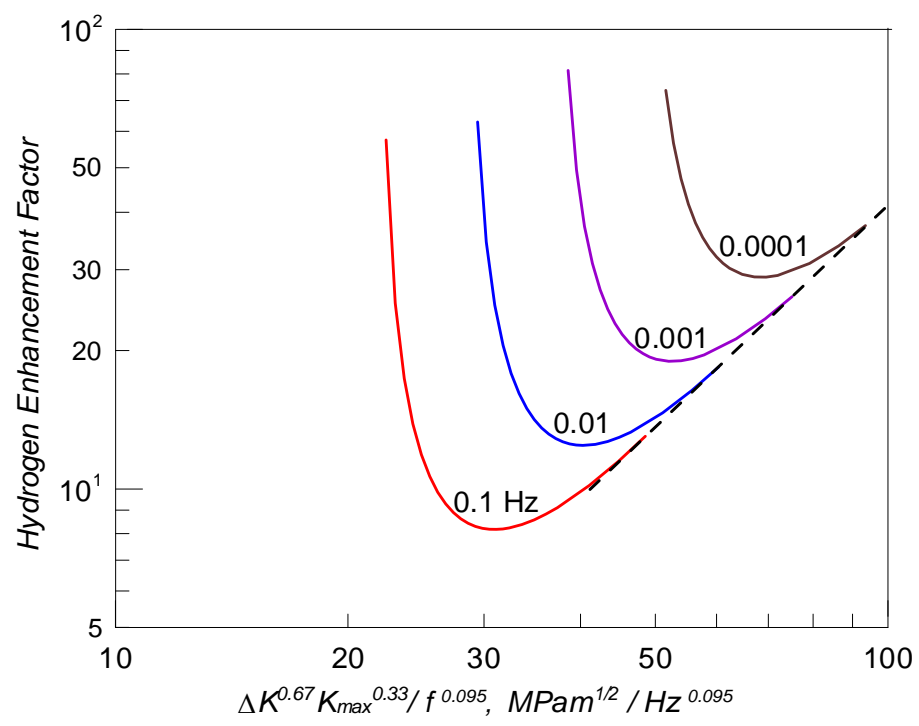

b)

Fig. 4-9 $[\mathrm{HEF}]$ as a function of $\left.(\Delta \mathrm{K})^{0.67} \mathrm{~K}_{\max }{ }^{0.33} \mathrm{a}\right)$ and $[\mathrm{HEF}]$ normalized by $(\Delta \mathrm{K})^{0.67} \mathrm{~K}_{\max }{ }^{0.33} / f^{0.095}$ b).

Inserting Eq. 5) and Eq. 3) into Eq. 2) yields a predicted crack growth rate of the current X-52 pipeline steel in near-neutral $\mathrm{pH}$ solution. This is presented in Fig. 4-10 together with the experimental values obtained in the current study. 


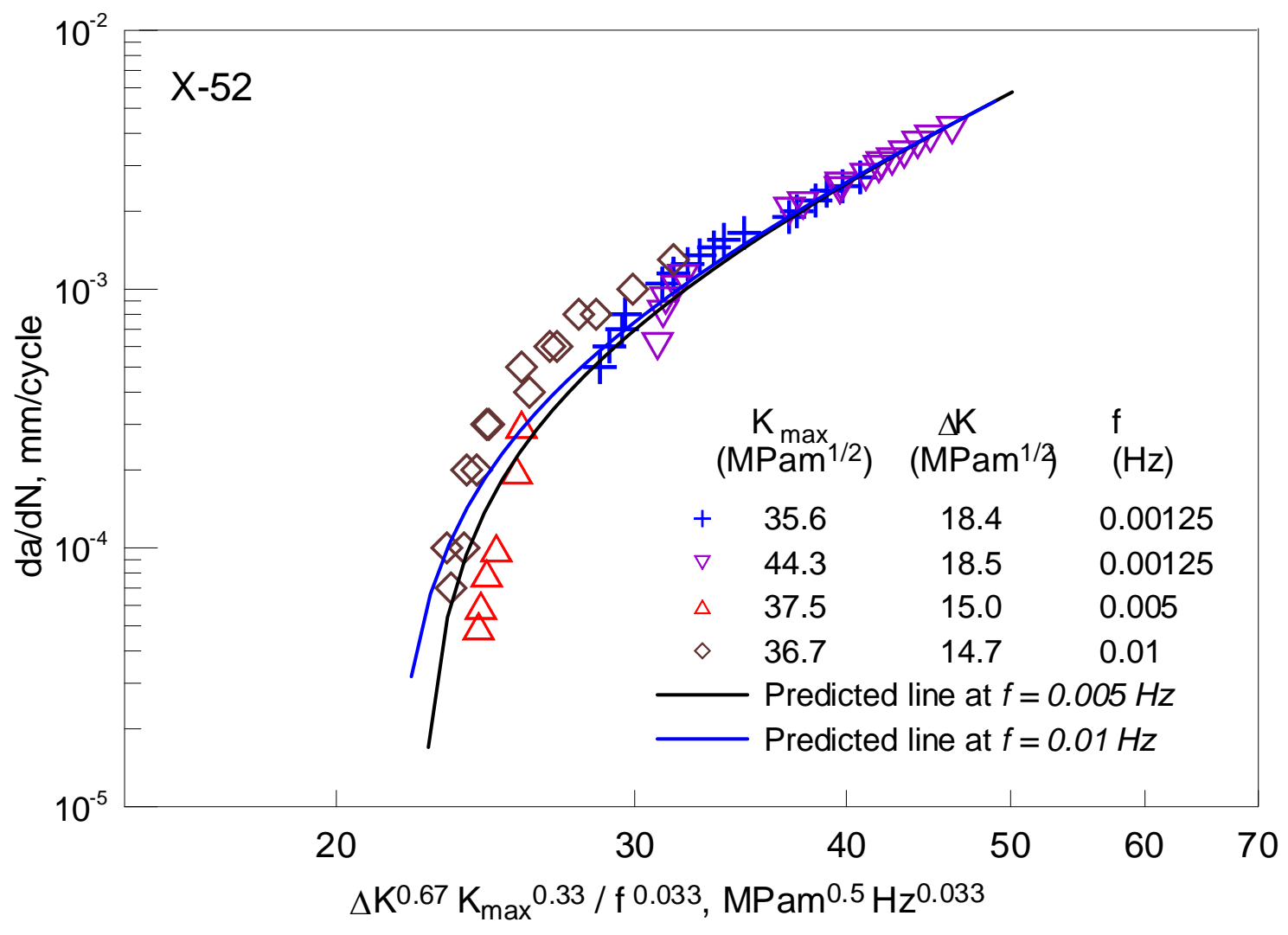

Fig. 4-10 Comparison of experimental results with the prediction.

The above modelling as shown in Fig. 4-10 demonstrates an excellent agreement between the prediction and the experimental results. It predicts a converged single linear relation at high combined loading factors, but $f$-dependent growth behaviour at low combined loading factors. For the latter situation, higher growth rate was found at higher $f$, consistent with the experimental findings. It should be noted that the experimental data at the beginning of tests in low combined loading factor region is slightly below the predicted value. This reflects the effects of hydrogen equilibrium in the beginning stage of tests (lasting about 10 days) as is commonly seen at high combined loading factor region.

\subsubsection{The nature of corrosion fatigue crack growth correlation}

Understanding the nature of the crack growth rate correlation shown in Fig. 4-7 is very important in several aspects:

1) The correlation of crack growth rate to a single term in the form of $\Delta K^{\alpha} K_{\max }{ }^{\beta} / f^{\gamma}$ allows a consideration of all possible crack growth affecting variables that can be found in the field operating, e.g., the effect of crack dimension is included in $\Delta K$ and $K_{\max }$; pressure fluctuation 
in $\Delta K$; maximum pressure in $K_{\max }$; the rate of pressure fluctuation in $f$, and material's factor in $\alpha, \beta$ and $\gamma$, and corrosion/hydrogen factor in $\gamma$ and $f^{\gamma}$. This serves as a base of integrity management based on the field operating conditions, e.g., crack growth can be predicted based on SCADA data recorded and future measures for integrity management can be decided based on the results of prediction. For the purpose of control of crack growth, on the other hand, certain operating conditions can be avoided if they would lead to a large crack advance.

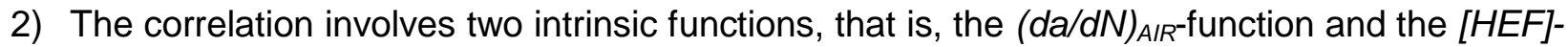
function. From mechanistic points of view, it is important to understand the rationale behind the compounding of these two functions and possible errors of the approach. On the other hand, it is necessary to understand the physical process of crack growth as governed by the synergistic interactions of the two intrinsic functions.

3) Last but the most important is the principle of material design. Since a given material can be represented by two intrinsic functions, materials must be designed and fabricated to yield intrinsic properties that will lead to the least crack growth and the highest threshold to crack initiation. A design approach combining both the intrinsic properties has not been developed.

\section{On the two intrinsic functions}

The fatigue test in air yields an intrinsic positive growth rate dependence of loading frequency $(f$ ${ }^{0.02}$ ), while the $\mathrm{CF}$ in $\mathrm{NNpH}$ environment yields a negative dependence of loading frequency $\left(f^{-}\right.$ $\left.{ }^{0.033}\right)$. From this, a more negative dependence of frequency $\left(f^{-0.095}\right)$ was found for the [HEF]function. The above different $f$-dependences of CFCGR are meaningful qualitatively. Under a given $\Delta K^{\alpha} K_{\max }^{\beta}$ factor, a lower $f$ would allow more plastic deformation that will increase the blunting of crack tip and reduce CFCGR, but at the same time would provide more time for hydrogen to diffuse into the crack processing zone ahead of the crack tip and therefore enhance the CFCG. The above two factors are opposite to each other in terms of crack growth rate. As a result, a $f$-dependence of CFCGR in NNpH environments is seen to have a $\gamma$ of -0.033 that falls between the two intrinsic values of -0.095 for hydrogen effects and 0.02 for mechanical effects.

The crack growth dependence of frequency in $\mathrm{NNpH}$ environments is still negative in the linear region shown in Fig. 4-7. This could somehow be interpreted as the predominant effect of [HEF]-function or hydrogen factor as compared with the effect of LTC. Under the circumstances, the mechanical driving force $\Delta K^{\alpha} K_{\max }{ }^{\beta}$ is high and the crack tip advances at high rates. The effects of LTC, which causes a positive f-dependence of CFCGR, should be secondary as compared with the effects of hydrogen, which gives a negative $f$-dependence.

From the above discussion, one may argue that a less negative or even a positive $f$ dependence of CFCGR should then exist when CFCGR is low (either caused by low $\Delta K^{a} K_{\max }{ }^{\beta}$ loading or by very low $f$-loading) and the LTC becomes predominant. Both the prediction and the experimental results shown in Fig. 4-10 are in excellent agreement with the above argument. First, for the predicted lines, the two lines at two different frequencies start to deviate 
as CFCGR reduces, indicating the breakdown of single $f$-dependence. Second, the prediction in the tail region shows that the CFCGR is still $f$-dependent with a higher CFCGR at higher $f$ because of less occurrence of LTC/crack tip blunting. It is certain that less negative $f$ dependence or even a positive $f$-dependence can be expected in this loading regime when the $f$-factor is fully cancelled.

One may further hypothesize on the above outcome of a positive $f$-dependence of CFCGR in $\mathrm{NNpH}$ environment attributing to the predominant effects of LTC. Under the circumstances, reducing $f$ will decrease crack growth rate, which could even yield zero growth at a critical low loading $f$ for a given $\left(\Delta K^{\alpha} K_{\max }^{\beta}\right)$ loading. Fortunately, such a hypothesized scenario has been confirmed recently in hydrostatic simulation of crack growth of pipeline steel in $\mathrm{NNpH}$ environment [39]. It was found that there existed a critical loading rate at which the maximum crack growth can be produced by monotonic loading, beyond which the crack growth is reduced either by reduced HE effects at higher loading rates/frequencies or by increased LTC effects at lower loading rates/frequencies. These findings will be communicated shortly.

\section{On the [HEF]-function}

The nature of the CFCGR correlation can be revealed through further examination of the modelling approach described in Section 3.3. The uncertainty of the correlation arises only from the $[H E F]$-function. The [HEF]-function given in Eq. 5 was obtained through a curve fitting of $[H E F]$-values at a given $\Delta \mathrm{K}^{0.67} \mathrm{~K}_{\max }{ }^{0.33}$ value. One may wonder if there exists an intrinsic [HEF]function for a given corrosion/hydrogen-material system. A logical attempt can be made to obtain the [HEF]-function using crack growth data obtained at loading conditions where LTC is minimum, e.g., at high $\Delta \mathrm{K}^{0.67} \mathrm{~K}_{\max }{ }^{0.33}$ and/or high $f$-loading conditions at which crack growth is fast and little time is available for LTC to occur.

With the above consideration, the normalization in Fig. 4-9b) was made at $\Delta \mathrm{K}^{0.67} \mathrm{~K}_{\max }{ }^{0.33}=100$ $\mathrm{MPa} \sqrt{\mathrm{m}}$. The results are shown in Fig. 4-11 and the corresponding [HEF]-function is given below.

$[H E F]=0.00326 *\left[\Delta K^{0.667} K_{\max }^{0.333} / f^{0.064}\right]^{2.14}$

Using the [HEF]-function in Eq. 6), the prediction of crack growth rate can be made, which is plotted in Fig. 4-11b. The crack growth data in Fig. 4-11b was plotted as a function of $\left(\Delta K^{0.667} K_{\max }^{0.333} / f^{0.033}\right)$ in order to be consistent with the experimental crack growth rate data shown in Fig. 4-7. As is seen in Fig. 4-11b, excellent agreement can be found only in the region with high $\left(\Delta K^{0.667} K_{\max }^{0.333} / f^{0.033}\right)$ values when the growth data are plotted as a function of $\left(\Delta K^{0.667} K_{\max }^{0.333} / f^{0.033}\right)$. The crack growth rate in the region with experimental data shown in Fig. 4-7 (the framed area in Fig. 4-11b) cannot be normalized into a single line.

However, the crack growth rate in the framed region in Fig. 4-11b could be better normalized if different $\left(1 / f^{\gamma}\right)$ factor is used, e.g., the crack growth rate can converge into a single point at low $\left(\Delta K^{0.667} K_{\max }^{0.333}\right)$ regime if a lower $\gamma$ value is assigned. This exercise of parameter selection 
reveals the nature of crack growth rate correlation shown in Fig. 4-7 and the prediction made in Section 4.4.3.3. It also points to some new directions on how experiments are to be conducted in order to obtain necessary characteristic values used for the prediction, which is further discussed below.

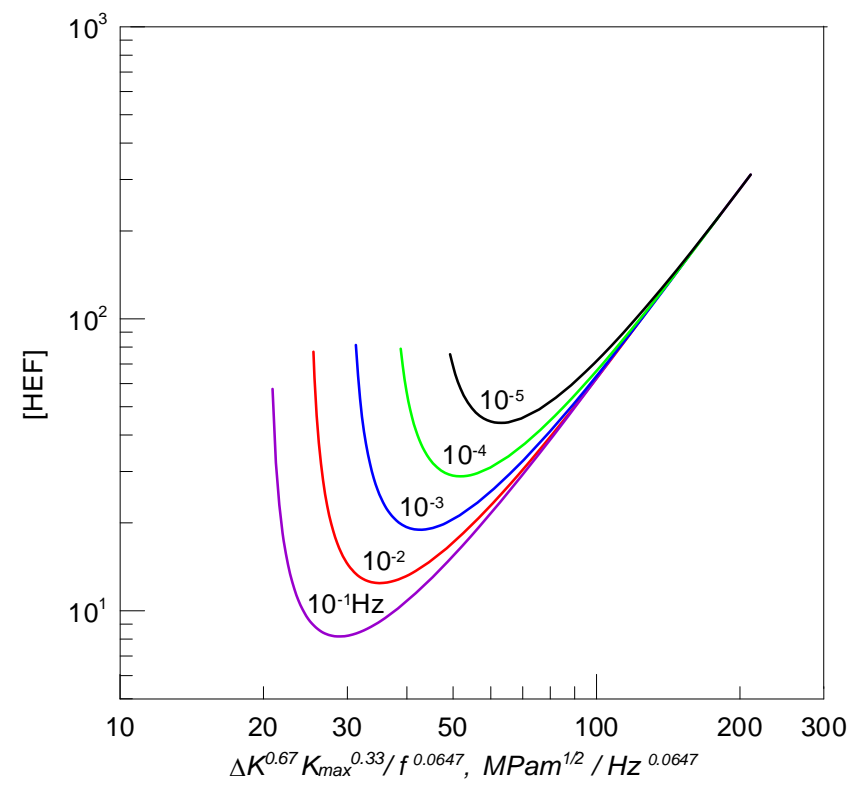

a)

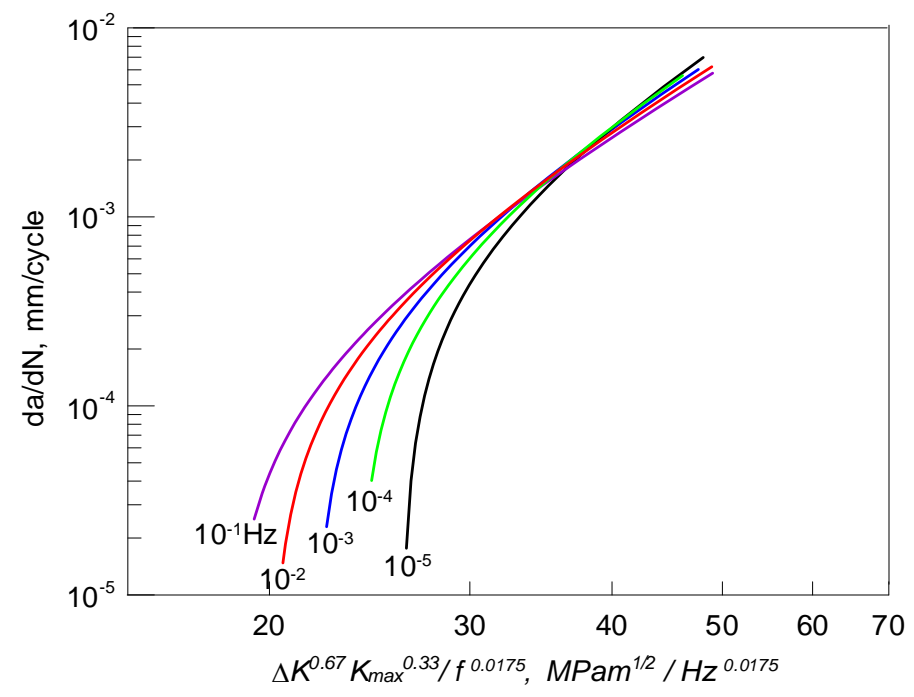

b)

Fig. 4-11 [HEF] normalized by $(\Delta \mathrm{K})^{0.67} \mathrm{~K}_{\max }{ }^{0.33} / f^{0.0647}$ a) and predicted crack growth rate as a function of $[\mathrm{HEF}]$ normalized by $\left.(\Delta K)^{0.67} K_{\max } 0.33 / f^{0.0175} \mathrm{~b}\right)$.

It is important to point out here that to find an intrinsic [HEF]-function at high $\left(\Delta K^{0.667} K_{\max }^{0.333}\right)$ loading is technically not realistic. The highest $K_{\max }$ can be applied to a cracked material is 
limited by the fracture toughness of the material $\left(K_{I C}\right)$ or by the limitation of linear elastic fracture mechanics (at high K-loading, elastic-plastic fracture mechanics equations should be considered). For example, if the material can be loaded to a maximum $K_{\max }$ of $60 \mathrm{MPa} \sqrt{\mathrm{m}}$ and assuming a tension-tension loading for the case of pipeline operating, the highest $\left(\Delta K^{0.667} K_{\max }^{0.333}\right)$ value would be $60 \mathrm{MPa} \sqrt{\mathrm{m}}$ at $R=0$. Increasing $\mathrm{R}$ reduces $\left(\Delta K^{0.667} K_{\max }^{0.333}\right)$ value, e.g., to about 27 $\mathrm{MPa} \sqrt{\mathrm{m}}$ at $R=0.7$. A reduced $\left(\Delta K^{0.667} K_{\max }^{0.333}\right)$ value also reflects an increased contribution of LTC: higher $\mathrm{R}$ ratio is closer to the static loading under which more LTC can occur.

\section{On the nature of crack growth rate modelling}

1) It seems true that the CFCGR in $\mathrm{NNpH}$ environments in the $f$-regime of interest can be resolved by compounding the LTC-dependent cyclic model and the [HEF].

2) The $\left(1 / f^{\gamma}\right)$-factor in each of the mechanistic models (e.g., the LTC-dependent cyclic model and the [HEF]-function) can be intrinsic for a given material or corrosion-material system. However, the single $f$-factor after compounding in order to obtain a unified CFCGR equation may not be truly intrinsic, which is thought to arise from a number of causes.

a. As is shown in prior equations, $[d a / d N]_{A I R}$ is a linear function of the combined loading factor (see Eq. 3), while the [HEF]-function (see Eq. 5) is a power function of the combined loading factor. Compounding both functions mathematically cannot yield a single $f$-contained power term.

b. Although the $[H E F]$-function can be intrinsic, a $[H E F]$-function that is intrinsic has not been obtained in this investigation. The [HEFl-function in Eq. 5) is intrinsic only at

$\Delta \mathrm{K}^{0.67} \mathrm{~K}_{\max }{ }^{0.33} \approx 39 \mathrm{MPa} \sqrt{\mathrm{m}}$. However, [HEF]-function at $\Delta \mathrm{K}^{0.67} \mathrm{~K}_{\max }{ }^{0.33}$ loading lower than $39 \mathrm{MPa} \sqrt{\mathrm{m}}$ is not very different as shown in Fig. 7 where the dash line overlaps the [HEF]-curve over a wide range of $\left(\Delta K^{0.667} K_{\max }^{0.333} / f^{0.095}\right)$. This is also the reason why a good correlation can be obtained between the experimental results and the prediction.

c. Further to point b), a [HEFl-function obtained at very high $\Delta \mathrm{K}^{0.67} \mathrm{~K}_{\max }{ }^{0.33}$ values and from the experimental data, would induce larger scatter because [HEF] also depends on $\Delta \mathrm{K}^{0.67} \mathrm{~K}_{\max }{ }^{0.33}$. A proof to this is that the predicted data can be normalized when different $\mathrm{Y}$ is used. In this normalization, the scatters away from the converging points are very large. This further reflects that the [HEF]-function at a $\Delta \mathrm{K}^{0.67} \mathrm{~K}_{\max }{ }^{0.33}$ value remote from the actual experimental $\Delta \mathrm{K}^{0.67} \mathrm{~K}_{\max }{ }^{0.33}$ is not appropriate.

d. An intrinsic [HEF]-function could be obtained from analyzing all the [HEF]-functions obtained at different $\Delta \mathrm{K}^{0.67} \mathrm{~K}_{\max }{ }^{0.33}$ values. The obtained intrinsic function should be further validated against materials factors and the actual concentration of diffusible and trapped hydrogen in a material. This requires extensive additional effort and is currently being undertaken by the investigators.

$\underline{\text { On future efforts of crack growth modelling }}$ 
1) It seems essential to determine the intrinsic crack growth function in air/inert environments that incorporates $f$ as a driving force, which will serve as a base of time-dependent consideration for modelling through compounding. Such an intrinsic function was found to be very material dependent and must be determined from experiments. In addition, new pipeline steels should be fabricated to achieve the highest thresholds and the slowest stage II growth. The pipeline steel should also be designed or fabricated to have the lowest hydrogen enhancement to crack growth under mechanical loading.

2) The crack growth assessment in $\mathrm{NNpH}$ environments can be simplified and minimized just to determine the [HEF]-function. Such evaluation tests should be designed to yield good sensitivity of CFCGR correlation and close relevance to the conditions seen in the field.

\subsubsection{The complete stages of crack growth}

Both the modelling and the experiments indicate the presence of thresholds. One may wonder if non-propagation of crack can actually occur when a combined mechanical loading factor below the thresholds is applied. In addition, the thresholds are relatively high, which implies that crack growth can be initiated only when there is a relatively large pressure fluctuation and/or the crack dimension is relatively large. Because of this, one may wonder how a short crack for which fracture mechanics is also applicable, grows to the dimension at which the combined mechanical driving force reaches the threshold.

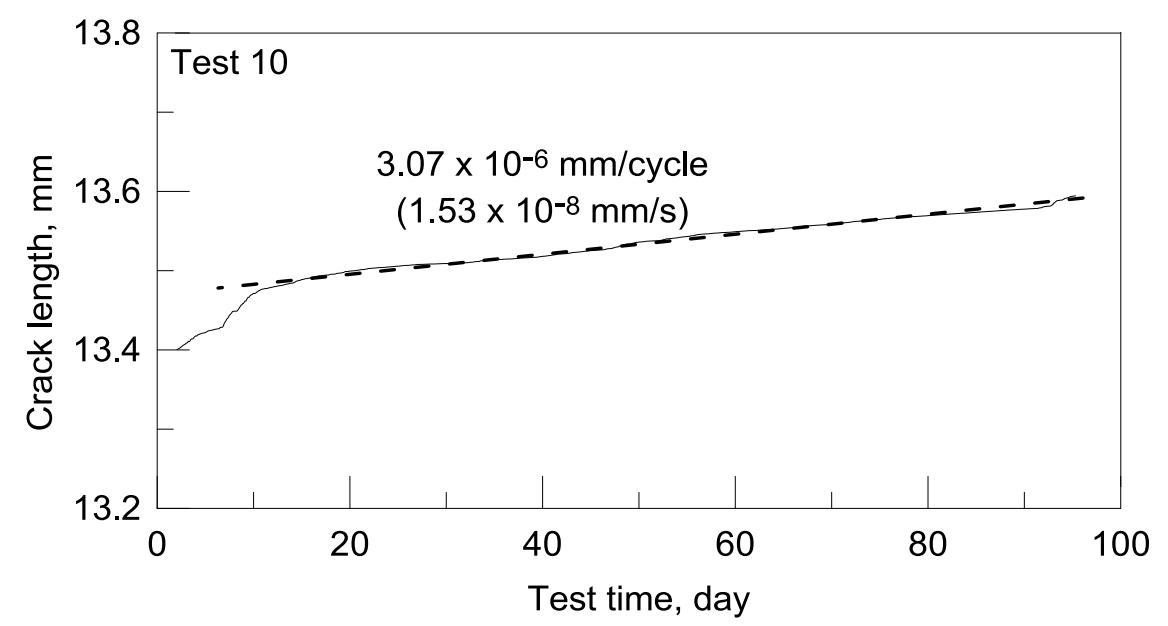

Fig. 4-12 Crack growth curve obtained from Test 10 listed in Table 3.

To rationalize the above dilemma, Test 10 in Table 4-5 was performed with a combined factor below the thresholds. As shown in Fig. 4-12, the entire test lasted over a period of 95 days, and crack growth rate appeared a little high in the initial stage of test, but decreased to a steady state value of about 85 days long after the initial stage of about 10 days. The initial transient stage has been well defined to be resulted from the following two factors: 1) temperature equilibrium of potential drop system after test solution was added, 2) the gradual blunting of the sharp crack tip generated in pre-fatigue loading in air. The total growth in the entire test period 
was about $0.1 \mathrm{~mm}$ (also measured on the fractured surface), which caused less than $0.1 \mathrm{MPa}$ $\sqrt{\mathrm{m}}$ increase in stress intensity factor. The crack growth rate was determined to be $3.07 \times 10^{-6}$ $\mathrm{mm} /$ cycle or $1.53 \times 10^{-8} \mathrm{~mm} / \mathrm{s}$, as re-plotted in Fig. 4-7 and shown in Fig. 4-13.

The CFCGR of Test 10 was over one order of magnitude lower than the lowest values obtained at slightly more aggressive condition. This reveals another cracking mechanism that might be also operating besides the above-defined mechanisms. A classical SCC mechanism is the anodic dissolution at the crack tip. Although crack growth under a constant stress has never been observed, this may be primarily caused by the fact that the anodic dissolution rate is very low in the current system and the test duration, even for a relatively long period, e.g., 10 20 days, is too short to resolve crack growth measurable by existing devices. The growth was detected under a combined mechanical loading condition under which mechanically driven cracking process is not possible, further confirming the dissolution nature of crack growth.

If the dissolution mechanism is also operating, the CFCGR detected should be comparable to the rate of corrosion. To prove this, a weight loss test using flat coupons made of the same pipeline steel was performed. The coupon tests had yielded a corrosion rate of about $5.93 \times 10^{-9}$ $\mathrm{mm} / \mathrm{s}$ [40], which was about 2.5 times slower than the CFCGR $\left(1.53 \times 10^{-8} \mathrm{~mm} / \mathrm{s}\right)$ detected in Test 10. This difference can be generally explained to be a result of enhanced anodic dissolution at the crack tip by plastic deformation or stress and may also reflect the difference in corrosion between a flat surface and the curved surface of the crack tip.

Based on the above discussion, the crack growth behaviour in near-neutral pH environments can be re-defined to be consistent with the classical superposition model in the following format:

$\left(\frac{d a}{d N}\right)_{\text {total }}=\left[(H E F)\left(\frac{d a}{d N}\right)_{A I R}\right]_{C F}+\frac{1}{f}\left(\frac{d a}{d t}\right)_{S C C}$

In most corrosion systems studied, the SCC term shows appreciable contribution to the crack growth only under a mechanical loading condition that is more aggressive than the cyclic thresholds. In the current corrosion system, however, the contribution of the SCC term is negligible and can be noticed only under mechanical conditions below the cyclic thresholds.

The above uniqueness also governs the cracking behaviour of NNpHSCC in the field. It has been well characterized that over $95 \%$ of the crack populations can only grow to a depth of about $1 \mathrm{~mm}$, beyond which less than $5 \%$ of total crack population can grow continuously and possibly lead to pipe rupture [7]. This 1-mm depth may demarcate the dissolution mechanism and the start-up of the hydrogen facilitated mechanically driven process. For crack colonies found on the same pipeline, the external mechanical conditions can be considered to be the same and therefore continuous crack growth of those $5 \%$ of total crack population would depend on 1) the internal mechanical condition such as residual stresses [37, 38] and 2) the degree of hydrogen enhancement at a given cracking location. The former factor has been addressed in previous investigations that the formation of micro-pitting was found to occur preferentially in areas where the tensile residual stresses were the highest (approximately 300 $\mathrm{MPa}$ ), while crack initiation occurred with a $71 \%$ normalized frequency in areas where the 
surface residual stress was in the range of 150 to $200 \mathrm{MPa}[37,38]$. These results are also consistent with findings from field studies. The second factor indicated above, i.e., the degree of hydrogen enhancement has been considered in detail in Ref. [7]. For the pipelines with shallow cracks detected in the field, rupture is possible only if hydrogen-enhanced mechanically driven process becomes active during pipeline operation.

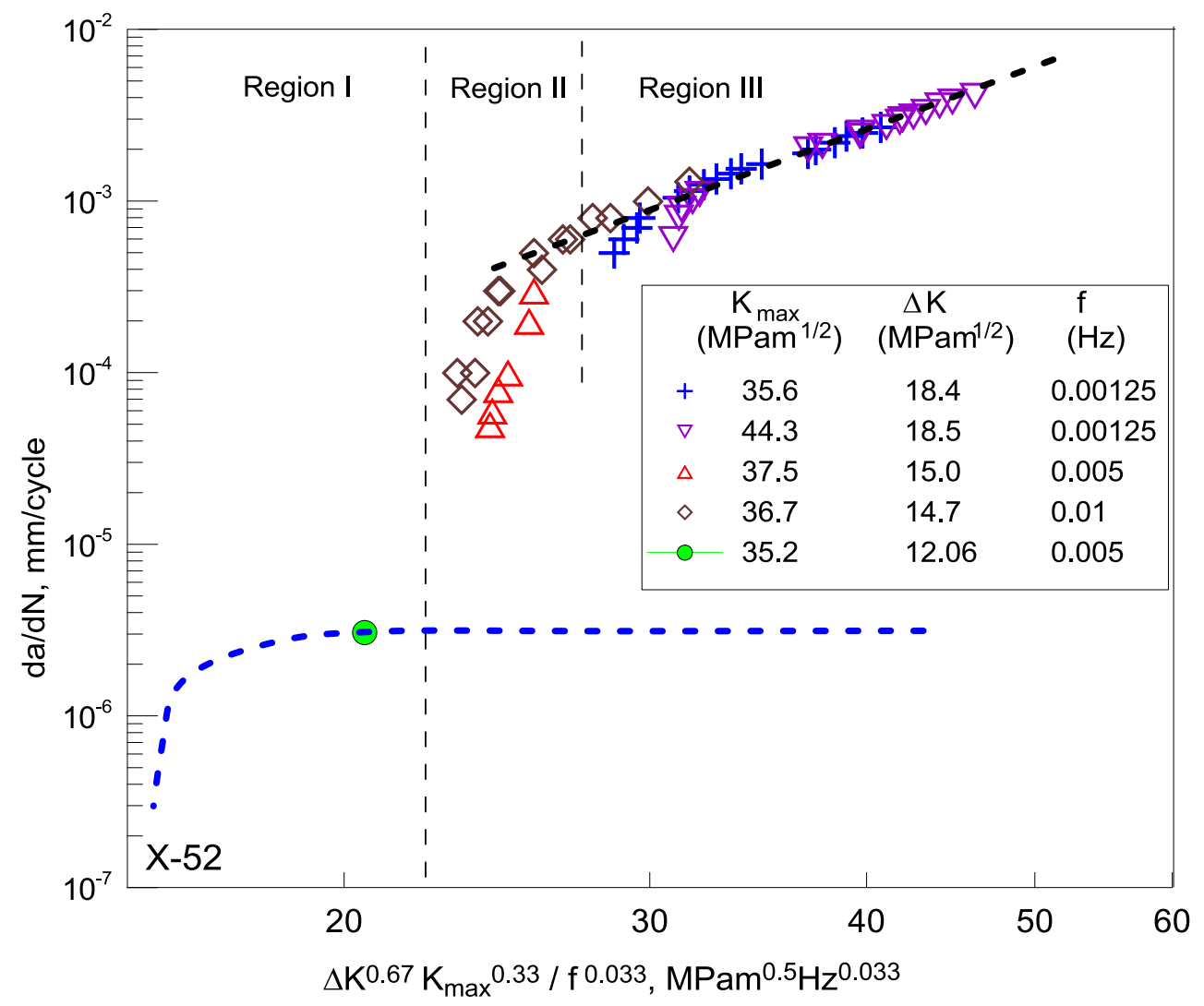

Fig. 4-13 Crack growth rate of X52 pipeline in near-neutral pH environment.

Finally there remains one issue to be addressed: a dissolution rate of $1.53 \times 10^{-8} \mathrm{~mm} / \mathrm{s}$ by SCC mechanism is still appreciable for a structure such as a pipeline with a very long design life. For example, at a rate of $1.53 \times 10^{-8} \mathrm{~mm} / \mathrm{s}$, it would need only about 6 year for a crack to reach to a depth of $3 \mathrm{~mm}$, one third of the wall thickness of a $9 \mathrm{~mm}$-thick pipe. For this dilemma, it is believed that such a high dissolution rate will decrease with increasing crack depth and would contribute little to crack growth when crack depth is beyond $1 \mathrm{~mm}$. That is to say, such a high dissolution rate is only possible at pipe surface and hydrogen-enhanced mechanically driven process is the only mechanism for cracks with a depth larger than the $1 \mathrm{~mm}$ limit. This seems consistent with the fact that 1 ) crack depth/length ratios usually evolve to a very low value (about 0.1 to 0.2 ), indicating the preferential dissolution on the surface rather than in the depth direction and 2) hydrogen generated at the tip of crack due to crack tip dissolution is secondary or insignificant comparing to the hydrogen generated at the pipe free surface in terms of crack growth by the hydrogen-enhanced mechanically driven mechanism. 


\subsubsection{Summery and Conclusions}

In this investigation, we have used the intrinsic cyclic behavior with an inclusion of $f$-factor as a base of modelling and the hydrogen/corrosion as an enhancement factor to predict CF crack growth in pipeline steels exposed to $\mathrm{NNpH}$ environment.

1) Crack growth rate of pipeline steels in near-neutral $\mathrm{pH}$ environments can be generally normalized by a combined term in the form of $\left(\Delta K^{\alpha} K_{\max }^{\beta} / f^{\gamma}\right)$.

2) A normalized crack growth curve will usually exhibit two stages on log-log scale: the linear stage in the region with high $\left(\Delta K^{\alpha} K_{\max }^{\beta} / f^{\gamma}\right)$ values and the parabolic growth stage in the region with reduced $\left(\Delta K^{\alpha} K_{\max }^{\beta} / f^{\gamma}\right)$ loading values (the tail). The linearity in the linear stage is achieved by adjusting the value of $\gamma$. In the parabolic stage, the crack growth rate is seen to be frequency dependent with higher growth rate at higher frequency, and crack growth rate decreases quickly with decreasing $\left(\Delta K^{\alpha} K_{\max }^{\beta} / f^{\gamma}\right)$ until a threshold is reached.

3) The entire crack growth stage can be modelled with excellent agreement with the experimental results through compounding the intrinsic hydrogen enhanced crack growth function and the intrinsic cyclic crack growth behaviour incorporating effects of low temperature creep determined in air.

4) It is believed that the outcomes of the modelling effort will shed new lights on the control of crack growth for structures in the field and on the principle of material design achieving better resistance to fatigue and corrosion fatigue.

\section{References}

1. M. J. Wilmott and R. L. Sutherby, "The Role of Pressure and Pressure fluctuations in the Growth of Stress Corrosion Cracks in Line Pipe Steels," Proceedings of the International Pipeline Conference (The American Society of Mechanical Engineers, New York, N.Y., 1998): pp. 409-422.

2. S. Wang, W. Chen, Corrosion, 58(6)(2002)526-534.

3. Evans JT, Parkins RN. Acta Metall 24(1976)511

4. Revie RW, Uhlig HH. Corrosion and Corrosion Control, John Wiley \& Sons Inc., 2008, p.173.

5. R. P. Wei and R. P. Gangloff, in Fracture Mechanics: Perspectives and Directions (Twentieth Symposium), ASTM STP 1020, R. P. Wei and R. P. Gangloff, Eds., American Society for Testing and Materials, Philadelphia, 1989, pp. 233-264.

6. R.P. Gangloff, Hydrogen-assisted cracking, in: I. Milne, R.O. Ritchie, B. Karihaloo (Eds), Comprehensive Structure Integrity, volume 6: Environmentally-Assisted Fracture. Elsevier, Oxiford, 2003, vol. 6, pp.31-34.

7. W. Chen, R. Kania, R. Worthingham, G. Boven, Acta mater., 57 (2009)6200-6214

8. Laird C, Charsley P. In: Wells J M, Buck O, Roth L D,Tien J K eds., Ultrasonic Fatigue, Proc 1st Int Conf on Fatigue and Corrosion Fatigue up to Ultrasonic Frequencies, Philadelphia: 
The Metallurgical Society of the American Institute of Mining, Metallurgical and Petroleum Engineers (AIME), 1982: 187

9. Roth L D, Willertz L E, Leax T R. In: Wells J M, Buck O, Roth L D, Tien J K eds., Ultrasonic Fatigue, Proc $1^{\text {st }}$ Int Conf on Fatigue and Corrosion Fatigue up to Ultrasonic Frequencies, Philadelphia: The Metallurgical Society of the American Institute of Mining, Metallurgical and Petroleum Engineers (AIME), 1982: 265

10. Taylor D, Knott JF. In: Proc 6th Int Conf Fracture, New Delhi: Pergamon Press, 1984; 3 : 1759

11. Lukas P, Kunz L, Knesl Z, Weiss B, Stickler R. Mater Sci Eng, 70(1985)91

12. Meininger J M, Gibeling J C. Metall Trans, 23A(1992)3077

13. Papakyriacou M, Mayer H, Pypen C, Plenk H Jr, Stanzl-Tschegg S. Mater Sci Eng, A308(2001)143

14. Hong, Youshi, Zhao, Aiguo, Qian, Gui'an, Acta Metall. Sinica, 45(7)(2009)769-780.

15. T. H. Alden, Metall. Trans. A, 18A(1987)811.

16. S. Wang and W. Chen, Mater. Sci. Eng., A325(2002) 144-151.

17. S. Wang, Y. G. Zhang and W. Chen, J. of Maters. Sci., 36(8)(2001)1931-1938.

18. S. Wang, W. Chen, Mater. Sci. Eng A. A301(2001)147-153.

19. W. Chen, H. Zhu and S-H. Wang, Canadian Metallurgical Quarterly, 48(3)(2009)271-284

20. W. Chen and R. L. Sutherby, Met. \& Mater. Trans A, 38A (2007) 1260-1268

21. M. Marvasti, W. Chen, R. L. Eadie, "Fatigue of Steel in Air at Low Cyclic Loading Frequency", submitted to Scripta Materialia, 64(6)(2011)552-555.

22. Parkins RN. A review of stress corrosion cracking of high pressure gas pipelines proceedings of corrosion 2000. Paper 00363. Houston, Texas: NACE International; 2000.

23. Parkins RN, Blanchard Jr WK, Delanty BS. Corrosion 50(1993)395.

24. Chen W, Eadie RL, Sutherby RL. "Environmental Effects on Near-Neutral pH Stress Corrosion Cracking in Pipelines", Second International Conference on Environment-Induced Cracking of Metals, September 19-23, 2004, The Banff Centre, Banff, Alberta, Canada

25. Vasudeven AK, Sadananda K, Louat N. Mater. Sci. Eng. A, A188(1994)1

26. Vasudevana AK, Sadananda K, Holtz RL. International J. of Fatigue, 27(2005)1519-1529

27. Vasudevan AK, Sadananda K. International Journal of Fatigue, 29(2007)1985-1989

28. Sadananda K, Vasudevan AK. Acta Materialia, 52(2004)4239-4249

29. Sadananda K, Vasudevan AK. International Journal of Fatigue, 26(2004)39-47

30. Sadananda K, Vasudevan AK, Kang IW. Acta Materialia, 51(2003)3399-3414

31. Sadananda K, Vasudevan AK. International Journal of Fatigue, 25(2003)899-914

32. Sadananda K, Vasudevan AK. Fatigue Fract Engng Mater Struct, 26(2003)835-845

33. Kang Y, Chen W, Corrosion Science, 53(3)(2011)968-975.

34. S.B. Lambert, J.A. Beavers, B. Delanty, R. Sutherby, and A. Plumtree, "Mechanical Factors Affecting Stress Corrosion Crack Growth Rates in Buried Pipelines", In Proceedings of International Pipeline Conference. ASME. pp. 961-966 (2000).

35. Y-Z. WANG, "Corrosion Fatigue", in Uhlig's Corrosion Handbook (2nd Edition) Edited by: Revie, R. Winston (C) 2000 John Wiley \& Sons, pp. 226

36. Z. Qin, B. Demko, J. Noel, D. Shoesmith, and F. King, Corrosion, 60 (10) (2004) 906.

37. G V Bovan, W.Chen, R. Rogge, "Role of Residual Stress in SCC Crack Initiation and Propagation” Part I-Experimental Investigation, Acta Mater., 55(2007) 29-42 
38. W. Chen, G. V. Bovan, R. Rogge, "Role of Residual Stress in SCC Crack Initiation and Propagation" Part II-Theoretic Analysis, Acta Mater., 55(2007)43-53

39. Kang Y, Chen W, Kania R, Van Boven G, Worthingham R, Competitive effects of low temperature creep and hydrogen embritlement in crack growth of pipeline steel, to be submitted to Scripta Materialia

40. M. H. Marvasti, "Crack Growth Behavior of Pipeline Steels in Near Neutral pH Soil

Environment”, MSc Thesis, University of Alberta, Edmonton, Canada, Spring 2010

\subsection{Effect of materials}

\subsubsection{Introduction}

The work presented in the above sections has dealt with one pipeline steel. It is important to determine whether the corrosion fatigue behavior modeled through a combined factor is true for different types and grades of pipeline steel. In this investigation, four different steels ranging from low grade to higher grades have been studied in terms their crack growth rate as affected by the combined loading factor and their corrosion behavior in a typical soil environment.

\subsubsection{Experiments:}

Four different pipeline steels including two types of X65, one X52 and one X80 were used in this study. Their chemical compositions and mechanical properties are shown in Tables 4-6 and 4-7, respectively. Compact tension (CT) specimens were used in all the tests. Specimens were machined from the pipes with the notch perpendicular to the circumferential direction of the pipe. The specimens were polished to 600 grit sand paper and then precracked by fatigue in air according to ASTM E647-93. The sharp crack initiated from the machined notch was controlled to be between 2- and 3- $\mathrm{mm}$ long with the difference of less than $0.1 \mathrm{~mm}$ on the sides of the sample.

Table 4--6 Chemical composition of the pipeline steels used in the investigation

\begin{tabular}{|c|c|c|c|c|c|c|c|c|c|c|c|}
\hline Steel & $\mathbf{C}$ & $\mathbf{M n}$ & $\mathbf{C u}$ & $\mathbf{N b}$ & $\mathbf{C r}$ & $\mathbf{M o}$ & $\mathbf{V}$ & $\mathbf{N i}$ & $\mathbf{A l}$ & $\mathbf{T i}$ & $\mathbf{N}$ \\
\hline $\mathbf{X 8 0}$ & 0.06 & 1.75 & 0.27 & 0.31 & 0.04 & 0.03 & 0.005 & 0.08 & 0.026 & 0.011 & 0.003 \\
\hline $\mathbf{X 6 5 ( \mathbf { I } )}$ & 0.13 & 1.55 & 0.05 & 0.05 & 0.08 & 0.01 & 0.002 & 0.05 & 0.042 & 0.002 & 0.009 \\
\hline X65(II) & 0.03 & 1.49 & 0.27 & 0.06 & 0.08 & 0.21 & 0.003 & 0.01 & 0.001 & 0.001 & 0.012 \\
\hline $\mathbf{X 5 2}$ & 0.07 & 0.80 & 0.28 & 0.09 & 0.05 & 0.01 & 0.002 & 0.01 & 0.031 & 0.019 & 0.001 \\
\hline
\end{tabular}

CT specimens were cyclic loaded in a near-neutral pH synthetic soil solution. The samples were pin hole loaded in sealed test cells with the solution filled up to the middle of their notches using a horizontal pneumatic cyclic loading frame. Minimum and maximum loads were controlled 
considering the precrack size to achieve $K \max$ and $\Delta \mathrm{K}$ in the range of 35 to 55 and 10 to 28 $\mathrm{MPam}^{0.5}$, respectively. Triangle waveform was used with three different frequencies of 0.01 , 0.005 and $0.00125 \mathrm{~Hz}$ and stress ratio $(\mathrm{R})$ of about 0.6 for most of the tests. Loading conditions for the tests are shown in Table 4-8.

Table 4-7 Mechanical properties of the pipeline steels used in the investigation

\begin{tabular}{|c|c|c|c|}
\hline Steel & $\begin{array}{c}\text { Yield Strength } \\
(\mathrm{MPa})\end{array}$ & $\begin{array}{c}\text { Tensile Strength } \\
(\mathrm{MPa})\end{array}$ & $\begin{array}{c}\text { Total } \\
\text { Elongation (\%) }\end{array}$ \\
\hline $\mathrm{X} 80$ & 619.5 & 705.1 & 20.6 \\
\hline $\mathrm{X65(I)}$ & 522.8 & 607.8 & 24.3 \\
\hline $\mathrm{X} 65(\mathrm{II})$ & 450.7 & 544.6 & 30.1 \\
\hline $\mathrm{X} 52$ & 382.2 & 485.3 & 32.2 \\
\hline
\end{tabular}

Table 4-8 Testing conditions for all corrosion fatigue tests including all of the samples

\begin{tabular}{|c|c|c|c|c|c|c|}
\hline Test No. & Steels & $K_{\max }$ & $\Delta \mathrm{K}$ & $\mathbf{R}$ & $f$ & $(\Delta K)^{2} K_{\max } / f^{0.1}$ \\
\hline 1 & X65(I) & 35 & 14 & 0.6 & 0.01 & 10872.4 \\
\hline 2 & X52 & 35 & 14 & 0.6 & 0.01 & 10872.4 \\
\hline \multirow[b]{2}{*}{3} & X65(I) & 35 & 14 & \multirow[b]{2}{*}{0.6} & \multirow[b]{2}{*}{0.005} & 11652.7 \\
\hline & X52 & 38 & 14.8 & & & 14138.7 \\
\hline 4 & X65(I) & 41 & 16 & 0.6 & 0.005 & 18732.7 \\
\hline \multirow[b]{2}{*}{5} & X80 & 35 & 14 & \multirow[b]{2}{*}{0.6} & \multirow[b]{2}{*}{0.005} & 11652.7 \\
\hline & X65(II) & 36.6 & 14.6 & & & 13252.2 \\
\hline \multirow[b]{2}{*}{6} & X80 & 40.5 & 16.2 & \multirow[b]{2}{*}{0.6} & \multirow[b]{2}{*}{0.005} & 18054.6 \\
\hline & X65(II) & 43 & 17.2 & & & 21608.6 \\
\hline \multirow[b]{2}{*}{7} & X80 & 43.13 & 18.05 & \multirow[b]{2}{*}{0.58} & \multirow[b]{2}{*}{0.00125} & 27418.4 \\
\hline & X52 & 43 & 18 & & & 27184.6 \\
\hline \multirow[b]{2}{*}{8} & $\mathrm{X} 80$ & 35 & 18.05 & \multirow[b]{2}{*}{0.48} & \multirow[b]{2}{*}{0.00125} & 22250.1 \\
\hline & X52 & 35 & 18 & & & 22126.9 \\
\hline \multirow[b]{2}{*}{9} & $\mathrm{X} 65(\mathrm{I})$ & 35 & 12 & \multirow[b]{2}{*}{0.65} & \multirow[b]{2}{*}{0.005} & 8561.2 \\
\hline & X65(II) & 35 & 12 & & & 8561.2 \\
\hline \multirow[b]{2}{*}{10} & X80 & 35 & 12 & \multirow[b]{2}{*}{0.65} & \multirow[b]{2}{*}{0.005} & 8561.2 \\
\hline & X52 & 35 & 12 & & & 8561.2 \\
\hline
\end{tabular}

$\mathrm{C} 2$ solution $(\mathrm{pH}=6.29)$ was used as the near-neutral $\mathrm{pH}$ synthetic soil solution and its chemical composition was provided in shown in Section 3.2. Design of testing solution was detailed in Reference [1]. The design was based on the compositions of electrolytes extracted with distilled water from soils removed from near-neutral pH SCC sites. The solution was purged with the gas 
mixture of 5 pct $\mathrm{CO}_{2}$ balanced with $\mathrm{N}_{2}$ in a sealed glass container for at least 24 hours before the test to achieve the near-neutral $\mathrm{pH}$ value. Gas purging was also continued during the test to keep the $\mathrm{pH}$ of the solution near-neutral (6.29) at all times.

Corrosion resistance of the steels was determined using weight loss tests. 6 small coupons of about $10 \times 10 \times 1 \mathrm{~mm}$ were cut from each of the samples. Coupons of different steels were suspended in the sealed glasses filled with $\mathrm{C} 2$ solution with no connection to each other. A total of 24 coupons and 6 glasses (corresponding to different exposure times) were used for each weight loss test with 4 coupons of different steels in each glass. Solutions were purged with 5 pct $\mathrm{CO}_{2}+\mathrm{N}_{2}$ prior to and during the exposure to achieve near-neutral pH conditions. After a specific exposure time, samples were removed from the solutions, immersed in rust remover

and weighted. Coupon weights after the tests were compared to their initial weights and their weight loss values were correlated to the testing time.

Crack growth was monitored by potential drop system. Details of this system were reported in reference [2]. A constant current of $10 \mathrm{~A}$ was applied through the crack crevice and changes of potential due to crack growth were converted to crack length using ASTM E647-05 equations. At least 20 data points were collected for each loading cycle depending on the test's frequency. Each of the data points were the average of ten measurements at positive and ten measurements at negative current polarity. Testing temperature was controlled to be $30{ }^{\circ} \mathrm{C} \pm$ $0.1^{\circ} \mathrm{C}$ so that no temperature effect being observed on the potential changes measurements.

\subsubsection{Results and Discussions:}

\section{A. Steel's Characteristics:}

As it can be seen in Table 4-6, the four steels have low carbon contents with the highest carbon content (13\%wt) in X65(I). Microstructures of different steels are shown in Figure 4-14. Pearlite phases are present in the ferric matrix in X65(I), while other steels consist of dispersed carbide particles in a ferritic matrix. X52 has the largest grain size among the steels with lowest yield strength (382.2 MPa) and highest total elongation (32.2\%) (Table 4-7) while X80 has the finest grain size, highest yield strength (619.5 MPa) and lowest total elongation (20.6\%).

Corrosion resistance of the steels was measured using weight loss coupon tests and their weight loss data are compared in Figure 4-15. The amount of weight loss represents the amount of corrosion occurrence on the surface of the coupons and the amount of hydrogen which can be generated at the surface respectively as a corrosion product. Little difference in weight loss was observed among different steels in first 10 days but the difference became significant after longer exposure times. The highest weight loss was observed in X80 represents its lowest corrosion resistance among the steels while highest corrosion resistance was observed in X65(II) with lowest amount of weight loss. 


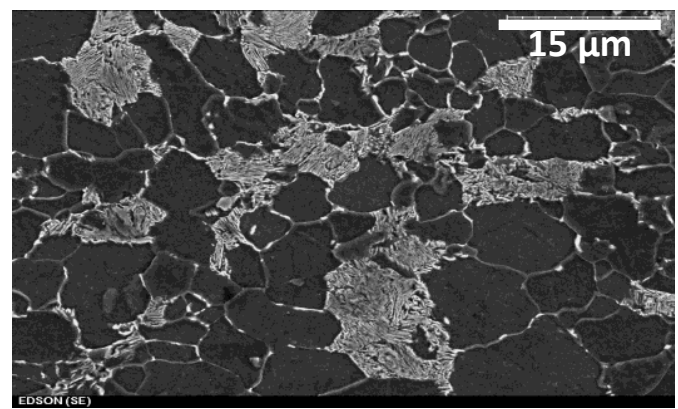

X65(I)

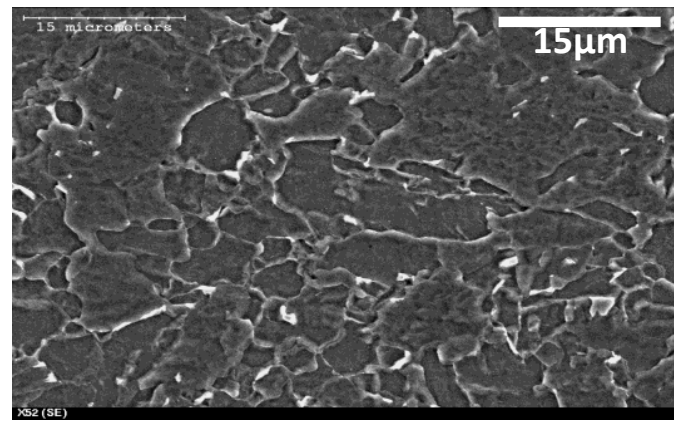

X52

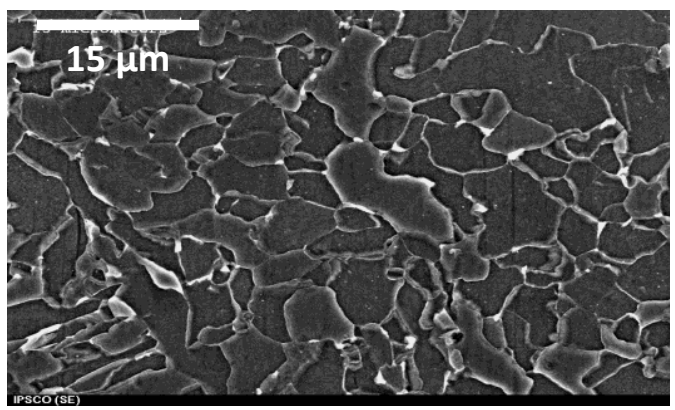

X65(II)

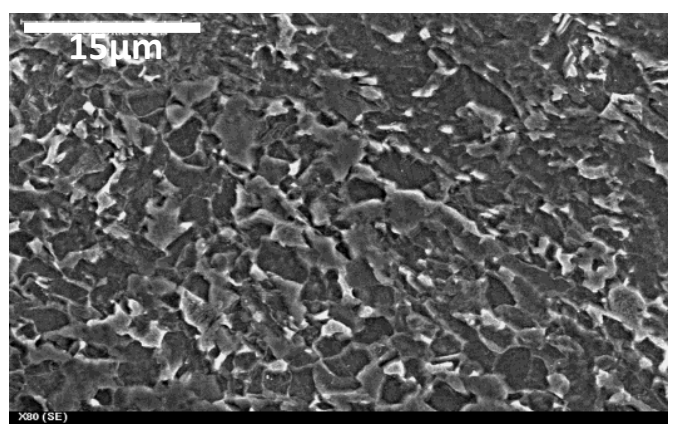

$\mathrm{X} 80$

Fig. 4-14 SEM microstructure pictures of X65(I), X65(II), X52 and X80 pipeline steels.

weight loss test 1

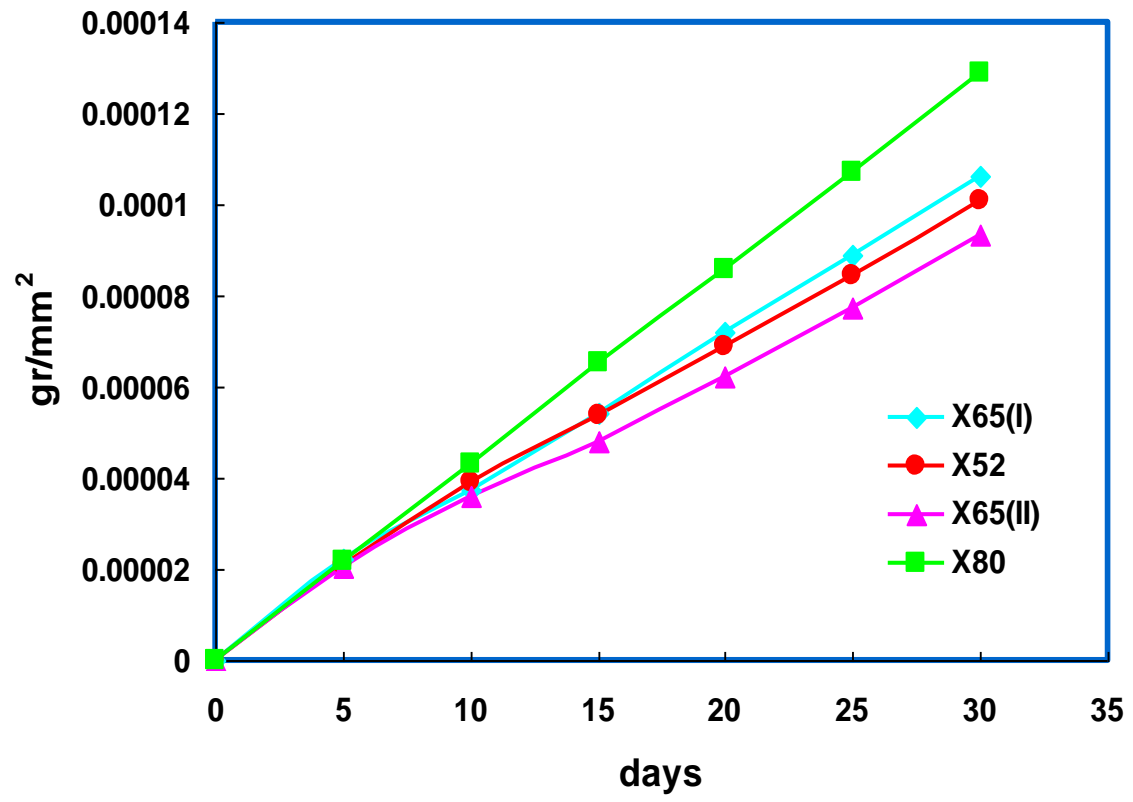

Fig. 4-15 Variations in weight loss of different pipeline steels with time when exposed to C2 solution 


\section{B. Crack Growth Curves:}

Crack growth data were correlated to $\Delta \mathrm{K}$ in many previous near-neutral $\mathrm{pH}$ cracking studies. As indicated by researchers before, crack growth data in near-neutral $\mathrm{pH}$ environment cannot be related to $\Delta \mathrm{K}$ alone as the growth rate was also found to depend on environmental effects and other fatigue driving force $\left(\mathrm{K}_{\max }\right)$. Different growth trends were observed in growth data of both $X 52$ and $X 80$ pipeline steels when their growth data were correlated to $\Delta \mathrm{K}$, Fig. 4-16. Under the same $\Delta \mathrm{K}$ value, higher growth rate corresponds to the test with higher Kmax. However when the same data were plotted using $(\Delta \mathrm{K})^{2} \mathrm{~K}_{\max } / \mathrm{f}^{0.1}$ factor, the consistency was seen in the growth data of both X52 and X80 pipeline steels, Fig. 4-16.
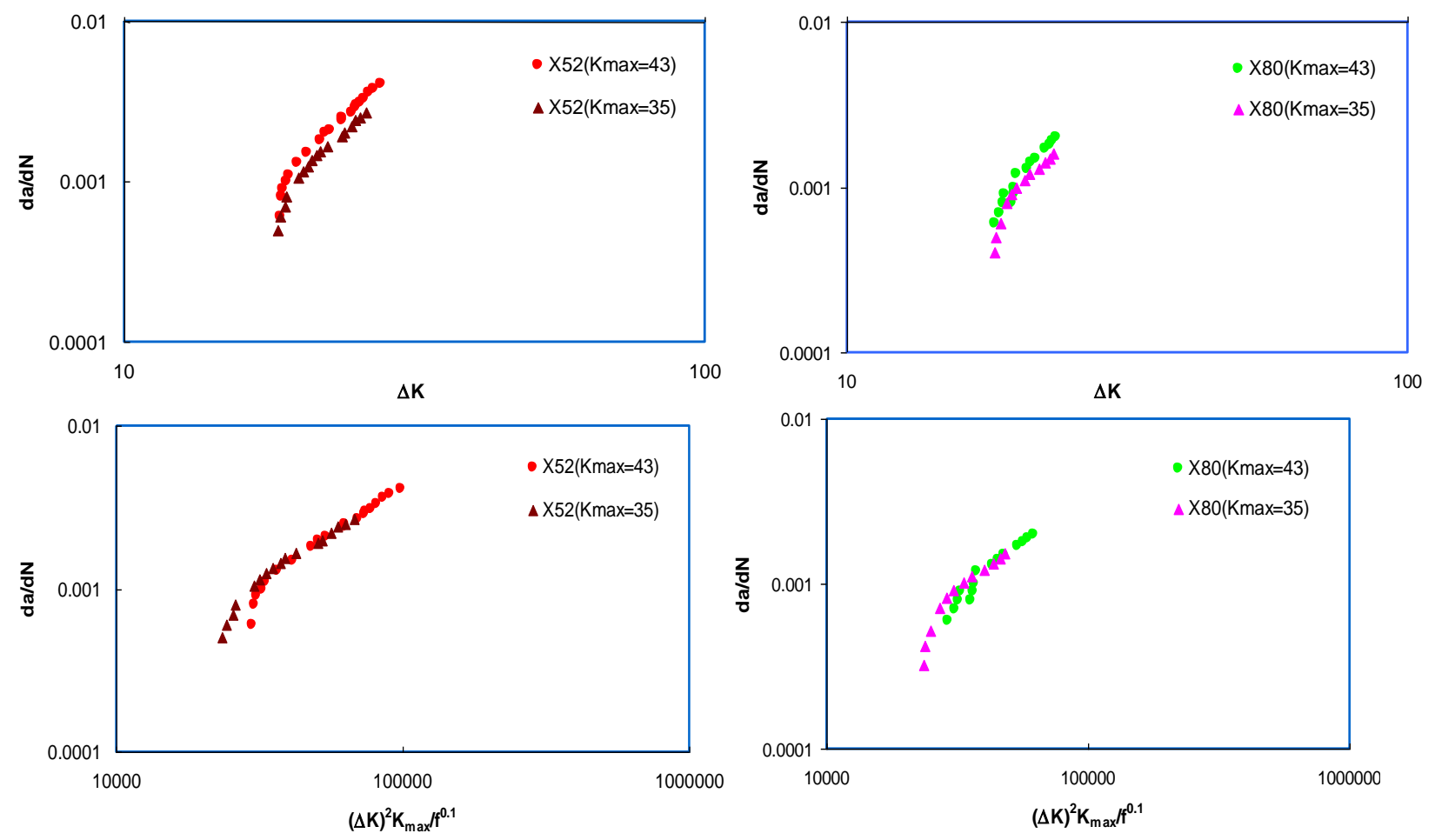

Fig. 4-16 Crack growth rate $\mathrm{da} / \mathrm{dN}$ as a function of $\Delta \mathrm{K}$ and $(\Delta \mathrm{K})^{2} \mathrm{~K}_{\mathrm{max}} / \mathrm{f}^{0.1}$ for $\mathrm{X} 80$ and $\mathrm{X} 50$.

The curves obtained using $(\Delta \mathrm{K})^{2} \mathrm{~K}_{\max } / \mathrm{f}^{0.1}$ can also show the effect of hydrogen on cracking procedure. Data points representing lower growth rates are present at the beginning of the crack growth curves which are followed by data points representing higher growth rates joining to the straight flat growth region. The resulted tail shape at the beginning of the tests represents the time required to achieve hydrogen equilibrium throughout the sample [3]. Sample's surface is the main source of hydrogen as corrosion occurs on the surface due to its exposure to the corrosive solution (C2). Generated hydrogen atoms on the surface diffuse throughout the sample as a result of hydrogen atoms concentration differences (Fick's law). After some time depending on hydrogen diffusion coefficient of the steel and the thickness of the CT specimen, the whole sample will be saturated with atomic hydrogen, achieving maximum effects of hydrogen on fatigue crack growth at the crack tip $[4,5,6]$. A jump (tail) is seen when hydrogen 
effects start, and the flat region in the growth curves represents the occurrence of full hydrogen effects on crack growth.

Crack growth curves of all the steels are shown in Figure 4-17. Different test with various loading conditions were used to obtain the crack growth curve of steels (Table 4-8). Although each specimen tested at different loading conditions leading to different starting $(\Delta K)^{2} K_{\max } / f$ ${ }^{0.1}$ factor, a great consistency can be seen in the growth data of all the steels (dashed line). The tail shape of the growth curve at the beginning of the tests becomes shorter in the test with more aggressive mechanical loading conditions (higher initial $(\Delta K)^{2} K_{\max } / f^{0.1}$ values) as it is believed that hydrogen effect is more dominant in less aggressive loading conditions. The effect of hydrogen (environment) becomes less noticeable in the presence of aggressive cyclic stresses [3, 7].
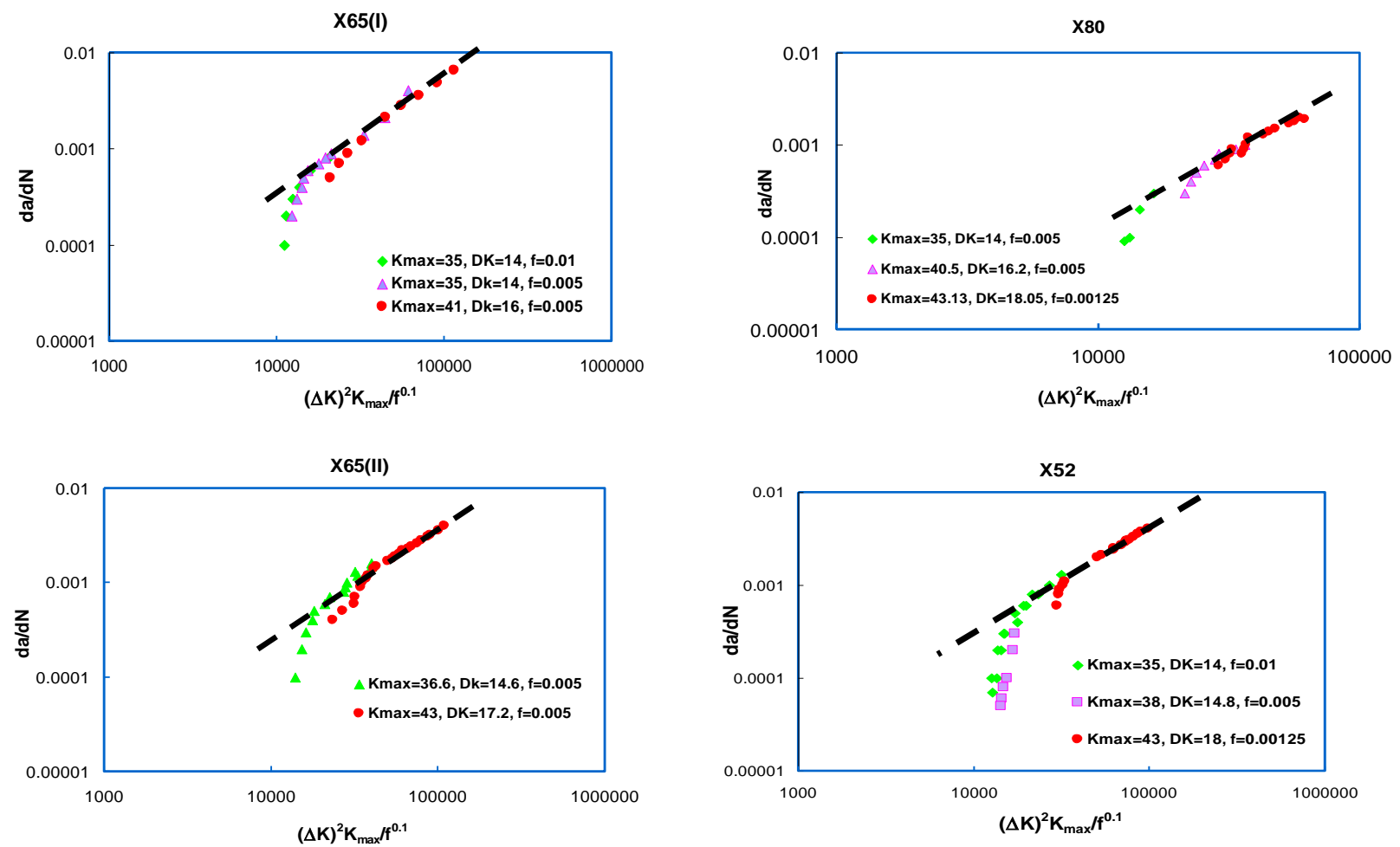

Fig. 4-17 Crack growth rate $d a / d N$ as a function of $(\Delta K)^{2} K_{\max } / f^{0.1}$ for the steels used in this study.

Crack growth curves of all the steels were plotted together in Figure 4-18. The relative positions of the growth curve reflect the resistance of the steel to corrosion fatigue in near-neutral $\mathrm{pH}$ environments. This resistance could be related to the microstructure and mechanical properties of the steels. According to Figure 4-18, X65(I) has the highest crack growth rate while X80 represents the lowest crack rate. To understand the growth behaviour of different steels, factors affecting crack growth rate of various grades of pipeline steels are further discussed below. 


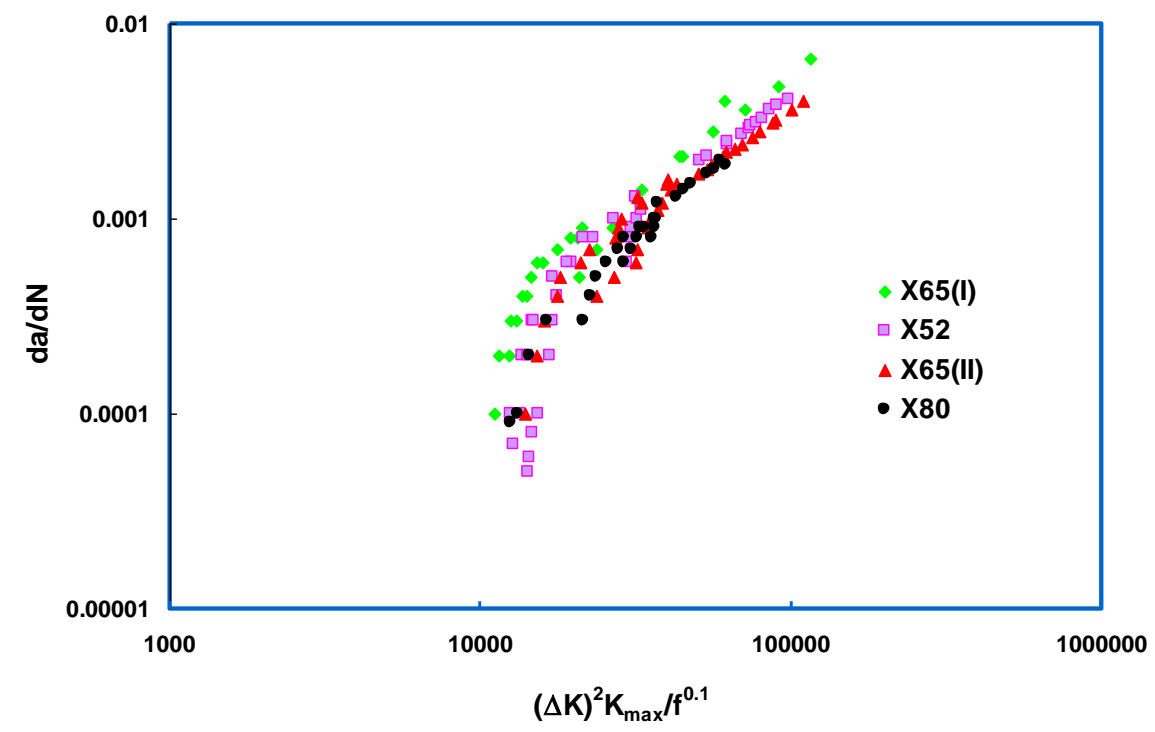

Fig. 4-18 Crack growth rate $\mathrm{da} / \mathrm{dN}$ as a function of $(\Delta \mathrm{K})^{2} \mathrm{~K}_{\max } / \mathrm{f}^{0.1}$ for the steels used in this investigation

\section{Factors Affecting Crack Growth Rates:}

It was revealed that cracking of pipeline steels in near-neutral $\mathrm{pH}$ environments can be explained with corrosion fatigue cracking mechanism. Corrosion fatigue cracking is a result of synergistic interaction of fatigue loadings and corrosion occurrence so that both the corrosion resistance and fatigue resistance of steels define their corrosion fatigue cracking (near-neutral $\mathrm{pH}$ cracking) resistance. Figure 4-1 and Figure 4-2 show the contribution of corrosion and fatigue in corrosion fatigue cracking. Two competitive processes of crack tip blunting and crack tip sharpening define the growing probability of existent crack due to corrosion fatigue mechanism [3]. The main crack growth driving force is cyclic loading (fatigue). Crack tip can become blunted by corrosion induced closure effect when corrosion products (steel's dissolution) are stored in the crack crevice. Atomic hydrogen (other corrosion product) and fatigue stresses can act as crack tip re-sharpeners. Steel's toughness and ductility decreases dramatically when hydrogen is introduced to the steel's microstructure so that cracking potential is increased [8]. Hydrogen introduces appropriate brittle regions ahead of the crack tip for crack growth so that the blunted crack tip gets the opportunity to become sharp again. As a result different corrosion fatigue cracking of steels can be explained due to their different corrosion and fatigue resistances which are influenced by steel's microstructures and mechanical properties.

Atomic hydrogen generated at the specimen's surface (corrosion) diffuse throughout the sample but only the hydrogen which reaches the crack tip contributes in the cracking procedure. Hydrogen atoms are highly movable in the lattice, but can also be trapped in microstructural defects such as voids, dislocations, grain boundaries and interfaces of different phases $[9,10]$. As a conclusion the amount of hydrogen generated at the specimen's surface cannot represent the amount of hydrogen which contributes in cracking procedure at the crack tip. X80 represents 
a clear evidence for the current argument. X80 has the lowest crack growth rate among the steels (Figure 4-18) while the highest amount of hydrogen is generated on its surface due to its highest corrosion rate (Figure 4-15). Microstructure has a great influence on the amount of hydrogen atoms which can be present at the crack tip. In phase interfaces, micro plastic deformations can occur due to different formability of phases under the applied stresses and hydrogen atoms can be easily trapped in these micro plastically distorted regions. On the other hand it is reported by many researchers [11-14] that cracking is enhanced in steels with nonuniform microstructures. Higher hydrogen content in the microstructure increases the probability that higher amount of hydrogen can be reached to the crack tip to enhance cracking.

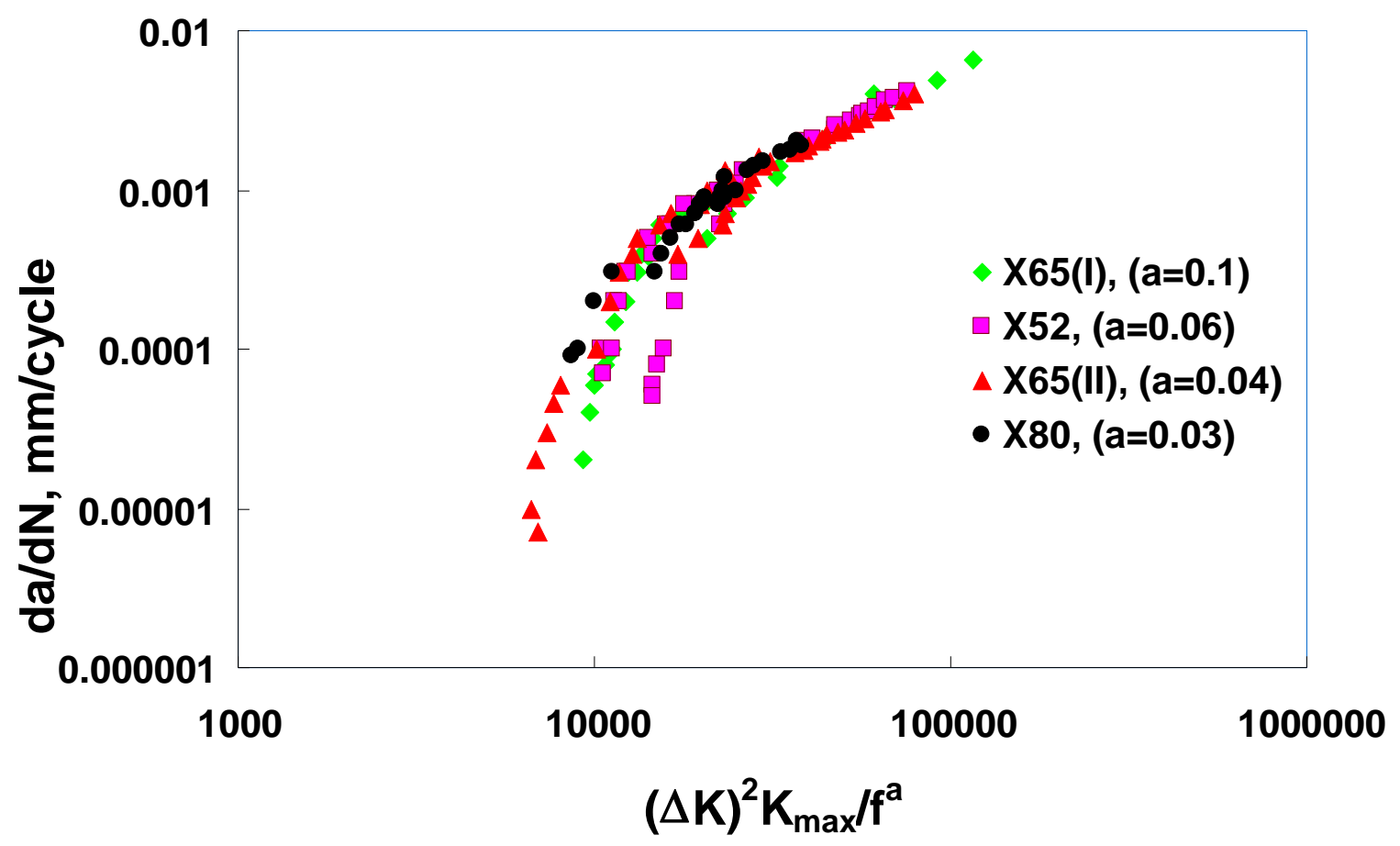

Fig. 4-19 Crack growth data normalization representing different $\alpha$ values for different steels

Hydrogen atoms can also be easily trapped in grain boundaries because of high density of dislocations. It can be expected that more hydrogen atoms be trapped in microstructures with finer grain sizes $[15,16]$. Lower grain sizes can also increase the fatigue crack resistance of the steel. Near-neutral $\mathrm{pH}$ cracks are known to be transgranular and their growth rates can be decreased as they reach to the grain boundary. As mentioned before $\alpha$ in $(\Delta K)^{2} K_{\text {max }} /{ }^{0.1}$ term represents the effect of environment (hydrogen) on crack growth. In other words a reflects the amount of available hydrogen atoms at the crack tip which contributes in cracking process considering both influences of the amount of hydrogen generation on the sample's surface and hydrogen diffusion path through the microstructure. Growth data of all the steels were normalized to the single crack growth curve (X65(II)'s growth curve) in Figure 4-19 by selecting different $\alpha$ values for each steel ( $\alpha=0.1$ was kept for X65(I)). Specific $\alpha$ value of the steels are known to be their response to the environment based on its corrosion resistance (hydrogen 
generating ability) and its microstructure (hydrogen trapping and diffusible hydrogen in the lattice). New a values of steels were compared to the ranks of the steels in terms of crack growth rates and their corrosion rates (obtained from slope of the curves in Fig. 4-15) in Table 4-9. It is interesting to see that new $\alpha$ values are in the same order of the ranks based on growth rates as $X 65(I)$ and $X 80$ have the highest $(\alpha=0.1)$ and lowest $(\alpha=0.03) \alpha$ values, respectively. This reflects the fact that higher amount available diffusible hydrogen on the surface that can reach to the crack tip after diffusing through the microstructure leads to higher growth rate.

Table 4-9 Environmental and corrosion rate comparison of different steels.

\begin{tabular}{|c|c|c|}
\hline Steels & $\begin{array}{c}\text { Environmental } \\
\text { Factor }(\alpha)\end{array}$ & $\begin{array}{c}\text { Corrosion rates } \\
\text { gr.mm } \mathrm{mm}^{2} / \text { days }\end{array}$ \\
\hline $\mathrm{X65}(\mathrm{I})$ & 0.1 & $4 \times 10^{-6}$ \\
\hline $\mathrm{X} 52$ & 0.06 & $3 \times 10^{-6}$ \\
\hline $\mathrm{X} 65(\mathrm{II})$ & 0.04 & $3 \times 10^{-6}$ \\
\hline $\mathrm{X} 80$ & 0.03 & $5 \times 10^{-6}$ \\
\hline
\end{tabular}

X65(I) has an non-uniform microstructure compared to other steels. X80 has the smallest grain size (largest grain boundary area) and X52 has coarser grain size than X65(II). Highest crack growth rate observed in $\mathrm{X} 65(\mathrm{I})$ may be related to the presence of pearlite phases in its microstructure. This observation agrees with those of other researchers who observed that small cracks were more likely to initiate and propagate in the pearlite colonies or along the pearlite-ferrite boundaries [12-14]. Figure 4-20 shows SEM picture of a crack which was propagated in $\mathrm{X65}(\mathrm{I})$ pipeline steel. It is seen that when the crack has reached to the area close to pearlite phase, it has changed its direction toward the pearlite and has continued to grow in pearlite rather than in ferrite. According to the above discussion this behavior was a result of high amount of hydrogen available at pearlite-ferrite interface which can facilitate crack growth by hydrogen embrittlement effect. Figure 4-21 shows SEM picture of crack tip in X65(I) pipeline steel. This sharp crack tip can be represented as another evidence of high hydrogen content of the microstructure.

X52 has lower crack growth rate than X65(I). It has more uniform microstructure than X65(I). Lower amount of diffusible hydrogen is also available on X52's surface due to higher corrosion resistance of X52 (Figure 4-15). Conclusively, it can be expected that lower amount of hydrogen can be available in X52's microstructure to contribute in crack growth process. X52 is also known to be less susceptible to hydrogen embrittlement at the crack tip. Stresses inside the fracture process zone ahead of crack are proportional to the steel's yield strength. Lower yield strength results in less distortion of crystal lattice ahead of crack with less welcoming area for atomic hydrogen to concentrate and cause embrittlement. Figure 4-22 shows an evidence of 
this conclusion. This figure shows the crack tip branching occurrence in X52 sample. Crack tip branching represents crack growth difficulty. Crack tip branches to different directions to find the appropriate path (presence of higher amount of hydrogen) which facilitates its growth with the sharp condition.

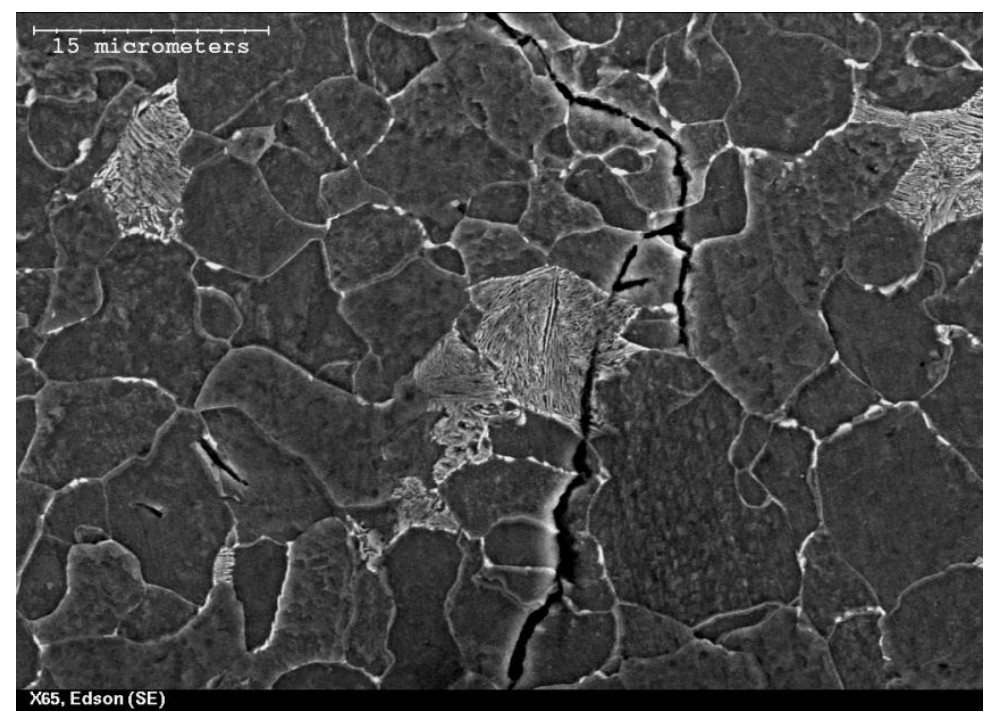

Fig. 4-20 SEM picture of a crack which was propagated in X65(I) pipeline steel.

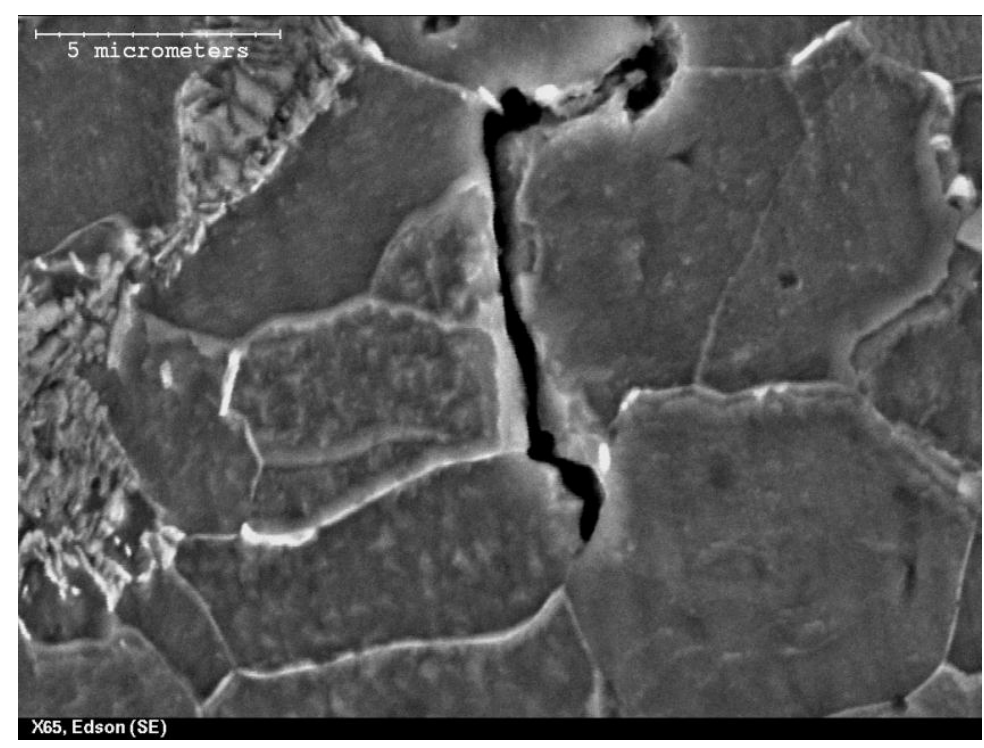

Fig. 4-21 SEM picture of a sharp tip of a crack which was propagated in X65(I) pipeline steel.

Hydrogen content is known to be even lower in X65(II)'s microstructure which agrees with its lower crack growth rate to be lower than X52 and X65(I). On one hand the amount of hydrogen generated on X65(II)'s surface is lower than X52 and X65(I) according to Figure 4-15, On the other hand the generated hydrogen has more difficulty to reach the crack tip with high 
probability of being trapped in grain boundaries. X65(II) has lower grain size than both X65(I) and X52 and larger grain boundary areas which represents higher hydrogen trapping ability. Great amount of diffused hydrogen can be trapped in grain boundaries without diffusing to the crack tip to contribute in cracking process. The same scenario can be applied to explain the lowest crack growth rate of X80 among the steels. Although Figure 4-15 shows X80 to have the lowest corrosion resistance among the steels it represents the lowest crack growth rate. Table 5 shows that $X 80$ has also the lowest $\alpha$ value. It means that the environmental factors (hydrogen) have less effect on crack growth behavior of X80. Very fine grain size of $X 80$ is known to be responsible for its lowest crack growth rate. Large grain boundary area in X80's microstructure makes its $\alpha$ value to be the lowest as high amount of hydrogen is trapped in the grain boundaries although it has the highest amount of available diffusible hydrogen atoms on its surface. Fine grain size can also lead to a very high fracture toughness of the steel. Which leads to higher fatigue resistance of steel as higher amount of maximum stress intensity factor $\left(\mathrm{K}_{\max }\right)$ should be reached at the crack tip for crack advancement. It can be concluded that high fatigue resistance of X80 and lowest hydrogen's contribution in its cracking procedure makes X80 to have the lowest crack growth rate among the steels.

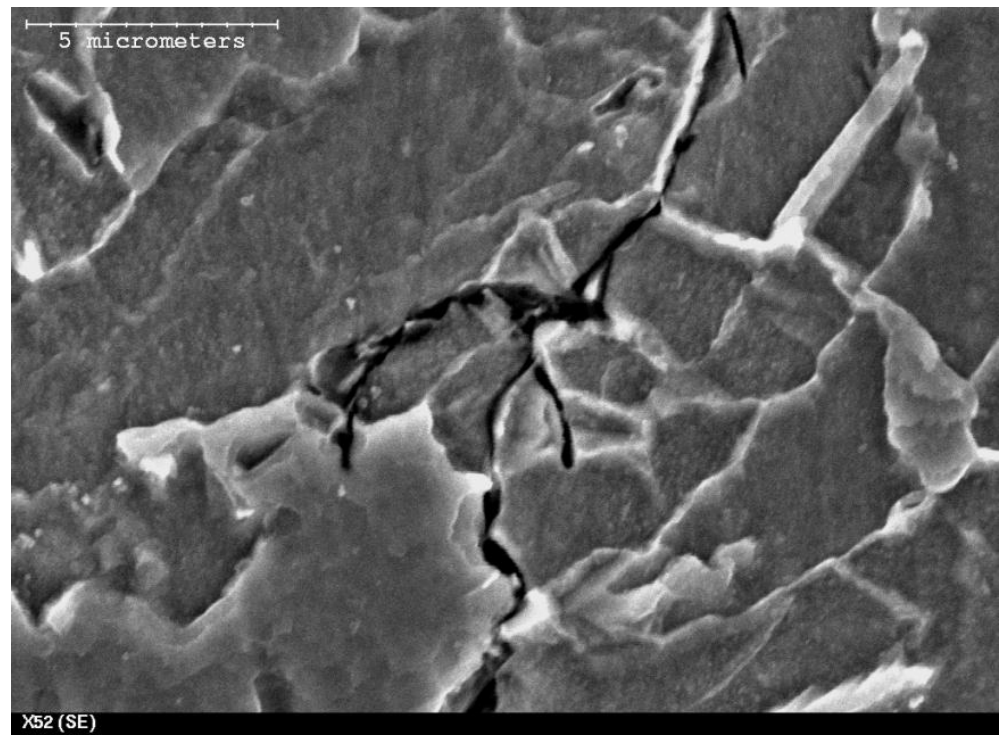

Fig. 4-22 SEM picture of a crack tip branching of a crack which was propagated in X52 pipeline steel

\section{Summery and Conclusions}

This article reports the crack growth behavior of different pipeline steels in near-neutral $\mathrm{pH}$ environment using corrosion fatigue model. Growth rate data were rationalized using $(\Delta K)^{2} K_{\max } / f$ ${ }^{0.1}$ factor. It was seen that cracking behaviour of steels in near-neutral $\mathrm{pH}$ environment is well consistent with the corrosion fatigue cracking behaviour. Hydrogen plays the main role in cracking procedure. The hydrogen atoms which diffuse to the crack tips can enhance the fatigue crack growth by embrittleing the fracture zone ahead of crack tip. Crack growth is material dependent as the amount of hydrogen which is generated and reaches to the crack tip depends 
on the materials microstructure and its corrosion resistance. Higher crack growth rates can be obtained in steels in which higher amount of hydrogen can be provided at the tip of the crack propagate in their microstructure.

\section{References:}

1 W. Chen, R.L. Eadie, and R.L. Sutherby: 2nd Int. Conf. on Environment-Induced Cracking of Metals, Banff, AB, Canada, Sept. 19-23, 2004.

2 W. Chen and R.L. Sutherby: Proc. Int. Pipeline Conf. 2004, IPC, Calgary, AB, Canada, Oct. 4-8, 2004, paper no. IPC04-0449.

3 W. Chen, R. Kania, R. Worthingham, G.V. Boven, Tansgranular crack growth in the pipeline steels exposed to near-neutral pH soil aqueous solutions: the role of hydrogen, Acta Mater., 57 (2009), 6200-6214.

4 Been, J., King, F., Sutherby, R., "Environmentally Assisted Cracking of Pipeline Steels in Near-Neutral pH Environments", Environment-Induced Cracking of Materials, (2008): 221230.

5 Anderson, T. L. "Fracture Mechanics: Fundamentals and Applications", $3^{\text {rd }}$ edition, Boca Raton, FL: CRC Press, c2005

6 Wang, Y. Z. "Corrosion Fatigue", Uhlig's Corrosion Handbook. Ed. R. Winston Revie. $2^{\text {nd }}$ edition, John Wiley \& Sons, Inc. 221-232.

7 Chen, W., and Sutherby, R. L., "Crack Growth Behavior of Pipeline Steel in Near-Neutral pH Soil Environments", Metallurgical and Materials Transactions A, Vol. 38, No. 6 (2007): 1260-1268

8 Chattoraj, I. "The Effect of Hydrogen Induced Cracking on the Integrity of Steel Components." Sadhana, Vol. 20, No. 1, (1995): 199-211

9 Asher, S. L. and Singh, P. M., "Role of Stress in Transgranular Stress Corrosion Cracking of Transmission Pipelines in Near-Neutral pH Environments" Corrosion, Vol. 65, No. 2, (2009): 79-87.

10 Qiao, L. J., Luo, J. L., and Mao, X., "The Role of Hydrogen in the Process of Stress Corrosion Cracking of Pipeline Steels in Dilute Carbonate-Bicarbonate Solution", Journal of Materials Science Letters, Vol. 16, No. 7, (1997): 516-20

11 Chu, R., Chen, W., Wang, S., King, F., Jack, T. R., and Fessler, R. R., "Microstructure Dependence of Stress Corrosion Cracking Initiation in X-65 Pipeline Steel Exposed to a Near-Neutral pH Soil Environment", Corrosion, Vol. 60, No. 3 (2004): 275-83

12 Kushia, T., Nose, K., Asahi, H., Kimura, M., Yamane, Y., Endo, S., and Kawano, H., "Effects of Metallurgical Factors and Test Conditions on Near Neutral pH SCC of Pipelines Steels", Corrosion, (2001): Paper No. 01213.

13 Bulger, J. T., Lu, B. T., Luo, J. L., "Microstructural Effect on Near-Neutral pH Stress Corrosion Cracking Resistance of Pipeline Steels" Journal of Materials Science, Vol. 41, No. 15, (2006): 5001-5005

14 Martínez-Madrid, M., Chan, S. L. I., Charles, J. A., López L., J. A., and Castaño, V., "Effect of Grain Size and Second Phase Particles on the Hydrogen Occlusivity of Iron and Steels", Materials Research Innovations, Vol. 3, No. 5, (2000): 263-270 
15 Lessar, J. F., and Gerbrich, W. W., "Grain Size Effects in Hydrogen-Assisted Cracking", Metallurgical Transaction A, Vol. 7A, No. 6, (1976): 953-60.

16 Chan, S. L. I., "Hydrogen Trapping Ability of Steels With Different Microstructures", Journal of the Chinese Institute of Engineers, Vol. 22, No., 1, (1999): 43-53

\subsection{Surface short/shallow cracks vs. long crack/deep cracks}

\subsubsection{Introduction}

The findings reported in the above sections were obtained by using compact tension specimens, which simulate a structure with long and through thickness cracks. In reality, failures of pipeline steel by stress corrosion cracking in near neutral $\mathrm{pH}$ environments start first from a pit, then to an initiation of shallow surface cracks, and finally the growth and coalescence of shallow/short/small cracks to the critical size, leading to the final failure.

Results from contemporary research in fatigue crack growth suggests that shallow cracks tend to grow at significantly higher rates than through- thickness cracks and may grow under conditions where through-thickness cracks are typically dormant [1-16]. This difference in the behaviour of shallow and through thickness cracks may be responsible for the underestimation of the growth rate of NNPHSCC cracks. The current industry approach also has the shortcoming of assuming that the rate of crack propagation in pipelines is constant rather than dependent on pipeline operating conditions, crack size and morphologies. This is evidently simplistic.

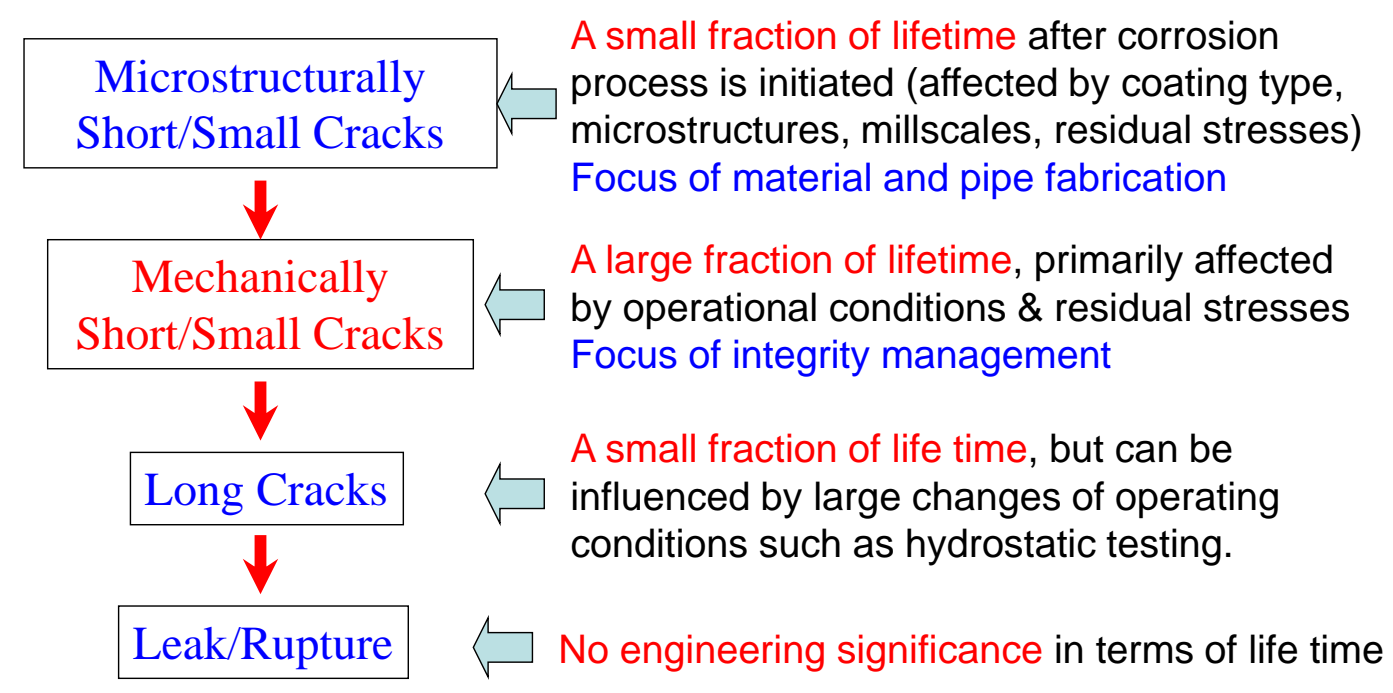

Fig. 4-23 Illustration showing the evolution of crack dimension and its significance in terms of integrity managements 
Basic fracture mechanics classifies cracks into two categories: long/deep cracks and short/shallow cracks (short in the direction of propagation). Short cracks are further divided into microstructurally short cracks and mechanically short cracks. The characteristics of these different categories and the evolution of a typical NNPHSCC crack over its lifespan are summarized in Figure 4-23. A NNPHSCC crack spends a very small fraction of its lifetime as a microstructurally short crack after coating is bonded and groundwater is able to contact the pipe surface. The microstructurally short cracks are usually in grain size level and need about a few month to in initiate according to many lab simulations. A mechanically short crack spends the most significant portion of its lifetime. Growth rate in this region is primarily determined by pipeline operation conditions and residual stresses. This stage is usually the focus of integrity management programs.

Hence, in order to generate more accurate mathematical models, there is a need to simulate NNPHSCC using surface type flaws rather than through-thickness flaws as commonly done. Preliminary results of a study employing this approach in the study of the growth of NNPHSCC cracks are reported in this communication.

\subsubsection{Experimental}

Custom made flat tensile specimens (Figure 4-24) having three reduced sections were machined from the longitudinal direction of a sectioned pipe. All samples were made from a section of X-65 pipeline steel removed from service. This material had been found to be susceptible to NNPHSCC both in laboratory and field studies. Only pipe sections unaffected by NNPHSCC and other forms of corrosion, and external damage were used. Gauge sections were $23 \mathrm{~mm} \times 45 \mathrm{~mm} \times 9.2 \mathrm{~mm}$ in dimension and identical semi-circular shallow notches with dimensions $\mathrm{c}=5 \mathrm{~mm}$ and $\mathrm{a}=2.5 \mathrm{~mm}$ were made by electrical discharge machining (EDM) in the middle of each gauge section.

A corrosion test cell consisting of two chambers was designed and fabricated from acrylate (Figure 4-24c). The inner tube, named the shielding, was designed to simulate coating disbondment at the surface of a pipe. The width of this inner tube was made adjustable so that coating disbondment of various sizes can be studied. The outer tube holds the bulk solution which simulates the surrounding soil around a pipe in the field while the solution contained in the inner shielding simulates the solution trapped between the coating and the pipe surface on an actual pipeline. The bulk solution in the outer tube was purged by a mixture of certified grade $5 \%$ or $20 \% \mathrm{CO}_{2}$ (nitrogen balance) fed in through openings at the bottom of the cell, so that $\mathrm{CO}_{2}$ can only diffuse into the simulated disbondment from the open mouth.

A reference (saturated calomel electrode) and counter electrode (platinum mesh) arrangement was used to apply cathodic protection to the sample using a three electrode configuration. In all cases, cathodic protection was applied just above the open mouth of the inner shielding. An EG\&G potentiostat operating in constant voltage mode was used to apply cathodic protection voltage of $-1.2 \mathrm{~V}$ SCE for tests requiring cathodic protection. 


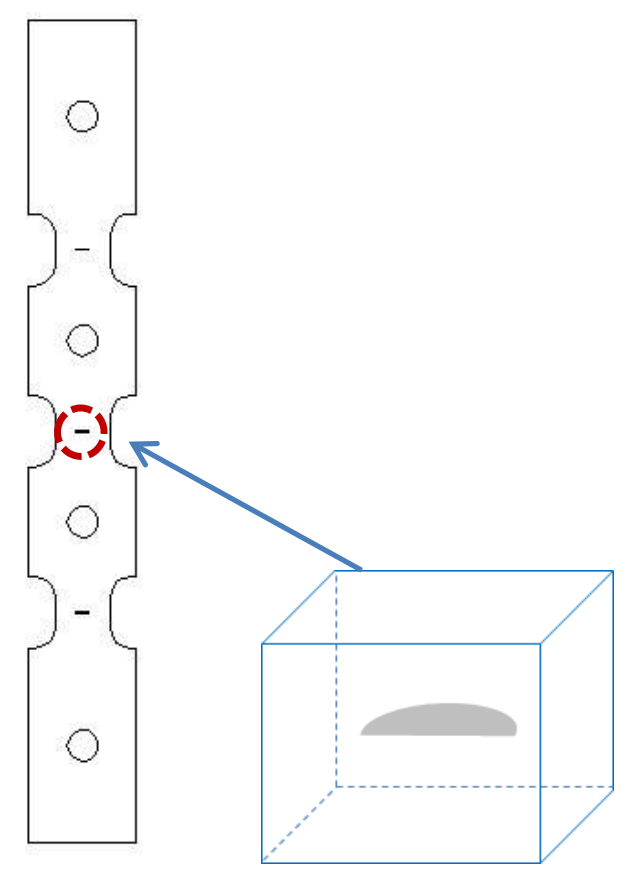

a)

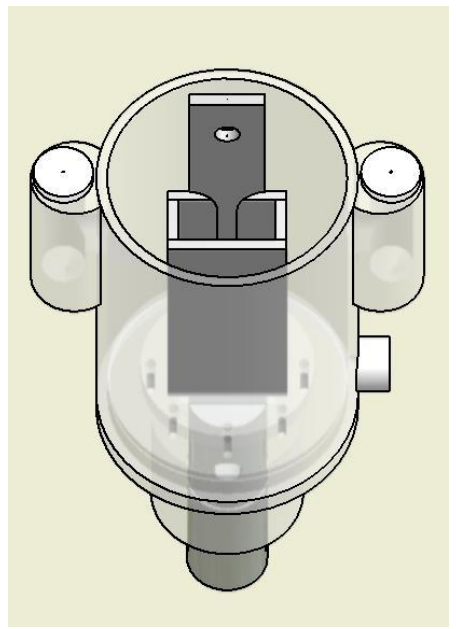

c)

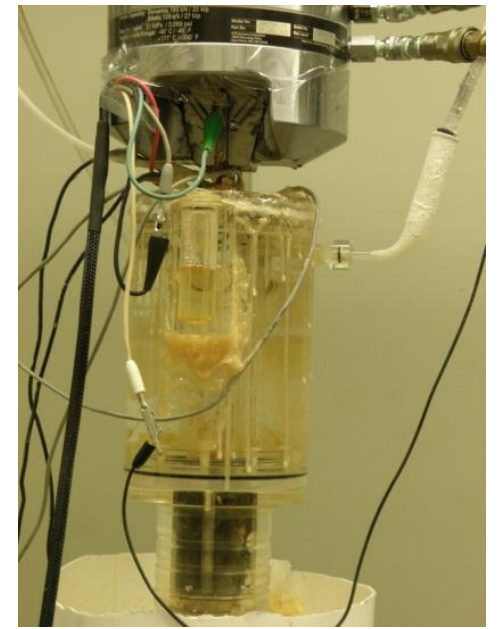

d)

Fig. 4-24 Specimen design and test setup for studying surface cracks: a) geometry of the specimen with three surface cracks within the reduced section, b) surface crack in the reduced section of a), c) test cell used, d) actual test cell and specimen mechanically loaded by Instron.

In an attempt to closely simulate real pipeline service conditions, the sides and back surface of each specimen (the one without the surface cracks) were coated with epoxy in order to isolate these surfaces from the corrosion media. Crack growth rates were monitored using a selfassembled potential drop system through copper wire leads soldered across the back of the EDM slots in each gauge section. A constant current of $20 \mathrm{~A}$ was applied by the potential drop system in order to measure the potential drop across each crack.

For the tests reported in this report, a maximum stress of $100 \%$ specified minimum yield strength and the following stress ratios were used: for test I in $5 \% \mathrm{CO}_{2}, \mathrm{R}=0.65$ for 15 days and $R=0.60$ for 15 days, and $R=0.58$ for 9 days because of rupture, while for test II in $20 \% \mathrm{CO}_{2}, \mathrm{R}=$ 0.65 for 15 days, $R=0.6$ for 15 days, $R=0.58$ for days, at $R=0.56$ for 2.5 days before interrupted (see Fig. 4-25). For test I and test II, the pre-crack size was $3.3 \pm 0.05 \mathrm{~mm}$ and $0.9 \pm 0.1 \mathrm{~mm}$ respectively, while a cyclic frequency of $0.005 \mathrm{~Hz}$ was used for both tests.

The pre-cracked samples were then exposed to the corrosion media in a sealed test cell and filled with $\mathrm{C} 2$ solution $\left(0.0035 \mathrm{KCl}, 0.0195 \mathrm{NaHCO}_{3}, 0.0255 \mathrm{CaCl}_{2} . \mathrm{H}_{2} \mathrm{O}, 0.0274 \mathrm{MgSO}_{4} .7 \mathrm{H}_{2} \mathrm{O}\right.$, $\left.0.0606 \mathrm{CaCO}_{3} \mathrm{~g} / \mathrm{l}\right)$. Cyclic stresses with a maximum stress of $100 \%$ specified minimum yield strength and varying stress ratios was applied during the test. 
Test 1 - OCP, $5 \% \mathrm{CO}_{2}$

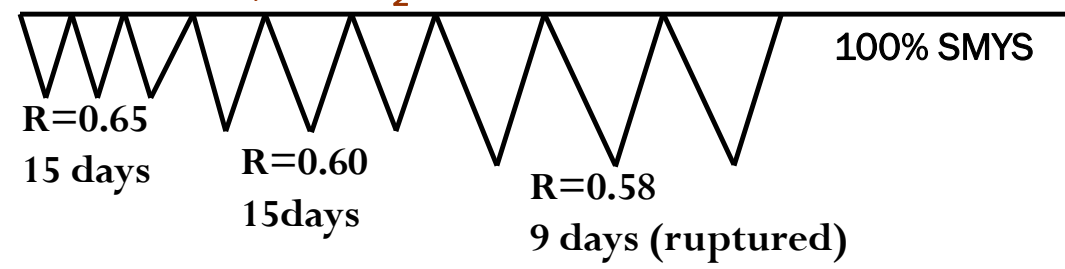

Test 2 - OCP, $20 \% \mathrm{CO}_{2}$

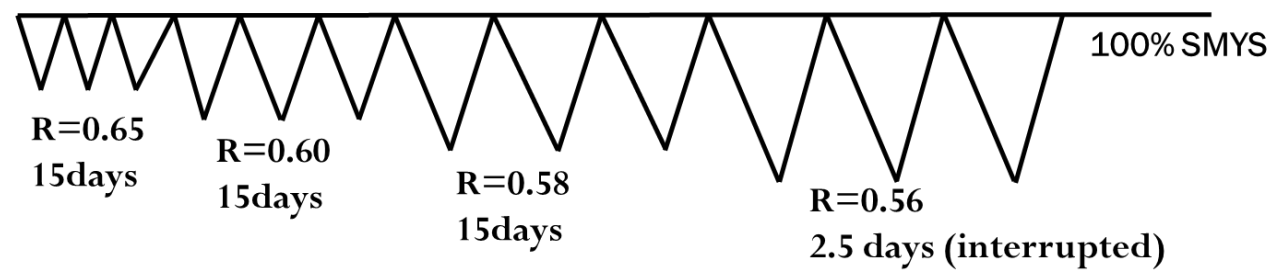

Fig. 4-25 Loading schemes used for Test I and Test II, respectively. Both tests started with the same loading conditions. Crack growth was monitored using accurate potential drop system.

After each test, the fracture surface was examined and post-test crack lengths determined in order to validate potential drop measurements with actual crack growth measured from the surface of fractured specimens. Prior to fracture surface examination, iron oxide-type corrosion products were removed using a rust remover solution composed of water $(100 \mathrm{ml}), \mathrm{HCl}(3 \mathrm{ml})$, and cis-2-but-1-4-diol. Initial fracture face examination was done using an optical microscope. More detailed examination of fracture surfaces was carried out using a Hitachi scanning electron microscope equipped with an energy dispersive x-ray spectrometer for chemical compositional analysis.

\subsubsection{RESULTS AND DISCUSSION}

The X65 steel used for this study had an elongated grain structure and was ferrite-pearlite in nature. Grain sizes vary with the direction of measurement and were typically in the range of 10$30 \mu \mathrm{m}$. Careful examination of the microstructure revealed the presence of non-massive but locally continuous bands of pearlite dispersed across the microstructure of the alloy. Also, finely dispersed carbides were observed within the ferrite grains.

A typical micrograph of the sample surface face, showing the original machined slot, blunt crack which was originally the pre-fatigue cracked section, and crack growth from the root of prefatigue crack is in Figure 4-26. The pre-fatigue crack was originally has a sharp morphology shown in Fig. 4-27. It is obvious that the sharp configuration had been evolved into a notch, which is considered to result from low temperature creep. For the data of potential drop data, it was found that crack did not grow in the first 30 days of test I under loading with $\mathrm{R}=0.65$ and 0.60 and 45 days of Test 2 under loading with a loading ratio higher than 0.56 . This long non- 
propagating periods allowed the ample time for low temperature creep to occur at the tip of prefatigue crack. By gradual reducing R-ratio, the mechanical driving force as measured by the combined factor was increased and crack was initiated at and grew from the blunt root. This corrosion fatigue crack is relatively sharp.

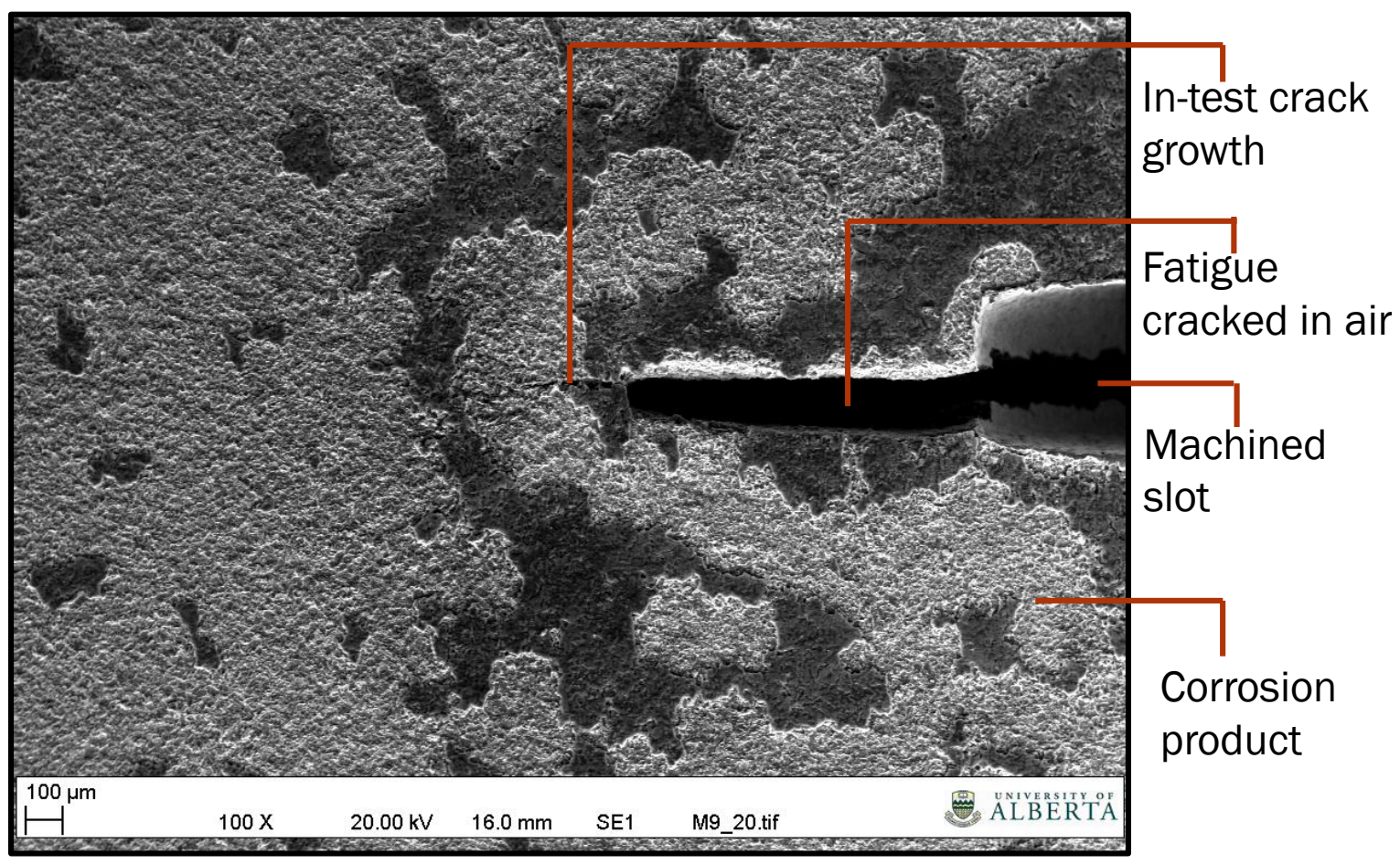

Fig. 4-26 Surface morphology of the specimen after Test II.

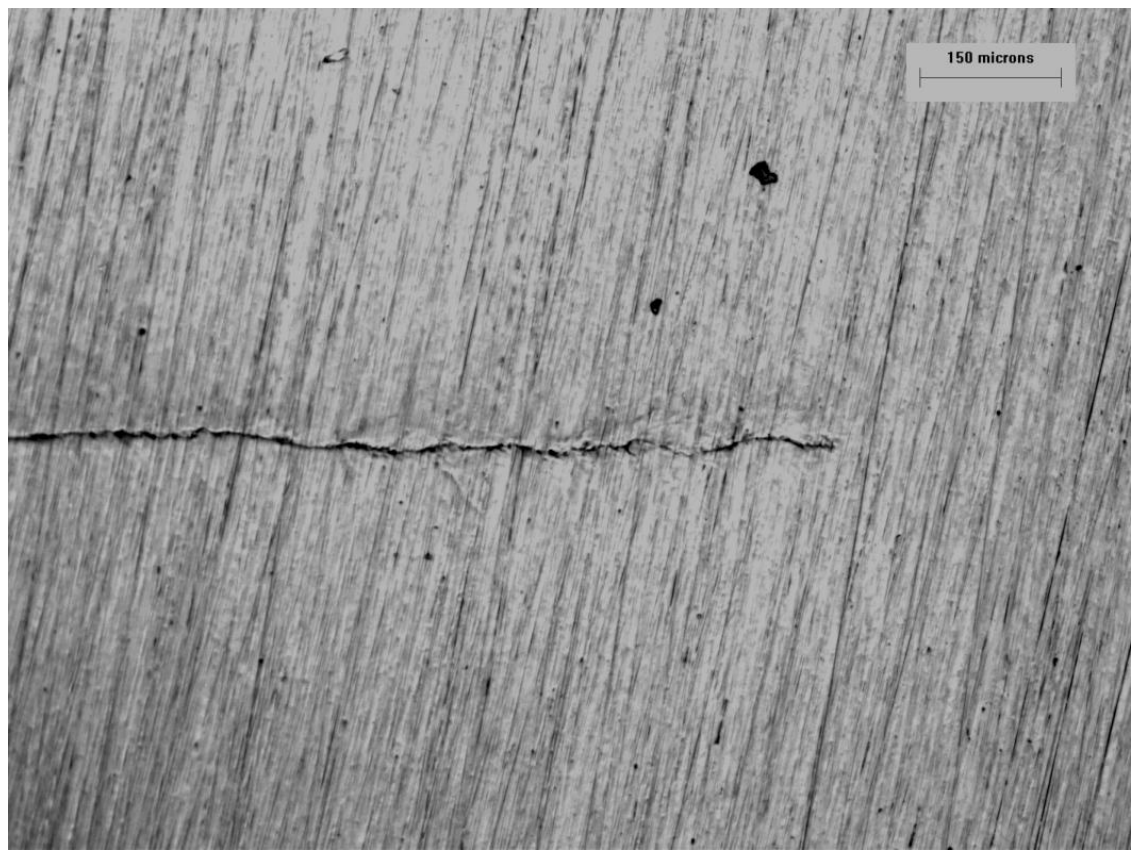

Fig. 4-27 Crack morphology after pre-fatigue loading in air 
A comparison of crack tip morphology on specimen surface at different positions along the length direction of the specimen and in two different environments is made in Fig. 4-28. The top crack in Test I was ruptured and therefore the morphologies of the top cracks from the two tests was not included. It seems common that the sharp pre-fatigue crack has evolved into a notch and new cracks were initiated from the blunt notch when $\mathrm{R}$ ratio is reduced. The morphology at the notch root seems different depending on the $\mathrm{CO}_{2}$ level in the soil solution. A square-like appearance is seen in the soil solution with $20 \% \mathrm{CO}_{2}$. It is not clear at the moment how this different morphology was formed.

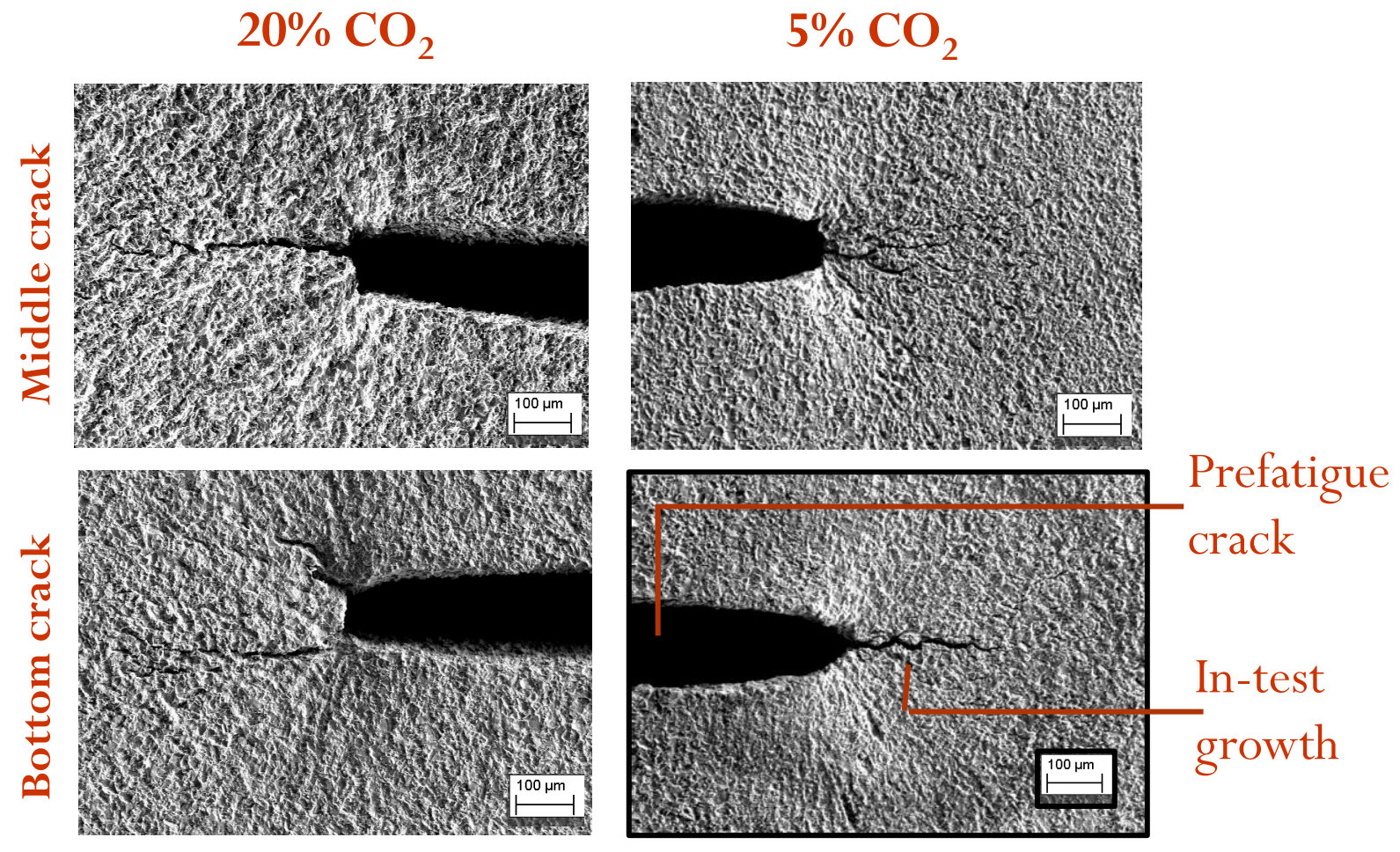

Fig. 4-28 A comparison of crack tip morphology on sample surface after Test I and Test 2.

Fig. 4-29 shows the crack morphology on the cross section made along the depth direction of the surface crack. The blunting of the pre-fatigue crack during non-propagating loading is very obvious. The morphology of the cracks initiated from the notch during propagation loading is slightly different in two soil environments. The crack appears much narrower in the case of $5 \%$ $\mathrm{CO}_{2}$. Part of the reason could be related to the higher dissolution rate of the soil solution with $20 \%$ $\mathrm{CO}_{2}$.

Fig. 4-30 shows a typical micrograph of the fracture-opened surface crack after corrosion test (less than half is shown). The surface consists of the original slot, the pre-fatigued crack section, the distinct ledge formed between the pre-fatigue region and the SCC crack propagation region. The ledge should have resulted from the non-propagating cyclic loading at $R=0.65$ and $R=0.60$ for Test 1 for about 30 days of corrosion exposure. 

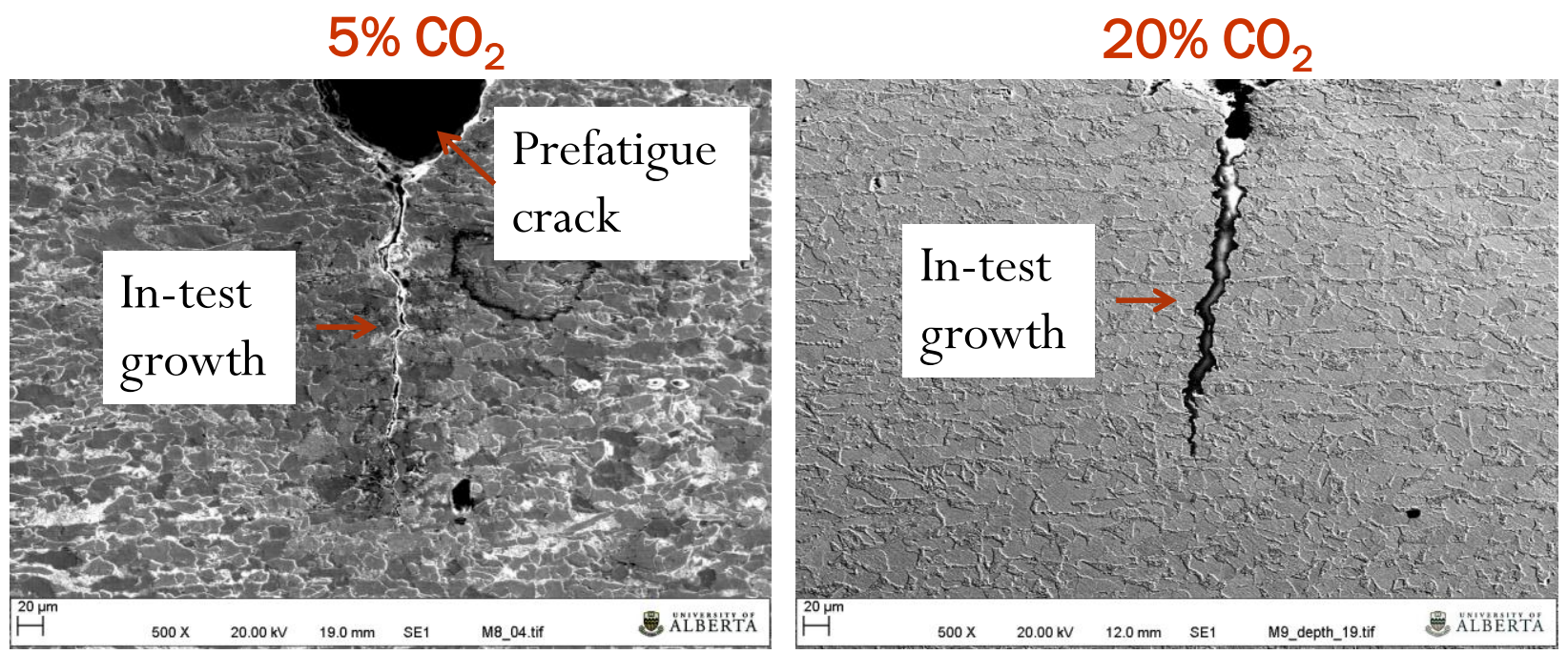

Fig. 4-29 A comparison of crack tip morphology on the cross section along the crack depth direction after Test I and Test 2.

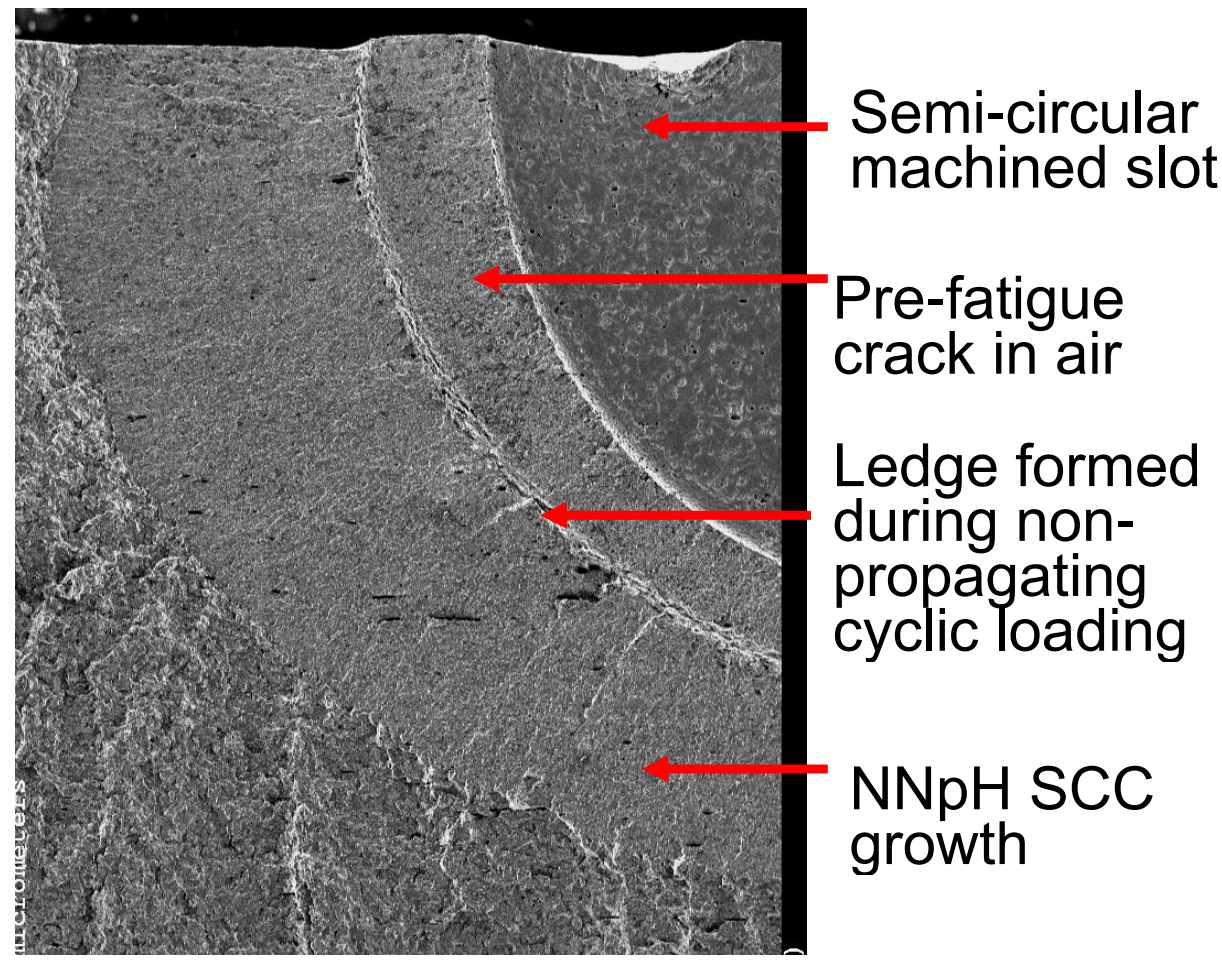

Fig. 4-30 Morphology of fractured surface of surface crack after exposure in near-neutral $\mathrm{pH}$ soil solution

Along the boundary between the pre-fatigue and crack propagation growth regions, pit-like structures were observed alongside ledges (Figure 4-31). These pits initially appear to be dissolution pits formed by the selective removal of inclusions, however on closer examination, it was determined that they may not be dissolution pits. These pits are closely associated with and are very similar to microvoids found in the fast fracture ligament of the fracture face. The close 
association of these pits with microvoids, and the absence of same in the immediately adjoining areas where quasi-cleavage mechanism dominates, suggests that these pits are produced by intense plastic deformation. Recall that these samples were initially subjected to benign mechanical loading conditions under which crack dormancy occurred. Under such conditions, crack tip blunting due to localized dissolution could occur. A measure of creep damage at the crack tip might also occur due to high stress concentration at the tip of a dormant crack. Thus some plastic work may be required to re-initiate the crack from its dormant state. In such a case, continued growth of crack will necessitate that fracture commences by the nucleation of microvoids and microcracks on different planes. These microcracks will then merge to produce a bigger crack resulting in the ledges, microvoids and pits observed at this boundary. Considering that the conditions for NNPHSCC cracking in the field are cyclical, with start and stop times varying with seasonal fluctuations, these features may point to an important mechanism in the re-initiation of dormant cracks.

Fig. 4-31 also provide some insights on the effect of long term hold. A hold can lead to crack tip blunting by plastic deformation but at the same time the plastic deformation will cause void formation and damage similar to overloading. It is believed such a mechanical damage would facilitate crack re-sharpening and even accelerate the subsequent crack growth. Further research is needed to quantify its effect.

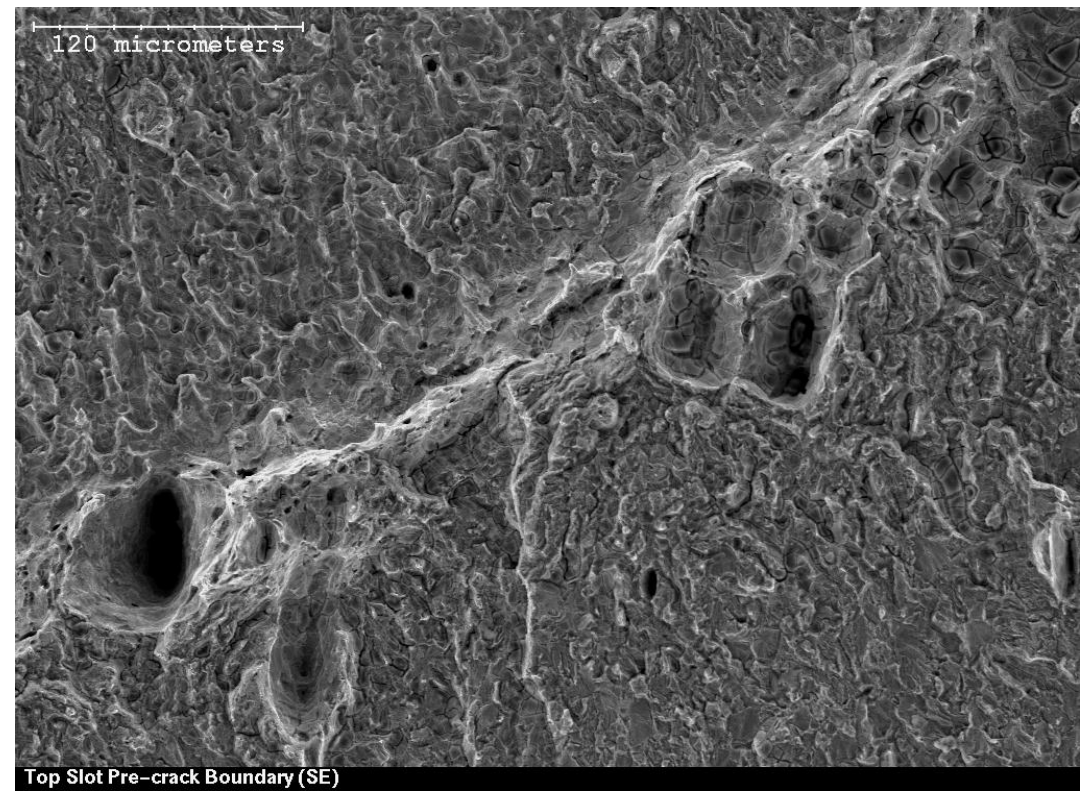

Fig. 4-31 Enlarged SEM image showing the morphology at the ledge found on the fractured surface in Fig. 4-30.

Figure 4-30 also shows that shape deviated from its original semi-circular shape during crack propagation in air (during pre-cracking) and in the corrosion media resulting in an elliptical crack 
shape after the test. Aspect ratios generally decreased during the test and the extent of this decrease seemed to increase with distance from the open mouth. Decrease in aspect ratios during the test implies that cracks propagated faster near the sample surface than in the depth direction during the test. This behaviour is contrary to what mechanical loading considerations ordinarily suggests. Since a free surface cannot support any stress, the surface of the specimen will be in plane stress loading while the inner portions that experience more constraint will be in plane strain. Under this condition, crack propagation should have been slower near the specimen surface. The fact that the crack grew faster at the surface in this situation points to the fact that a second mechanism must have enhanced the growth rate near the surface.

Table 4-10 summarizes the average crack growth rates obtained during exposure under propagating cyclic loading and the threshold combined factors of the two tests. The threshold combined factors for both the tests are similar. This is consistent with the modelling made in previous section that the threshold conditions are determined by the intrinsic cyclic behaviour of the pipelines in inert environment. The presence of a threshold condition also confirms the effect of low temperature creep. The crack growth rates in the soil environment with $20 \% \mathrm{CO}_{2}$ was about 2 times higher than those obtained in the soil solution with $5 \% \mathrm{CO}_{2}$. Higher $\mathrm{CO}_{2}$ makes the solution more acidic and has been measured with higher dissolution and therefore more atomic hydrogen being generated. The increased growth rate can be related to the increased diffusible hydrogen content in the pipeline steels as extensively studied in previous sections. The decreased crack growth rate with increasing the distance to the open mouth can be related to lower $\mathrm{CO}_{2}$ toward the bottom of the disbonded coating.

Table 4-10 Critical combined factors and crack growth rate

\begin{tabular}{|c|c|c|c|c|}
\hline \multirow{3}{*}{$\begin{array}{l}\text { Distance from } \\
\text { open mouth }(\mathrm{mm})\end{array}$} & \multicolumn{4}{|c|}{ Combined factors and growth rates } \\
\hline & \multicolumn{2}{|c|}{$20 \% \mathrm{CO}_{2}$} & \multicolumn{2}{|c|}{$5 \% \mathrm{CO}_{2}$} \\
\hline & $\begin{array}{c}\Delta \mathrm{K}^{0.667} \mathrm{~K}_{\max }{ }^{0.333} / \mathrm{f}^{0.033} \\
\left(\mathrm{MPa} \sqrt{\mathrm{m}} / \mathrm{Hz}^{0.033}\right)\end{array}$ & $\begin{array}{c}\mathrm{da} / \mathrm{dN} \\
(\mathrm{mm} / \mathrm{cycle})\end{array}$ & $\begin{array}{c}\Delta \mathrm{K}^{0.667} \mathrm{~K}_{\max }{ }^{0.333} / \mathrm{f}^{0.033} \\
\left(\mathrm{MPa} \sqrt{\mathrm{m}} / \mathrm{Hz}^{0.033}\right)\end{array}$ & $\begin{array}{c}\mathrm{da} / \mathrm{dN} \\
(\mathrm{mm} / \text { cycle }) \\
\end{array}$ \\
\hline 0 & 22.7 & $13.0 \times 10^{-4}$ & 22.5 & $6.7 \times 10^{-4}$ \\
\hline 75 & 22.2 & $3.4 \times 10^{-4}$ & 22.4 & $1.1 \times 10^{-4}$ \\
\hline 150 & 22.6 & $3.2 \times 10^{-4}$ & 22.4 & $1.8 \times 10^{-4}$ \\
\hline
\end{tabular}

\section{SUMMARY}

- There exists a critical mechanical condition below which surface cracks will attain dormancy due to low temperature creep, which is consistent with the results obtained from tests using compact tension specimens. 
- There is slight difference between conditions required for reinitiating long and surface type cracks. Long cracks are slightly easier to reinitiate from dormant state.

- Although increased $\mathrm{CO}_{2}$ concentrations may furnish more hydrogen, formation of carbonates may retard hydrogen assimilation into the material.

- Increased dissolution at higher $\mathrm{CO}_{2}$ concentrations may aid crack tip blunting, delaying crack re-initiation from dormancy.

\section{References:}

1. R.C. McClung, H. Sehitoglu, "Closure and Growth of Fatigue Cracks at Notches", ASMEJ. Engng Mater. Technol. 114 (1992) 1-7.

2. M.H.E. Haddad, T.H. Topper, B. Mukherjee, Review of New Developments in Crack Propagation Studies, ASTM Journal of Testing and Evaluation.Vol.9. 9 (1981) 65-81.

3. M.E. Fine, R.O. Richie, Fatigue and microstructure, in: M. Meshii (Ed.), , American Society for Metals, Metals Park, Ohio, 1979, pp. 245.

4. R.P. Gangloff, Advances in Crack Length Measurement, in: C.J. Beevers (Ed.), , Engineering Materials Advisory Ltd., Warley, West Midlands, 1983, pp. 175.

5. S.J. Hudak, J., Small Crack Behavior and the Prediction of Fatigue Life, Journal of Engineering Materials and Technology (Transactions of the ASME).Vol.103. 103 (1981) 26-35.

6. J. Schijve, Fatigue Thresholds, in: J. Backlund et al (Ed.), , Engineering Materials Advisory Ltd., Warley, West Midlands, 1982, pp. 881.

7. M.H. El Haddad, K.N. Smith, T.H. Topper, A strain based intensity factor solution for short fatigue cracks initiating from notches, Fracture Mechanics ASTM STP 677 (1979) 274289-289.

8. B.N. Leis, T.P. Forte, Fatigue Growth of Initially Physically Short Cracks in Notched Aluminum and Steel Plates (1981) Fracture Mechanics; Philadelphia; Pa ; 16-18 June 1980.

9. [12] B.N. Leis, R.D. Galliher, Growth of Physically Short Corner Cracks at Circular Notches (1982).

10. B.N. Leis, Fatigue Crack Propagation Through Inelastic Gradient Fields, International Journal of Pressure Vessels and Piping.Vol.10. 10 (1982) 141-158.

11. C.S. Shin, R.A. Smith, Fatigue Crack Growth at Stress Concentrations--the Role of Notch Plasticity and Crack Closure, Eng.Fract.Mech.Vol.29. 29 (1988) 301-315.

12. S. Sun, K. Shiozawa, J. Gu, N. Chen, Investigation of deformation field and hydrogen partition around crack tip in fcc single crystal, Metall.Mater.Trans.A. 26A (1995) 731-739.

13. C.S. Shin, R.A. Smith, Fatigue Crack Growth From Sharp Notches, Int.J.Fatigue.Vol.7. 7 (1985) 87-93.

14. K. Tanaka, Y. Nakai, Propagation and Nonpropagation of Short Fatigue Cracks at a Sharp Notch, Fatigue Eng.Mater.Struct.Vol.6. 6 (1983) 315-327.

15. H. SEHITOGLU, Fatigue Life Prediction of Notched Members Based on Local Strain and Elastic--Plastic Fracture Mechanics Concepts, Eng.Fract.Mech.Vol.18. 18 (1983) 609-621.

16. H. Sehitoglu, Characterization of Crack Closure, Fracture Mechanics: Sixteenth Symposium; Columbus (1985). 


\section{DEVELOPMENT OF HYDROSTATIC TEST GUIDLINES}

\subsection{Introduction}

Based on the experimental findings from hydrostatic test simulations and the fundamental studies of corrosion cracking of pipeline steels in near-neutral $\mathrm{pH}$ environments, some new guidelines can be developed for performing hydrostatic test enabling achieving maximum crack remediation effects.

To design a proper hydrostatic test procedure, one must understand the purpose of the hydrostatic tests, which is often obscured by other considerations such as reducing crack growth rate through retardation effects. Hydrostatic test is originally designed to detect whether cracks with certain critical sizes are present in the structure. If that is the sole purpose of hydrostatic test, hydrostatic test should be conducted under the worst conditions of the defected pipeline to yield a conservative assessment of the safe remaining operating lifetime if pipeline failures have not occurred during hydrostatic loading.

On the other hand, one may perform hydrostatic tests under an ideal situation that will lead to a reduced risk of failure during hydrostatic tests by managing the external testing conditions.

For the above two situations, the hydrostatic test should be always performed under the condition enabling the best benefits for the post-hydrotest operation. The above situations are further demonstrated below on the basis of residual strength diagram.

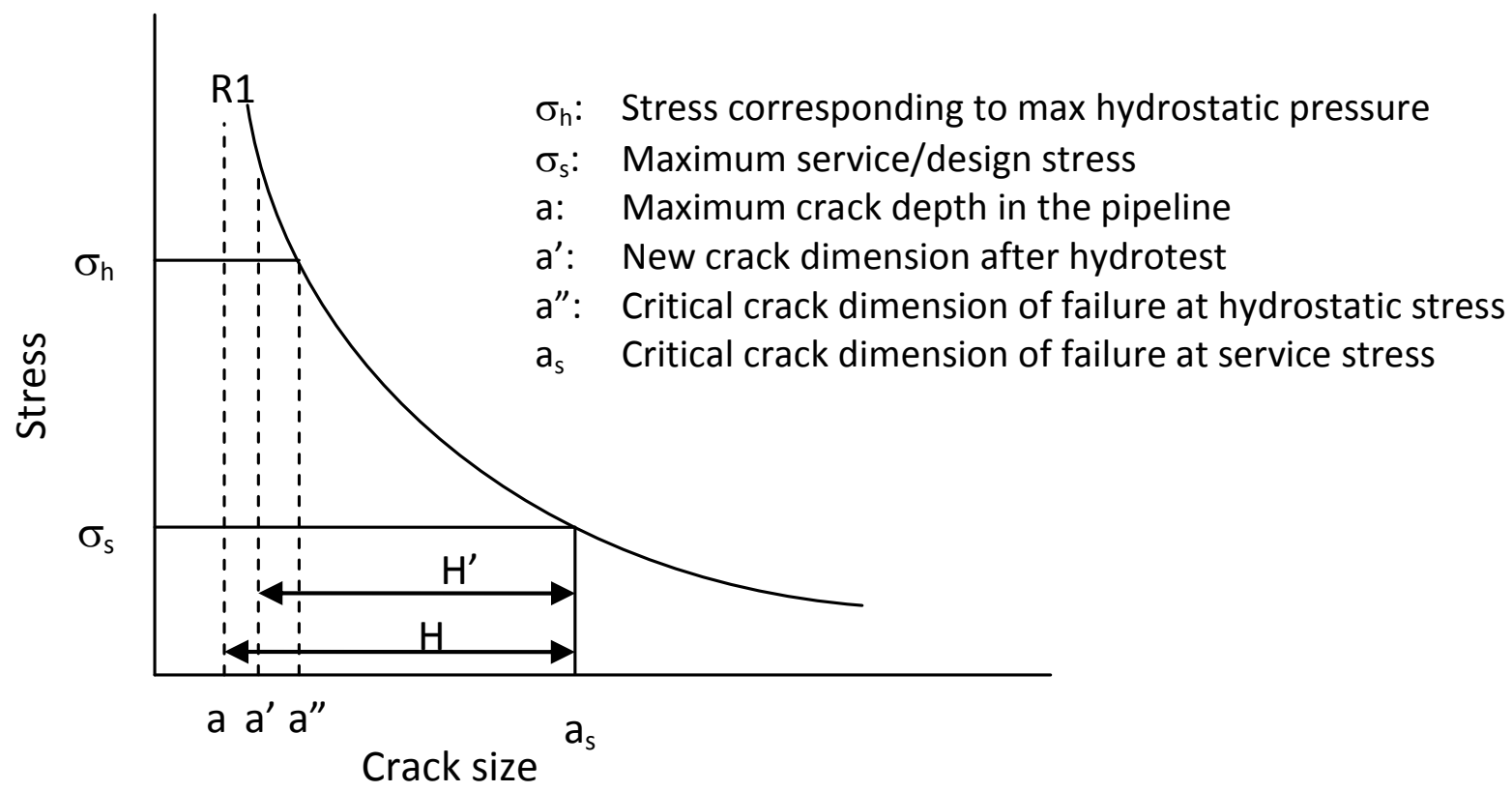

Fig.5-1 Crack growth during hydrotest reduces the remaining life of the pipeline. 


\section{Scenario I}

Hydrostatic tests can be performed under the worst scenarios of operating conditions pertinent to crack growth, such as at a loading rate with maximum crack growth and when crack tip is sharp. This would yield the largest increase of crack dimension during hydrostatic test. If there were no cracks of critical size present, this test would shorten the actual remaining life of the pipeline. This situation is further illustrated in Fig. 5-1, in which, the actual crack depth before hydrotest is $a$, but is increased to $a^{\prime}$ after hydrotest. This would shorten the remaining life by $(\mathrm{H}-$ $\left.\mathrm{H}^{\prime}\right)$ for pipelines that have survived the tests. According to the results of hydrostatic simulation, the growth during one hydrostatic loading can be well over $1 \%$ wall thickness.

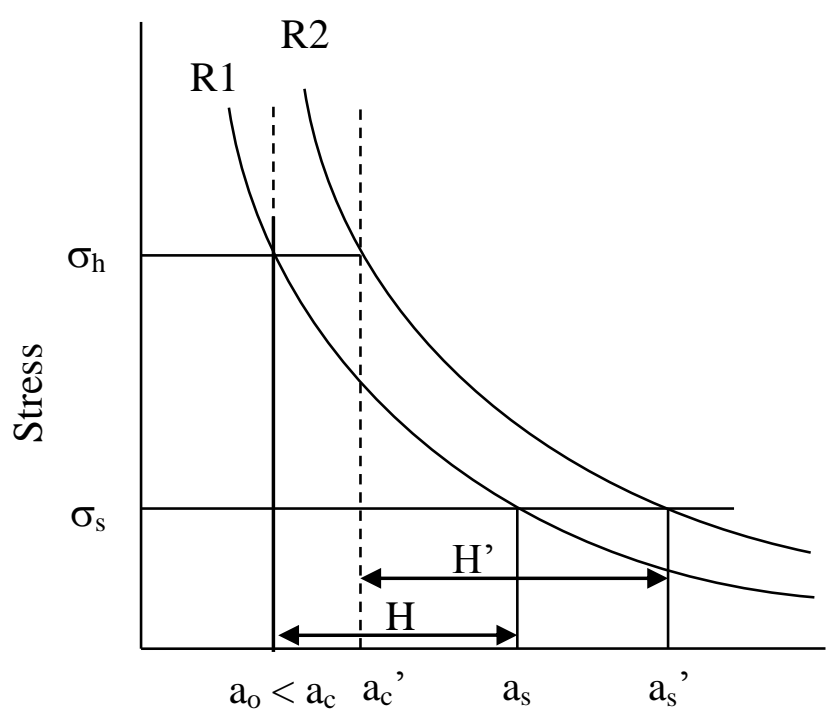

Crack size
R1: Residual strength curve under worst crack growth scenario (sharp crack tip)

R2: Residual strength curve under the least crack growth scenario (blunt crack tip)

$\sigma_{\mathrm{h}}$ : Maximum hydrostatic stress

$\sigma_{s}$ : Maximum service/design stress

$a_{c}$ : Critical crack dimension of failure at hydrostatic stress corresponding to R1 (sharp crack tip)

$a_{0}$ : Actual crack dimension in the pipeline

$a_{c}^{\prime}$ : Critical crack dimension of failure at hydrostatic stress corresponding to R2 (blunt crack tip)

$a_{s}$ : Critical crack dimension of failure at service stress corresponding to R1 (sharp crack tip) Critical crack dimension of failure at service stress corresponding to R2 (blunt crack tip)

Fig.5-2 Crack growth behaviour during hydrotest and remaining pipeline lifetime as discussed in Scenario II for actual cracks with a dimension shorter than the critical crack dimension defined by $\mathrm{R} 1$.

\section{Scenario II}

Hydrostatic test can be performed under idealized conditions that will lead to the least crack growth or zero crack growth during hydrostatic loading. The situation is illustrated in Fig. 5-2, in which R1 and R2 are assumed to be the residual strength curves of the defected pipeline when hydrostatic testing pipeline steels with sharp cracks and when hydrostatic testing under an idealized condition (that is, crack tip is blunt), respectively. If the actual crack dimension, $a_{0}$, is shorter than $a_{c}$, the idealized hydrotest would lead to a minimum or zero crack growth during hydrotest and failure of pipeline will not occur during hydrostatic loading. Under the circumstances, the actual life of the pipeline could be extended, e.g., to $\mathrm{H}^{\prime}$, depending on the crack tip morphology after hydrostatic testing. The following are two possibilities: 
1) If crack tip remains sharpened, the remaining life of the pipeline will be governed by $R 1$ curve and will be the length of $\mathrm{H}$.

2) If crack tip remains blunt, the remaining life of the pipeline will be governed by $R 2$ curve and will be the length of $\mathrm{H}^{\prime}$, indicating an extension of remaining life.

The above two situations represent two extreme conditions, that is, crack tip remains either sharp or blunt all the time. Because of the nature of pressure fluctuation and the occurrence of low temperature creep, the crack tip morphology can be in a mixed state, and the actual pipeline life will be between $\mathrm{H}^{\prime}$ and $\mathrm{H}$.

On the other hand, through crack tip blunting, a pipeline that contains a sharp crack with a dimension longer than the critical dimension corresponding to R1 may survive the hydrotest because of pre-blunting of the crack tip, as illustrated in Fig. 5-3. The pipeline still have some remaining life as given by $\mathrm{H}^{\prime}$ in Fig. 5-3. This can be a "false" life if crack tip becomes sharpended.

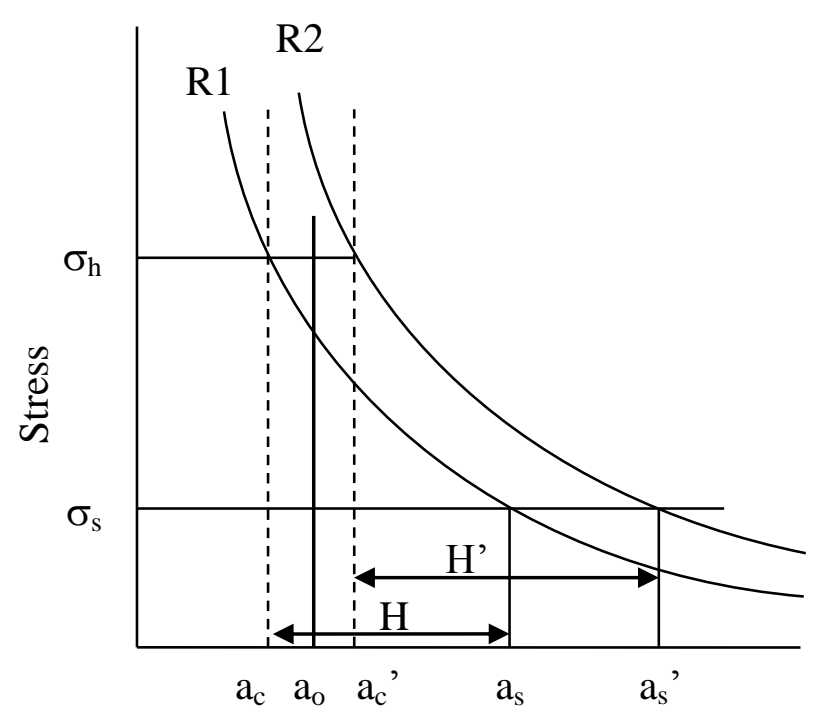

Crack size
R1: Residual strength curve under worst crack growth scenario (sharp crack tip)

R2: Residual strength curve under the least crack growth scenario (blunt crack tip)

$\sigma_{\mathrm{h}}$ : Maximum hydrostatic stress

$\sigma_{\mathrm{s}}$ : Maximum service/design stress

$a_{c}$ : Critical crack dimension of failure at hydrostatic stress corresponding to R1 (sharp crack tip)

$a_{0}$ : Actual crack dimension in the pipeline

$a_{c}{ }^{\prime}$ : Critical crack dimension of failure at hydrostatic stress corresponding to R2 (blunt crack tip)

$a_{s}$ : Critical crack dimension of failure at service stress corresponding to R1 (sharp crack tip)

$a_{s}^{\prime}$ : Critical crack dimension of failure at service stress corresponding to R2 (blunt crack tip)

Fig.5-3 Crack growth behaviour during hydrotest and remaining pipeline lifetime as discussed in Scenario II for actual cracks with a dimension longer than the critical crack dimension defined by R1.

\section{Scenario III}

Regardless of the situations described in Scenario I and II, one should perform the hydrostatic test that will achieve the best post-test benefits, for example, a reduced crack growth rate after hydrotests. For this purpose, one should distinguish whether the benefits can be achieved in the same way in both the oil pipelines and high pressure gas pipelines. The oil pipelines are 
normally operated under more intensive cyclic loading and it is well established that overloading, such as the case of hydrotests, will reduce crack growth after overloading. On the other hand, the high pressure gas pipelines are operated under a near-static loading condition. The pipeline might be operated without experiencing any significant pressure fluctuation. The retardation effects may be retained to affect crack growth once a significant pressure fluctuation is met. To the contrary, the overloading can substantially work-hardened the material at the crack tip, which may enhance the hydrogen effects to incur even greater crack growth. This later hypothesis is to be further experimentally proven.

\subsection{Best strategies of hydrostatic testing}

With the above analysis, one may wonder what would be the best scenario/strategies to perform hydrotests. It is believed that hydrotests can be best performed if the following three conditions can all be met:

1) Producing the least crack growth during hydrostatic loading - avoiding the problem defined in Scenario I

2) Avoiding over-estimate of the remaining life, which could occur when crack tip remains at a sharp state, as one of the situations described in Scenario II

3) Achieving maximum post-test benefits - situation described in Scenario III.

From the current investigation, it is believed that above three conditions could be achived. The following sections are made to provide detailed considerations for achieving the above strategies.

\subsection{Strategies for producing the least crack growth during hydrostatic loading}

From the results of mechanistic studies presented previously, crack growth caused by mechanical loading in near-neutral pH environments will depend on

1) The crack tip morphology, that is, blunt or sharp

2) The susceptibility to hydrogen embrittlement which is affected by both the level of diffusible hydrogen generated in the environments and the material's susceptibility to hydrogen embrittlment

3) Mechanical loading severity, which is determined by a combined factor expressed as $\Delta K^{2} K_{\max } / f^{\gamma}$

Based on the above mechanistic principles, the following guidelines are suggested: 
1) Hydrostatic test preparation:

a. It is recommended that pipeline can be held at the highest operating pressure possible for at least 24 hour before being unpressurized for filling water or other medium to be used for hydrostatic testing.

b. It is suggested that hydrostatic test be performed at the time the hydrogen effects could be minimized, for example, not in the season when $\mathrm{CO}_{2}$ level in the environment surrounding the pipe is high, or when cathodic protection is intensified.

c. It is suggested that pipeline could be pre-heated over $60^{\circ} \mathrm{C}$ if possible for the release of diffusible hydrogen in the pipeline steels.

2) Hydrostatic loading

a. It is recommended that the initial loading up to $75 \%$ be controlled at least over a long period of time achieving crack tip blunting.

b. It is recommended that a hold at $75 \%$ for a few hours before Stage II loading can be performed.

c. It is recommended that the hold at maximum pressure at least for one hour to blunt the crack tip.

3) Additional consideration for possible reactivation of crack growth of a blunt crack

a. It is recommended that the hydrostatic testing should be performed to avoid reactivation of crack growth from a blunt tip.

\subsection{Strategies for avoiding over-estimate of the remaining life}

Avoiding over-estimate of the remaining life, a situation showing in Fig. 5-3, can be resolved if a proper residual strength curve in accordance with the hydrostatic loading procedures, can be determined and used for remaining life assessment. If the critical size of cracks is determined based on the results of CTOD tests, it is suggested the CTOD assessment be performed under both the worst field scenarios, for example, in near-neutral $\mathrm{pH}$ soil aqueous solution with full hydrogen effects achieved before tests and maintained during the course of tests, and loading the specimens at different loading rate to reflect the effect of low temperature creep.

\subsection{Strategies for achieving maximum post-test benefits}

a. It is recommended that a hold at maximum operating pressure for at least 24 hours be repeated to keep the crack tip at a blunt state. 
b. It is recommended that a hold at maximum operating pressure for at least for 24 hours when a combined loading factor is above the threshold.

c. It is recommended that the operating should avoid operating conditions that may exceed the critical value of the combined factor.

\section{RECOMMENDATIONS}

This research has revealed two competing processes, that is, crack tip sharpening and crack tip blunting, that are believed to be essential to crack growth and crack growth control during the routine services and hydrostatic testing of pipeline steels susceptible to near neutral $\mathrm{pH}$ cracking. It is recommended that additional research be done to further validate the findings and to develop specific methods and approaches of integrity managements of pipelines in the following areas based on the findings in the report:

- Conditioning pipelines achieving crack tip blunting

- Guideline for shallow crack grinding

- Control of pressure fluctuations achieving maximum pipeline safe operating lifetime

- Generalized experimental approaches for assessing the susceptibility of pipeline steels to environmentally-assisted cracking

- Modelling crack growth in all cracking stages - practical approach for field use

- New considerations for developing pipeline steels with improved resistance to environmentally-assisted cracking

- Investigating high $\mathrm{pH}$ cracking of pipeline steels using similar approaches described in this report. 